\title{
AGR-1 Compact 4-1-1 Post-Irradiation Examination Results
}

Paul A. Demkowicz, Jason M. Harp, Philip L. Winston, Scott A. Ploger, Isabella J. van Rooyen

February 2016

The INL is a

U.S. Department of Energy

National Laboratory

operated by

Battelle Energy Alliance

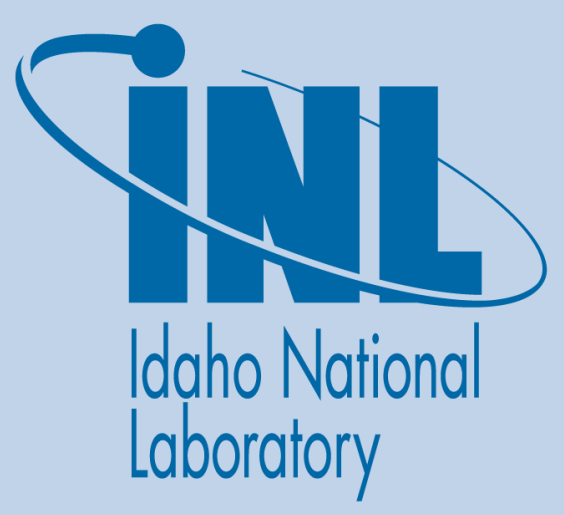

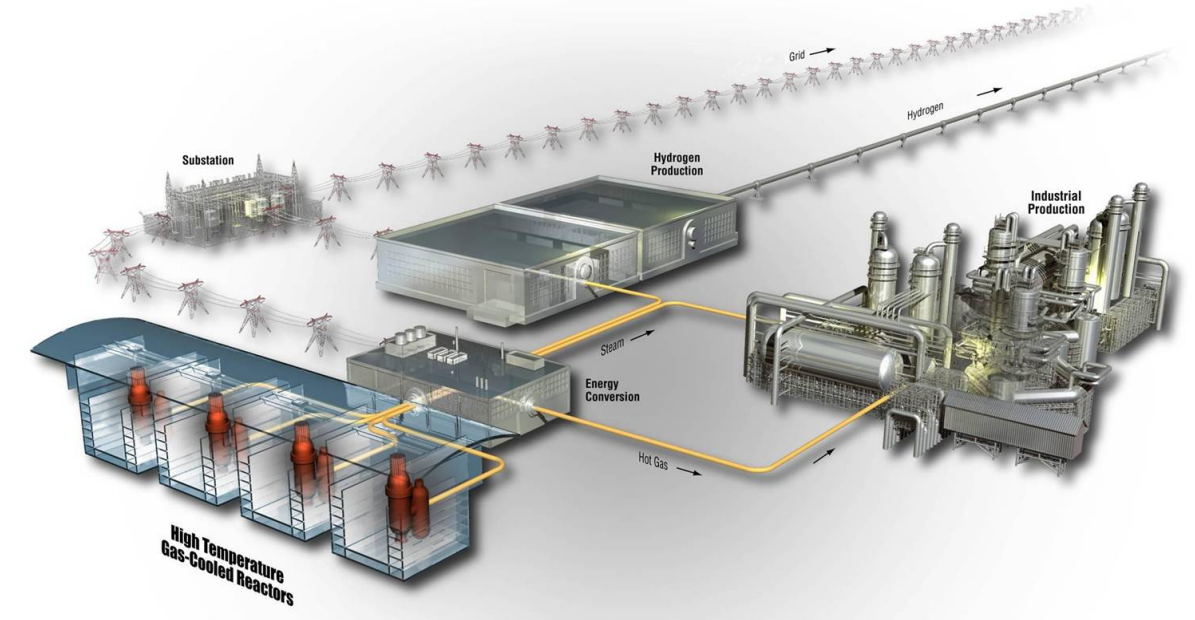




\section{DISCLAIMER}

This information was prepared as an account of work sponsored by an agency of the U.S. Government. Neither the U.S. Government nor any agency thereof, nor any of their employees, makes any warranty, expressed or implied, or assumes any legal liability or responsibility for the accuracy, completeness, or usefulness, of any information, apparatus, product, or process disclosed, or represents that its use would not infringe privately owned rights. References herein to any specific commercial product, process, or service by trade name, trade mark, manufacturer, or otherwise, does not necessarily constitute or imply its endorsement, recommendation, or favoring by the U.S. Government or any agency thereof. The views and opinions of authors expressed herein do not necessarily state or reflect those of the U.S. Government or any agency thereof. 
INL/EXT-15-36169

Revision 0

\title{
AGR-1 Compact 4-1-1 Post-Irradiation Examination Results
}

\author{
Paul A. Demkowicz, Jason M. Harp, Philip L. Winston, Scott A. Ploger, \\ Isabella J. van Rooyen
}

February 2016

\begin{abstract}
Idaho National Laboratory
Advanced Reactor Technologies Technology Development Office Idaho Falls, Idaho 83415
\end{abstract}

http://www.inl.gov

Prepared for the

U.S. Department of Energy

Office of Nuclear Energy

Under DOE Idaho Operations Office

Contract DE-AC07-05ID14517 


\section{Advanced Reactor Technologies Technology Development Office}

\section{AGR-1 Compact 4-1-1 Post-Irradiation Examination Results}

INLLEXT-15-36169

February 2016

Reviewed by:

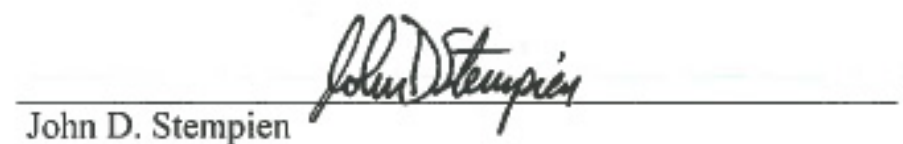

ART TRISO Fuels PIE Technical Lead

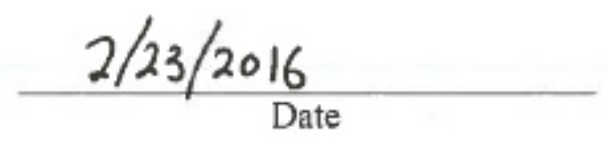

Approved by:

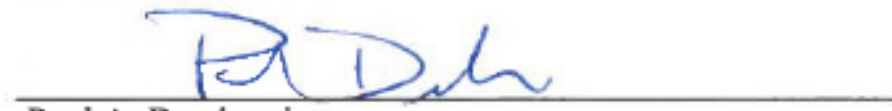

Paul A. Demkowicz

ART TRISO Fuels Technical Lead
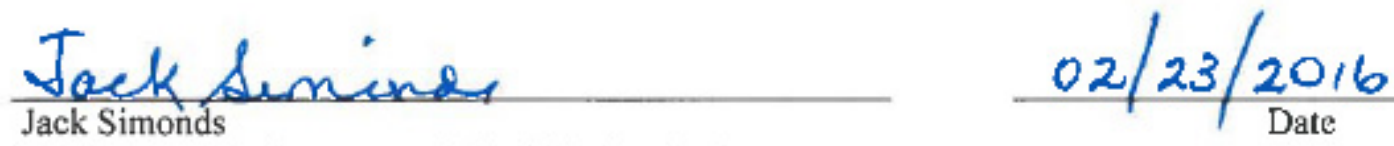

ART Fuels Development and Qualification Project

Manager

Michelle T. Sharp

$\frac{2 / 23 / 16}{\text { Date }}$ 


\section{SUMMARY}

Destructive post-irradiation examination was performed on AGR-1 fuel Compact 4-1-1, which was irradiated to a final compact-average burnup of 19.4\% FIMA (fissions per initial metal atom) and a time-average, volume-average temperature of $1072^{\circ} \mathrm{C}$. The analysis of this compact focused on characterizing the extent of fission product release from the particles and examining particles to determine the condition of the kernels and coating layers. The work included deconsolidation of the compact and leach-burn-leach analysis, visual inspection and gamma counting of individual particles, metallurgical preparation of selected particles, and examination of particle cross sections with optical microscopy, electron microscopy, and elemental analysis.

Deconsolidation-leach-burn-leach (DLBL) analysis revealed no particles with failed tristructural isotropic (TRISO) or failed SiC layers (as indicated by very low uranium inventory in all of the leach solutions). The total fractions of the predicted compact inventories of fission products Ce-144, Cs-134, Cs-137, and Sr-90 that were present in the compact outside of the SiC layers were $<2 \times 10^{-6}$, based on DLBL data. The Ag-110m fraction in the compact outside the SiC layers was $3.3 \times 10^{-2}$, indicating appreciable release of silver through the intact coatings and subsequent retention in the outer pyrolytic carbon $(\mathrm{OPyC})$ layers or matrix. The Eu-154 fraction was $2.4 \times 10^{-4}$, which is equivalent to the inventory in one average particle, and indicates a small but measurable level of release from the intact coatings.

Gamma counting of 61 individual particles indicated no particles with anomalously low fission product retention. The average ratio of measured inventory to calculated inventory was close to a value of 1.0 for several fission product isotopes (Ce-144, Cs-134, and Cs-137), indicating good retention and reasonably good agreement with the predicted inventories. Measured-to-calculated (M/C) activity ratios for fission products Eu-154, Eu-155, Ru-106, Sb-125, and Zr-95 were significantly less than 1.0. However, as no significant release of these fission products from compacts was noted during previous analysis of the AGR-1 capsule components, the low M/C ratios are most likely an indication of a bias in the inventories predicted by physics simulations of the AGR-1 experiment. The distribution of Ag- $110 \mathrm{~m}$ $\mathrm{M} / \mathrm{C}$ ratios was centered on a value of 1.02 and was fairly broad (standard deviation of 0.18 , with values as high as 1.42 and as low as 0.68 ). Based on all data gathered to date, it is believed that silver retention in the particles was on average relatively high, but that the broad distribution in values among the particles represents significant variation in the inventory of $\mathrm{Ag}-110 \mathrm{~m}$ generated in the particles.

Ceramographic analysis of particle cross-sections revealed many of the characteristic microstructures often observed in irradiated AGR-1 particles from other fuel compacts. However, there was no obvious correlation between the inner particle morphology and the measured silver inventory in the particles. Characterization of several dozen particles on a single mount at several successive polish planes demonstrated the importance of examining particles at multiple levels to better classify the coating behavior beyond what could be observed in a single plane.

Palladium-rich fission product clusters were observed in the IPyC and SiC layers near the IPyC-SiC interface of three Compact 4-1-1 particle cross-sections. The distribution of these clusters around the particle was relatively uniform in one of the particles. In a second particle the kernel was non-concentric with the outer coating layers, and the precipitates appeared to be concentrated toward the side of the particle that was closest to the kernel. In spite of the presence of fission product clusters in the SiC layer, no significant corrosion or degradation of the layer was observed in any of the particles examined. 


\section{ACKNOWLEDGEMENTS}

We acknowledge the valuable contributions of numerous Idaho National Laboratory staff members who performed experimental work and data analysis. This includes: Dennis Brough (performing deconsolidation-leach-burn-leach analysis, particle inspection, and particle gamma counting); Martin Kearns (mount loading); Jeffrey Berg (technical direction and data analysis of

deconsolidation-leach-burn-leach results); Dr. Christopher McGrath (data analysis of particle gamma counting data); Dr. Jeffrey Giglio (inductively coupled plasma mass spectroscopy experiments and data analysis); and Brian Frickey and Cad Christensen (preparation of ceramographic mounts). Contributions from Brandon Miller (scanning electron microscopy imaging) and Jessica Reisterer (preparing of scanning electron microscopy montages) are gratefully acknowledged. 


\section{CONTENTS}

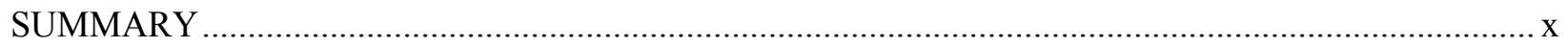

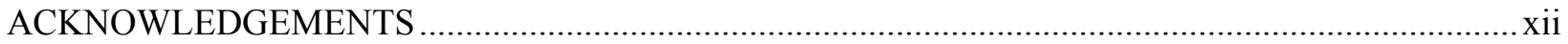

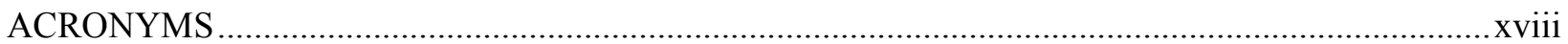

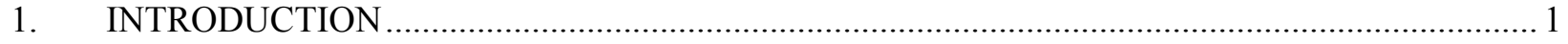

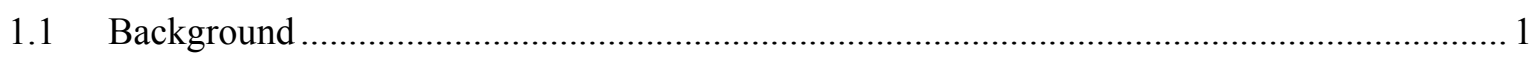

1.2 Compact 4-1-1 PIE Objectives and Overview …......................................................... 2

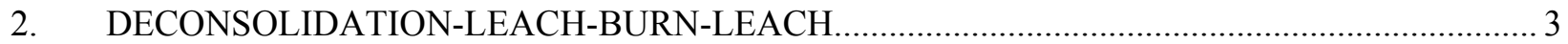

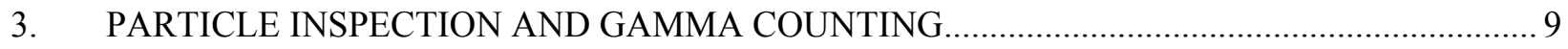

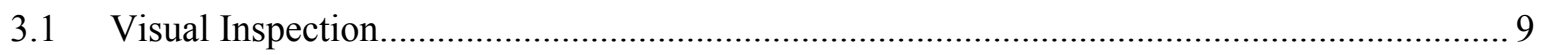

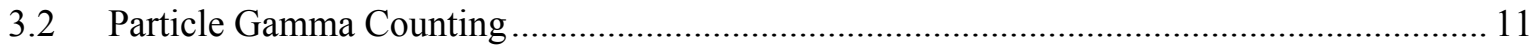

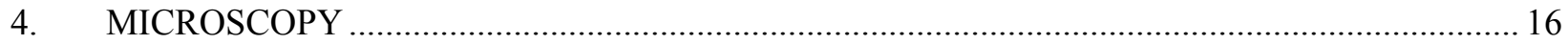

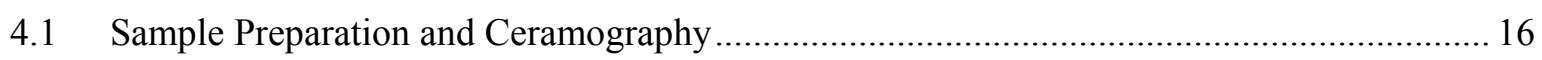

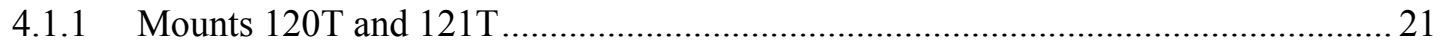

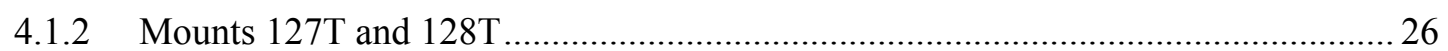

4.1.3 Particle Internal Morphology Correlation with Ag-110m Behavior ......................... 31

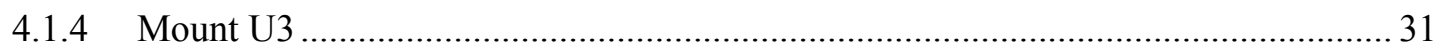

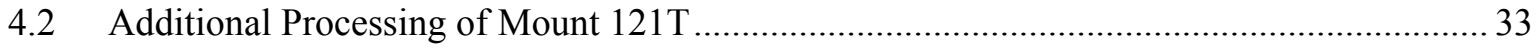

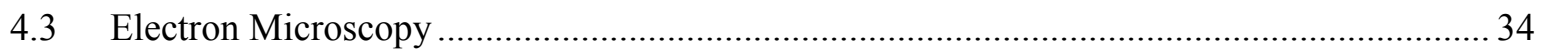

4.3.1 Sem Examination of Particle Agr1 -41 1-021 …...................................................... 35

4.3.2 SEM Examination of Particle AGR1-411-030 ......................................................... 39

4.3.3 SEM Examination of Particle AGR1-411-029 ….................................................. 40

4.3.4 Electron Microscopy Conclusions .................................................................... 42

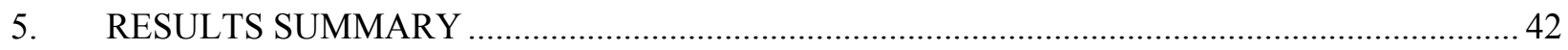

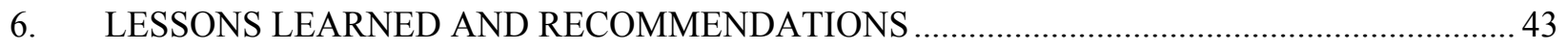

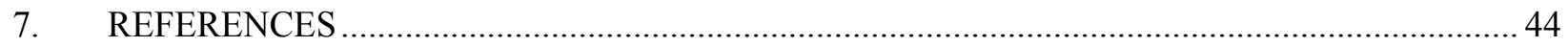

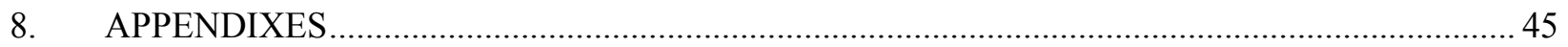

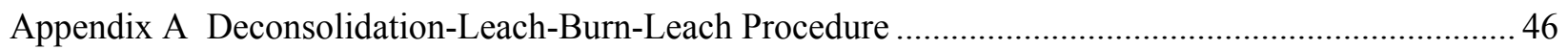

Appendix A Deconsolidation-Leach-Burn-Leach Procedure ............................................................. 48

Appendix B Particle Inspection and Irradiated Microsphere Gamma Analysis ................................... 52

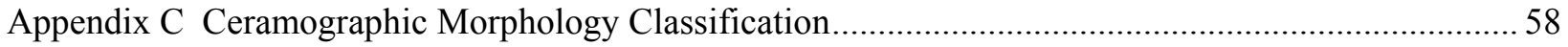




\section{FIGURES}

Figure 1. Photograph (left) and x-radiograph (right) of an unirradiated AGR-1 fuel compact. UCO kernels and nonfueled end caps are clearly visible in the $\mathrm{x}$-radiograph.................................... 2

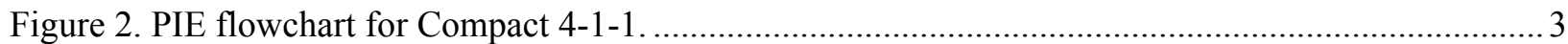

Figure 3. Deconsolidation of Compact 4-1-1 in Cell 5 showing particles dropping down from compact and accumulating on thimble frit. .............................................................................. 4

Figure 4. High turbidity observed at the end of deconsolidation. ............................................................ 5

Figure 5. Collected particles and matrix debris in the thimble following deconsolidation..........................5

Figure 6. Photograph of irradiated AGR-1 Compact 4-1-1 particles following the second post-burn leach. Note certain particles with white surface markings.

Figure 7. Several specific examples of irradiated AGR-1 Compact 4-1-1 particles with conspicuous white surface markings.

Figure 8. Normalized Ce-144 activity distribution for 61 particles from irradiated AGR-1 Compact 4-1-1. Note: Average activity and standard deviation shown on the figure do not include the double particle at 1.84 .

Figure 9. Distribution of Ce-144 measured-to-calculated activity ratios for 61 particles from irradiated AGR-1 Compact 4-1-1.

Figure 10. Distribution of measured-to-calculated Ag-110m activity ratios for AGR-1 Compact 4-1-1, normalized by the Cs-137 activity to account for variations in fissile content and burnup. Labels indicate the location of specific particles in the distribution.

Figure 11. Distribution of Eu-154 measured-to-calculated activity ratios of 61 particles from irradiated AGR-1 Compact 4-1-1.

Figure 12. Cross-sectional diagram through center of typical particle mount. (Shallow, narrow steps at peripheral base of steel mounts are not shown.).

Figure 13. Partial buffer-IPyC debonding and buffer fracturing in Type ABf particle AGR1-411-021.

Figure 14. Full cross section (a) and higher magnification of TRISO layers (b) in Type Ai particle AGR1-411-029.

Figure 15. Full cross section (a) and higher magnification of TRISO layers (b) in Type ABi particle AGR1-411-030.

Figure 16. Extensive buffer tearing in Type ABi particle AGR1-411-036

Figure 17. Cross-sectional (a) and higher magnification (b) views of Type Ai particle AGR1-411-051.

Figure 18. Type Ai particle AGR1-411-052 with very little buffer attached to the IPyC layer.

Figure 19. Type Af particle AGR1-411-032 in which buffer fragments moved before back-potting.

Figure 20. Type Bi particle AGR1-411-040 with full buffer-IPyC bonding and enlarged kernel pores.

Figure 21. Type Ai particle AGR1-411-049 with exaggerated buffer-IPyC gap .....................................28

Figure 22. Type Bi particle AGR1-411-033 with SiC fractured by debris impacts during grinding..........29 
Figure 23. Particle AGR1-411-038 after losing kernel and buffer during preparation of Mount 128T.

Figure 24. Type Ai particle AGR1-411-047 with exaggerated buffer-IPyC gap thickness....................... 30

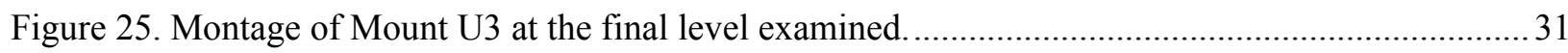

Figure 26. Multi-level results on morphology classification from 72 particles, where "i" signifies an intact buffer and "f" indicates a fractured buffer.

Figure 27. Single level morphology results from 157 particles in Compact 4-1-3 cross sections (left) and 59 particles at deepest level in Mount U3 (right).

Figure 28. SEM image montage (a) of particle AGR1-411-021 showing randomly distributed precipitates marked by blue circles. Inset image (b) shows an optical micrograph of the particle and the image in (c) shows an example of the precipitate clusters (encircled in blue).

Figure 29. Precipitate position as a function of the maximum distance away from the IPyC-SiC interlayer in particle AGR1-411-021 for each image acquired. Positive displacement represents distance into the $\mathrm{SiC}$ layer; negative displacement indicates distance into the IPyC layer.

Figure 30. IPyC-SiC interlayer thickness measured from SEM montage of particle AGR1-411-021.

Figure 31. Secondary electron (left) and backscattered electron (right) images of particle AGR1-411-021 fuel kernel.

Figure 32. SEM micrograph (left) and corresponding PdL $\alpha 1$ EDS map (right) showing presence of Pd-rich precipitates at the IPyC-SiC interface for particle AGR1-411-021. .38

Figure 33. SEM micrographs showing Pd-rich precipitates at the IPyC-SIC interface of particle AGR1-411-021, but no significant corrosion of the $\mathrm{SiC}$ layer. .38

Figure 34. Particle AGR1-411-030 SEM image montage showing precipitate clusters (indicated by blue circles). These precipitate clusters appear to be located at the bottom where the kernel is the closest to the IPyC-SiC layer interface (note that the positioning of the inner montage showing the kernel-buffer interface relative to the IPyC-SiC montage is approximate). Inset image at upper right is an optical micrograph of the particle cross-section.

Figure 35. Particle AGR1-411-030 micrographs showing the presence of loose debris on the surface making detailed quantification of the location of Pd precipitates impractical.

Figure 36. Porosity (indicated by arrows) observed in the buffer and $\mathrm{SiC}$ layers of particle AGR1-411-030.

Figure 37. SEM microgaphs of particle AGR1-411-029 showing Cs-containing crystallites on the fuel cross section (a) and a crack in SiC layer (b).

Figure 38. Micrograph (left) and Cs WDS (middle) and EDS (right) maps of the particle AGR1-411-029 fuel kernel cross section, indicating the presence of cesium-containing crystallites.

Figure A-1. Deconsolidation configuration. 49

Figure A-2. Framework with deconsolidation tube/vial (left) and two Soxhlet extractor stations. .50

Figure B-1. Cutaway view of camera optical orientation without shielding. .55 
Figure B-2. Assembled isometric view of microscope stages and shielding.

Figure B-3. Post deconsolidation particle viewed on the end of the vacuum tweezer needle.

Figure B-4. MFC Analytical Laboratory Cell 4 spectrometer configuration...

Figure C-1. Particle morphologies observed in AGR-1 fuel particle cross sections, where "i" denotes an intact buffer and " $\mathrm{f}$ " denotes a fractured buffer (Ploger et al. 2012).

\section{TABLES}

Table 1. Identification and irradiation conditions for AGR-1 Compact 4-1-1...................................... 3

Table 2. Predicted inventory of isotopes in AGR-1 Compact 4-1-1 based on physics calculations (Sterbentz 2013).

Table 3. Fission products in the deconsolidation and leach solutions from Compact 4-1-1 expressed as decay-corrected activity $(\mathrm{Bq})$ and compact fraction (based on calculated inventories [Sterbentz 2013]).

Table 4. Uranium and plutonium inventory in the deconsolidation and leach solutions from Compact 4-1-1 expressed as total mass ( $\mu \mathrm{g})$ and compact fraction (based on calculated inventories [Sterbentz 2013]).

Table 5. Decay corrected activities (in $\mathrm{Bq}$ ) for isotopes measured by gamma counting of particles from irradiated Compact 4-1-1. Values in gray indicate the MDA for cases in which no activity was detected. ${ }^{\mathrm{a}}$.

Table 6. Average ratio of measured-to-calculated activities.

Table 7. Compact 4-1-1 particle mounts. The Ag-110m measured-to-calculated (M/C) activity ratio is listed for each particle that was gamma counted.

Table 8. Decay-corrected activity measured and fraction of original particle inventory found in three $\mathrm{SiC}$ hemispheric shells from Compact 4-1-1 particles. .34

Table 9. Distance of precipitates from the IPyC-SiC interlayer of particle AGR1-411-021_................... 36

Table 10. IPyC SiC interlayer thickness measurements for particle AGR1-411-021. .37 


\section{ACRONYMS}

AGR Advanced Gas Reactor

AL Analytical Laboratory

ATR Advanced Test Reactor

DLBL deconsolidation-leach-burn-leach

EDS energy dispersive $\mathrm{x}$-ray spectroscopy

FIMA fissions per initial metal atom

HFEF Hot Fuel Examination Facility

INL Idaho National Laboratory

IPyC inner pyrolytic carbon

MDA minimum detectable activity

MFC Materials and Fuel Complex

OPyC outer pyrolytic carbon

ORNL Oak Ridge National Laboratory

PIE post-irradiation examination

SEM scanning electron microscopy

TRISO tristructural isotropic

WDS wavelength dispersive $\mathrm{x}$-ray spectroscopy 


\section{AGR-1 Compact 4-1-1 Post-Irradiation Examination Results}

\section{INTRODUCTION}

\subsection{Background}

The Advanced Gas Reactor (AGR) Fuel Development and Qualification Program was established to perform the requisite research and development on tristructural isotropic (TRISO)-coated particle fuel to support deployment of a high-temperature gas-cooled reactor (HTGR). The work continues as part of the Advanced Reactor Technologies (ART) TRISO Fuel program. The overarching program goal is to provide a baseline fuel qualification data set to support licensing and operation of an HTGR. To achieve these goals, the program includes the elements of fuel fabrication, irradiation, post-irradiation examination (PIE) and safety testing, fuel performance, and fission product transport (INL 2014).

A series of fuel irradiation experiments is being planned and conducted in the Advanced Test Reactor (ATR) at Idaho National Laboratory (INL). These experiments will provide data on fuel performance under irradiation, support fuel process development, qualify the fuel for normal operating conditions, provide irradiated fuel for safety testing, and support the development of fuel performance and fission product transport models. The first of these irradiation tests, designated AGR-1, began in the ATR in December of 2006 and ended in November 2009. This experiment was conducted primarily to act as a shakedown test of the multicapsule test train design and provide early data on fuel performance for use in fuel fabrication process development. It also provided samples for post-irradiation safety testing, where fission product retention of the fuel at high temperatures will be experimentally measured. The capsule design and details of the AGR-1 experiment have been presented previously (Grover, Petti, and Maki 2010, Maki 2009).

The AGR-1 UCO fuel kernels were fabricated by Babcock \& Wilcox Nuclear Operations Group, Lynchburg, VA (Barnes et al. 2008). Kernels were nominally $350 \mu \mathrm{m}$ in diameter and ${ }^{235} \mathrm{U}$ enrichment was $19.74 \%$. The TRISO coatings were applied at Oak Ridge National Laboratory (ORNL). Nominal coating thicknesses were $100 \mu \mathrm{m}$ for the porous carbon buffer, $40 \mu \mathrm{m}$ for the inner pyrolytic carbon (IPyC) layer, $35 \mu \mathrm{m}$ for the SiC layer, and $40 \mu \mathrm{m}$ for the outer pyrolytic carbon (OPyC) layer. The coated particles were formed into right cylindrical compacts at ORNL that were nominally $12.4 \mathrm{~mm}$ in diameter and $25.1 \mathrm{~mm}$ in length. The fuel compacts have $\sim 1.5 \mathrm{~mm}$-thick fuel-free end caps at the top and bottom as shown in Figure 1. A baseline fuel type and three fuel variants were included in the AGR-1 irradiation, with each variant fabricated by varying one step of the coating process to produce slightly different inner pyrolytic carbon (IPyC) or SiC coating properties (Hunn, Jellison, and Lowden 2007). A summary of particle and compact properties is presented in the AGR-1 Test Plan (Maki 2009). One key goal of the experiment is to identify any fuel performance differences between the fuel types, either during the irradiation or during post-irradiation high temperature safety tests, to support optimization of the fuel fabrication process and eventual selection of a reference fuel for qualification.

A total of 72 compacts were irradiated in the AGR-1 experiment. The experiment completed 620 effective full-power days in the reactor and achieved a peak calculated compact-average burnup of $19.6 \%$ fissions per initial metal atom (FIMA) with zero particle failures observed, based on the measured fission gas release-to-birth rate ratios (Grover, Petti, and Maki 2010). At completion of the irradiation, the test train was shipped to the Materials and Fuels Complex (MFC) at the INL to initiate PIE and hightemperature safety testing. The primary objectives of the AGR-1 PIE and safety testing are to: (a) assess the overall performance of the test train and components and provide data to verify the test train thermal analyses; (b) evalute the fission product retention of the fuel during the irradiation and during high temperature post-irradiation safety tests; and (c) characterize the fuel compacts and individual particles to assess the condition of the matrix material, kernels, and coatings and document any concerns. Details of 
the activities planned as part of the PIE and safety testing, including the planned activities for specific compacts, have been described in the AGR-1 Post-Irradiation Examination Plan (Demkowicz 2010).
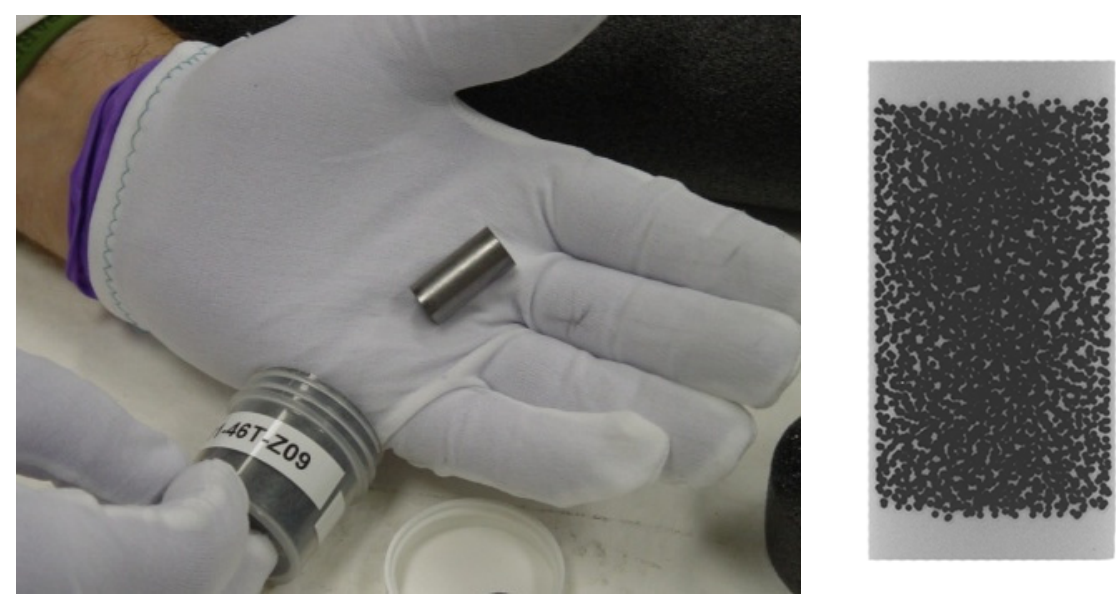

Figure 1. Photograph (left) and x-radiograph (right) of an unirradiated AGR-1 fuel compact. UCO kernels and nonfueled end caps are clearly visible in the x-radiograph.

Upon receipt at MFC, the AGR-1 test train was unpackaged, visually inspected, and examined using gamma spectrometry. The test train was then sectioned into individual capsules that were opened to remove the fuel compacts and other internal capsule components for PIE. The fuel compacts, graphite fuel holders, and metal capsule shells were measured to determine the degree of dimensional change that occurred during the irradiation. Results of test train inspection and nondestructive examination, disassembly, and dimensional measurements are presented in the report, AGR-1 Irradiated Test Train Preliminary Inspection and Disassembly First Look (Demkowicz et al. 2011). All of the irradiated AGR-1 fuel compacts were also gamma scanned in axial increments to determine the inventory of fission products and experimentally measure the burnup prior to proceeding with destructive PIE (Harp 2013).

\subsection{Compact 4-1-1 PIE Objectives and Overview}

Compact 4-1-1 is composed of Variant 3 fuel particles and was located in Stack 1, Level 1 of Capsule 4 in the AGR-1 experiment (Maki 2009). Details of the fuel fabrication and properties are presented in the AGR-1 Variant 3 particle and compact data packages (Hunn and Lowden 2006; Hunn, Montgomery, and Pappano 2006). Some of the irradiation conditions for this compact are listed in Table 1. The specific PIE objectives for Compact 4-1-1 are to:

1. Perform deconsolidation-leach-burn-leach analysis to (a) identify the number of particles with failed $\mathrm{SiC}$ that may be present in the compact, (b) determine the inventory of fission products outside of the $\mathrm{SiC}$ layer, and (c) provide particles for subsequent examination;

2. Perform gamma-ray spectrometry on a subset of particles to quantify the inventory of major fission products to examine variations in fission product retention.

3. Examine kernel and coating microstructures of selected particles to better understand fuel irradiation behavior and mechanisms of fission product diffusion and release. Examination methods include optical microscopy, electron microscopy (scanning electron microscopy, transmission electron microscopy), and elemental analysis (e.g., energy dispersive x-ray spectroscopy, wavelength dispersive $\mathrm{x}$-ray spectroscopy).

A flow chart of the analysis that has been completed on Compact 4-1-1 is provided in Figure 2. 
Table 1. Identification and irradiation conditions for AGR-1 Compact 4-1-1.

\begin{tabular}{|c|c|c|c|c|c|}
\hline Compact ID $^{\mathrm{a}}$ & Fabrication ID & Fuel type & $\begin{array}{c}\left.\text { Burnup }^{b, c}\right) \\
\left(\% \text { FIMA }^{b, c}\right)\end{array}$ & $\begin{array}{l}\text { Fast Fluence } \\
\times 10^{25}\left(\mathrm{n} / \mathrm{m}^{2}\right)^{\mathrm{c}} \\
\end{array}$ & $\begin{array}{l}\text { Irradiation } \\
\text { Temperature } \\
\left({ }^{\circ} \mathrm{C}\right)^{\mathrm{d}}\end{array}$ \\
\hline AGR-1 4-1-1 & LEU01-49T-Z58 & Variant 3 & 19.4 & 4.13 & 1072 \\
\hline \multicolumn{6}{|c|}{$\begin{array}{l}\text { a. The X-Y-Z naming convention denotes the location in the irradiation test train: Capsule-Level-Stack. } \\
\text { b. Fissions per initial metal atom. } \\
\text { c. Based on physics calculations (Sterbentz 2013) } \\
\text { d. Volume-averaged. time-averaged temperature, based on thermal calculations (Hawkes 2012). }\end{array}$} \\
\hline
\end{tabular}

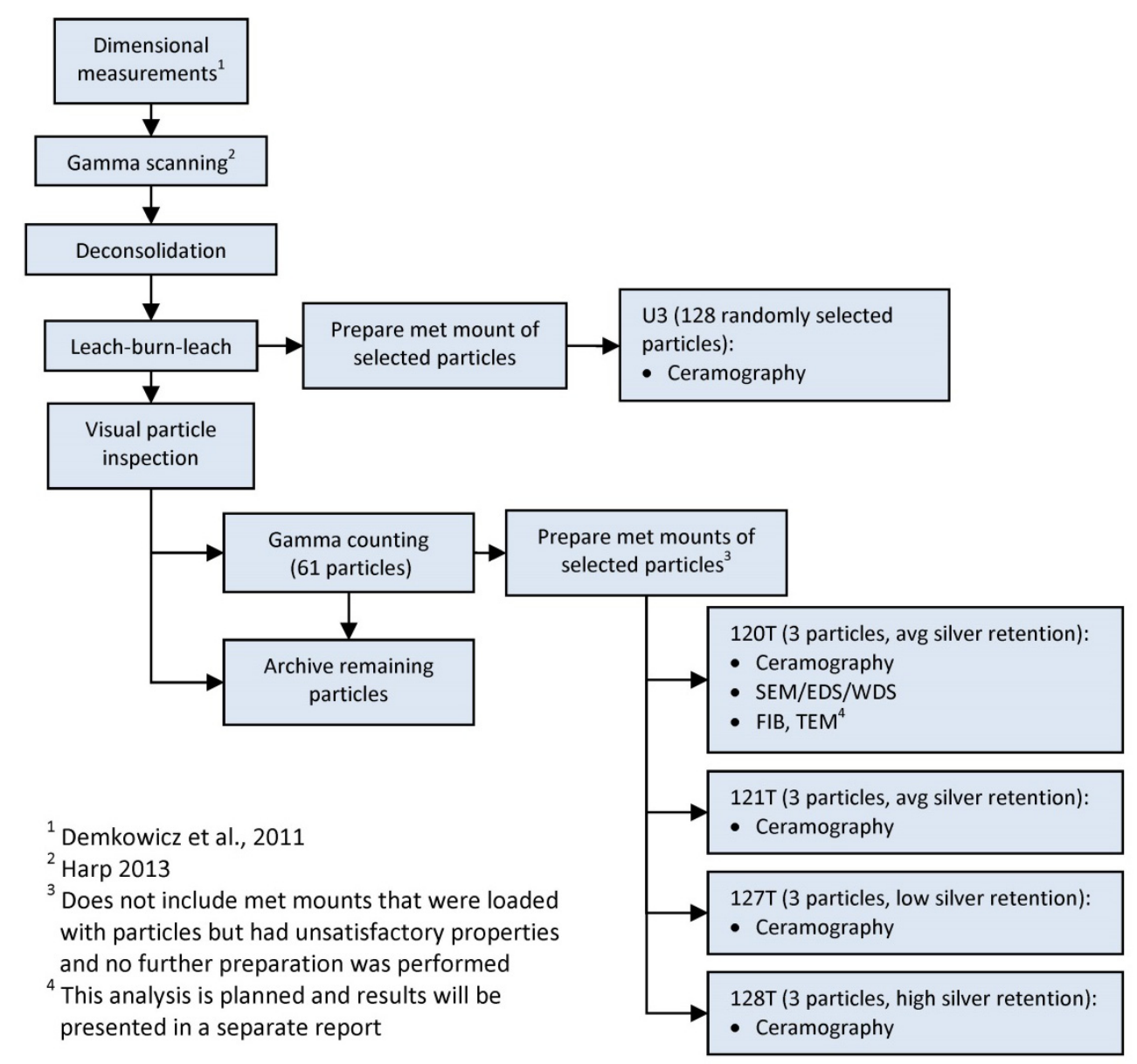

Figure 2. PIE flowchart for Compact 4-1-1.

\section{DECONSOLIDATION-LEACH-BURN-LEACH}

The general process for compact deconsolidation and leach-burn-leach analysis is given in Appendix A. Compact 4-1-1 was received in the Analytical Laboratory on December 10, 2010. Receipt weight was $5.6093 \mathrm{~g}$. The deconsolidation-leach-burn-leach (DLBL) process was performed in Hot Cell 5 in the Analytical Laboratory (AL) A wing. Deconsolidation was performed on January 4, 2011. During deconsolidation, the power supply was in constant current mode at 1 amp with negligible variation. Deconsolidation took 88 minutes and the average power input was 9.1 watts. The process began with some dark turbidity below the compact resulting from generation of graphite fines. Particles began to drop through the perforated support and continued to do so for the next 70 minutes. At 40 minutes, the 
compact appeared to be approximately 50\% deconsolidated. Between 70 and 88 minutes, hydrogen bubbles were emitted from the anode coil at the top of the compact, until the anode appeared to be resting on the perforated support. Following removal of the anode foot from the deconsolidation tube, two approximately $5-\mathrm{mm}$ diameter pieces remained. These were flushed into the thimble before transfer to the Soxhlet extractor. Because it was not practical to electrolytically decompose these pieces further, they were subjected to the first 2 pre-burn leaches. The pieces were not completely broken up during this process, so the particles were only released from the matrix as a result of oxidation in the burn step. Figure 3 through Figure 5 show some photographs taken during various stages of deconsolidation.

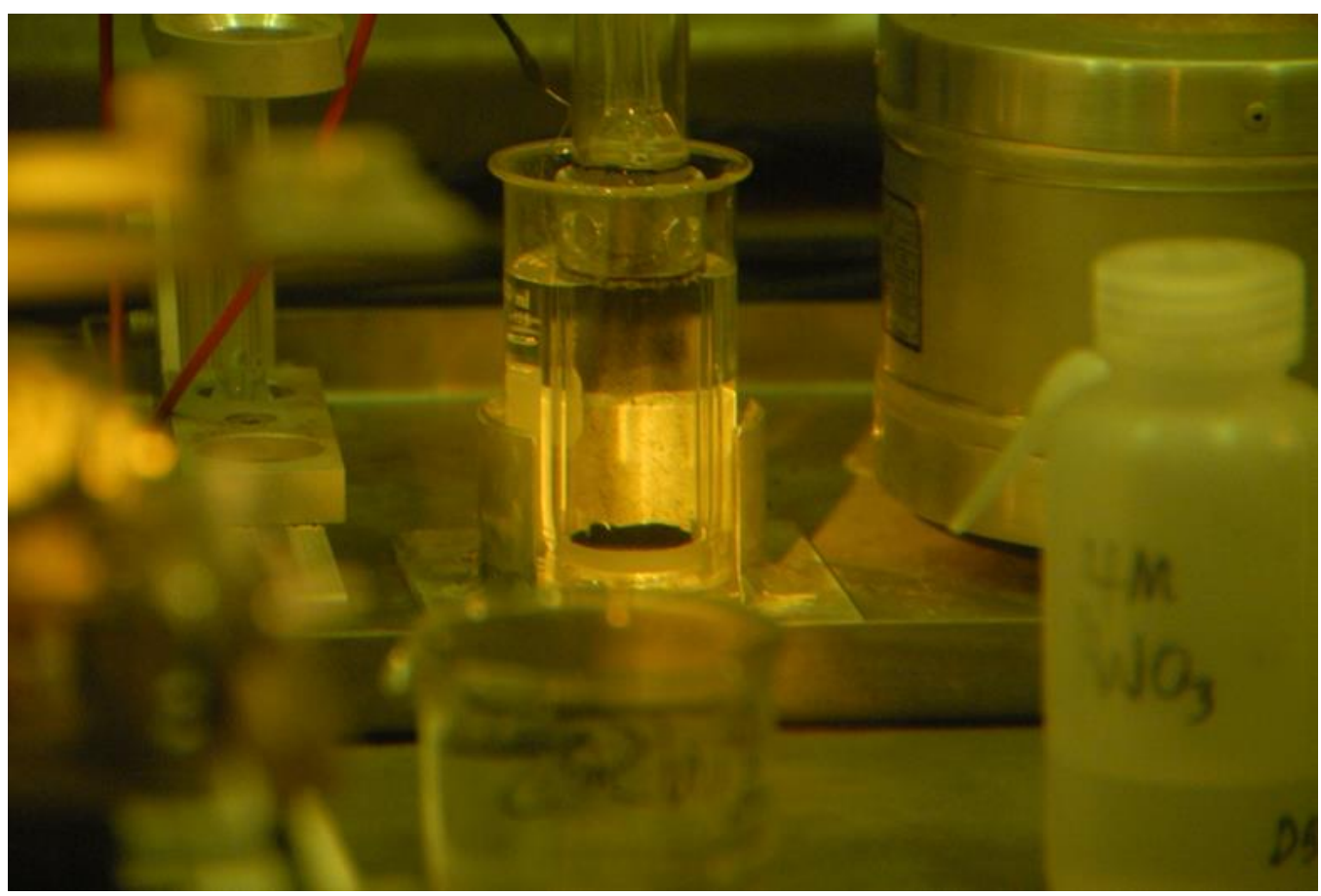

Figure 3. Deconsolidation of Compact 4-1-1 in Cell 5 showing particles dropping down from compact and accumulating on thimble frit. 


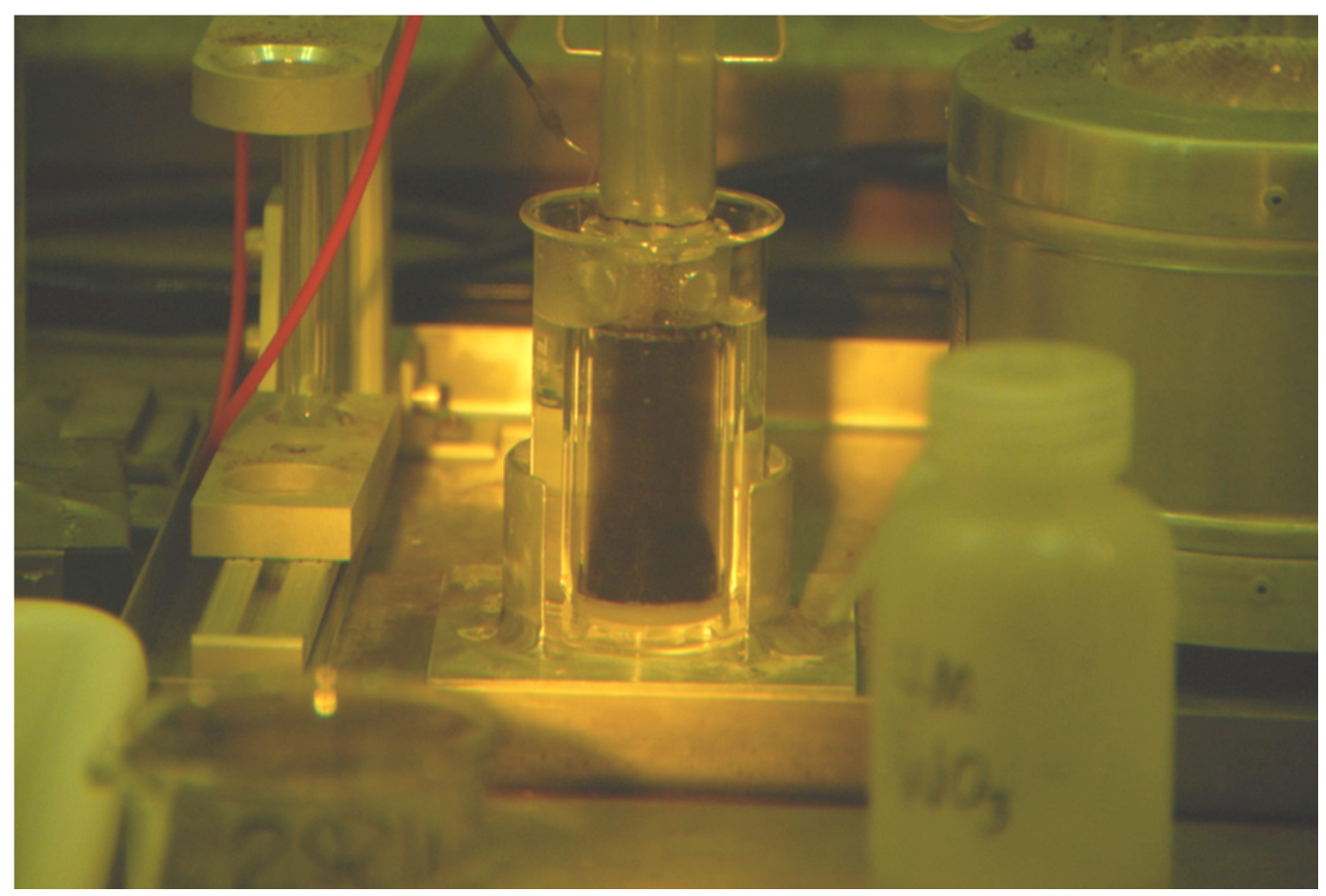

Figure 4. High turbidity observed at the end of deconsolidation.

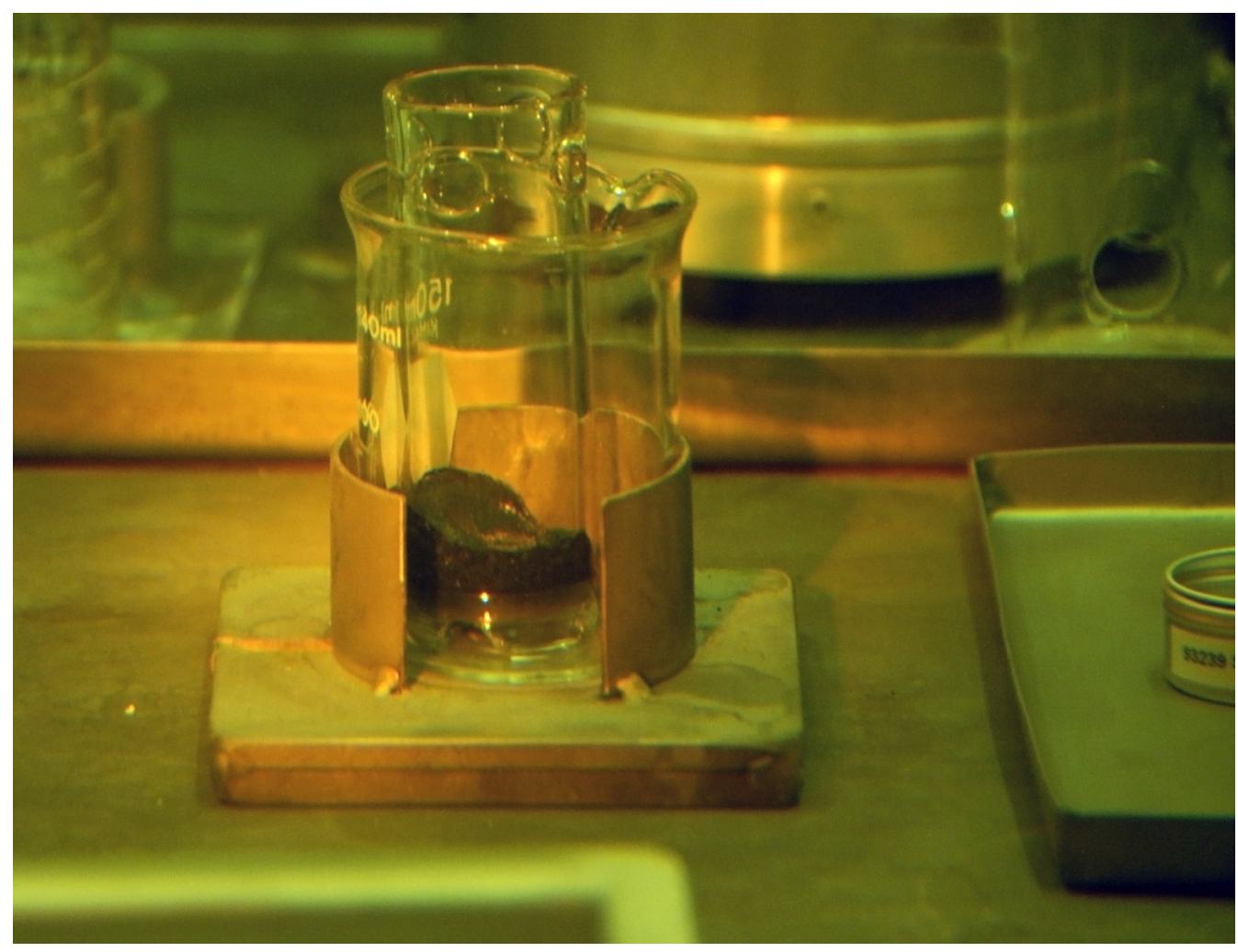

Figure 5. Collected particles and matrix debris in the thimble following deconsolidation. 
The first two 24-hour pre-burn leaches were performed between January 4 and 6, 2011. The period for the siphon cycle during the first leach was initially 14 minutes, but decreased to 7 minutes after 16 hours. The change in cycle duration results from progressive plugging of the frit in the bottom of the thimble with graphite fines. The thimble appeared to drain approximately $25 \%$ (i.e., leaving a $75 \%$ thimble heel remaining) during the 30 seconds in which the siphon drains the collection volume. Incomplete draining occurred because fines plugged the voids in the frit at the bottom of the thimble. The siphon cycle time for the second pre-burn leach was 6 minutes. Both leach steps were completed at 24 hours duration.

Following the second pre-burn leach step, the thimble was transferred to a covered fused-silica beaker, which was put into the Vulcan muffle furnace. The operating temperature of $750^{\circ} \mathrm{C}$ was reached at 12:30 pm. on January 7, 2011, and the burn step was terminated on January 10, 2011, after approximately 72 hours. To assure that a consistent oxygen flow was maintained, the furnace external ventilation fan was adjusted to yield a flow rate that caused the pinwheel mounted above the exhaust chimney to barely rotate.

The post-burn leaches were started on January 10, 2011, and completed on January 12, 2011. Both leach steps had 24-hour durations. Siphon cycle times for the first leach started at 11 minutes, and increased to 15 minutes, presumably as a result of dissolution or flushing of fines from the thimble frit. The thimble heel started at $40 \%$ and decreased to $20 \%$ at the end of the step. The Soxhlet recycle time for the second step was consistently 15 minutes. The thimble appeared to retain only $25 \%$ of its volume during siphon cycles.

Unlike the DLBL process for Compact 6-3-2 (Demkowicz et al. 2012), no grab samples of the particles were taken at intermediate steps. The net weight of the resulting particles was $2.2617 \mathrm{~g}$.

The deconsolidation solution and the pre-burn and post-burn leach solutions were analyzed using gamma ray spectrometry and mass spectrometry. Ten $\mathrm{mL}$ aliquots of all of the deconsolidation and leach solutions were taken from the nominal 150 to $200 \mathrm{~mL}$ leach volumes. The samples were transferred to the B-wing counting rooms of the Analytical Laboratory in MFC-752 to facilitate gamma spectrometry with less background interference than would be observed in the A-wing Hot Cell 4 spectrometer. In the B-wing the solutions were counted on Detector B. Detector B, located in lab B-30, is a $+3000 \mathrm{~V}$ highpurity germanium coaxial detector connected to a Canberra digital multi-channel analyzer and uses APEX peak-analysis software. The detector resides within a steel vault that has walls approximately $25-\mathrm{cm}$ thick to provide shielding. This detector is very flexible with respect to the counting geometries, and calibrated for use with a maximum sample-to-detector distance of $1 \mathrm{~m}$. Samples are placed on plastic jigs that allow precise placement in relation to the detector. Samples are placed in a jig to ensure repeatable geometry between calibration and various samples. A multiline gamma source ranging from $59.4-1,836 \mathrm{keV}$ was used to calibrate the detector.

To measure Sr-90 content of the solutions, strontium was separated onto a solid crown-ether ion exchange medium, then eluted from the media, and precipitated as a carbonate. A Tennelec gas-flow proportional unit was used to determine the amount of beta activity per mass of precipitate to determine sample Sr-90 content. Mass spectrometric analysis of the DLBL solutions was performed using a VG Plasma Quad Inductively-Coupled Plasma Mass Spectrometer (ICP-MS). 
The measured fission product radioisotope activities were decay-corrected to November 7, 2009, 12:00 GMT, the end of the AGR-1 irradiation (EOI) plus 1 day. Decay corrections discussed in this report were calculated using Equation (1).

$A=A_{o} e^{-\lambda t}$

where $A$ is the activity at time $t, A_{o}$ is the activity at $t=0$, and $\lambda$ is the decay constant $\left(\lambda=\ln (2) / t_{1 / 2}\right.$, and $t_{1 / 2}$ is the half-life). Isotope half-life data were taken from the ENDF/B-VII.1 library (Chadwick et al. 2011). Values were then compared to the predicted compact inventory at EOI plus one day based on ECAR-958 Rev. 2 (Sterbentz 2013) to calculate the fraction of the compact inventory. Predicted inventory of key isotopes presented in this report for Compact 4-1-1 are given in Table 2.

Table 2. Predicted inventory of isotopes in AGR-1 Compact 4-1-1 based on physics calculations (Sterbentz 2013).

\begin{tabular}{|l|c|}
\hline \multicolumn{1}{|c|}{ Isotope } & $\begin{array}{c}\text { Inventory (Bq) } @ \\
\text { EOI + 1 day }\end{array}$ \\
\hline Ag-110m & $2.98 \mathrm{E}+08$ \\
\hline Ce-144 & $2.16 \mathrm{E}+11$ \\
\hline Cs-134 & $2.82 \mathrm{E}+10$ \\
\hline Cs-137 & $1.97 \mathrm{E}+10$ \\
\hline Eu-154 & $8.61 \mathrm{E}+08$ \\
\hline Eu-155 & $6.14 \mathrm{E}+08$ \\
\hline Ru-103 & $2.05 \mathrm{E}+11$ \\
\hline Ru-106 & $6.60 \mathrm{E}+10$ \\
\hline Sb-125 & $1.47 \mathrm{E}+09$ \\
\hline Zr-95 & $2.28 \mathrm{E}+11$ \\
\hline
\end{tabular}

\begin{tabular}{|l|c|}
\hline \multicolumn{1}{|c|}{ Isotope } & $\begin{array}{c}\text { Inventory }(\mathrm{g}) \text { @OI } \\
\text { EOI year }\end{array}$ \\
\hline $\mathrm{U}-234$ & $1.55 \mathrm{E}-03$ \\
\hline $\mathrm{U}-235$ & $1.73 \mathrm{E}-02$ \\
\hline $\mathrm{U}-236$ & $2.52 \mathrm{E}-02$ \\
\hline $\mathrm{U}-238$ & $6.78 \mathrm{E}-01$ \\
\hline $\mathrm{Pu}-239$ & $8.42 \mathrm{E}-03$ \\
\hline $\mathrm{Pu}-240$ & $4.36 \mathrm{E}-03$ \\
\hline
\end{tabular}

The inventory of selected fission products in each of the five DLBL solutions is given in Table 3 , both as decay-corrected activity and the equivalent Compact 4-1-1 fraction, based on the predicted compact inventories provided in ECAR-958, Rev. 2 (Sterbentz 2013). The inventory of uranium and plutonium isotopes in the solutions is given in Table 4 in absolute measured mass and equivalent compact fraction. No decay correction has been applied to the $\mathrm{U}$ and $\mathrm{Pu}$ data due to the negligible impact on values; however, the $\mathrm{U}$ and $\mathrm{Pu}$ data are compared with the predicted compact inventories one year after end of irradiation (November 6, 2010, 12:00 GMT) to account for minor increases in predicted inventory due to decay of parent isotopes. Note that in these tables, a compact fraction of $2.42 \times 10^{-4}$ is equivalent to a single particle inventory based on 4,126 particles per compact (Hunn, Montgomery, and Pappano 2006). In cases where the activity or mass was below the detection limit for the method, the minimum detectable activity (MDA) was used to calculate the values in the tables and these values were included in the process totals. If the entries based on MDAs accounted for $>50 \%$ of the total for a particular isotope, then the total was listed as a threshold value (preceded by " $<$ "). 
Table 3. Fission products in the deconsolidation and leach solutions from Compact 4-1-1 expressed as decay-corrected activity (Bq) and compact fraction (based on calculated inventories [Sterbentz 2013]).

\begin{tabular}{|c|c|c|c|c|c|c|c|c|c|c|}
\hline & \multicolumn{10}{|c|}{ Activity $(\mathrm{Bq})^{\mathrm{a}}$} \\
\hline & Ag-110m & Ce-144 & Cs-134 & Cs-137 & Eu-154 & Eu-155 & Ru-106 & Sb-125 & Sr-90 & Zr-95 \\
\hline Deconsolidation & $6.61 \mathrm{E}+6$ & $<7 \mathrm{E}+4$ & $<5 \mathrm{E}+3$ & $3.31 \mathrm{E}+4$ & $1.12 \mathrm{E}+5$ & $9.19 \mathrm{E}+4$ & $1.02 \mathrm{E}+6$ & - & $2.26 \mathrm{E}+4$ & - \\
\hline $1^{\text {st }}$ Pre-burn leach & $4.91 \mathrm{E}+5$ & $1.23 \mathrm{E}+4$ & $<1 \mathrm{E}+3$ & $1.91 \mathrm{E}+3$ & $2.13 \mathrm{E}+4$ & $1.65 \mathrm{E}+4$ & 一 & $<4 \mathrm{E}+3$ & $1.90 \mathrm{E}+3$ & $<4 \mathrm{E}+5$ \\
\hline $2^{\text {nd }}$ Pre-burn leach & $3.20 \mathrm{E}+4$ & $2.76 \mathrm{E}+3$ & $1.83 \mathrm{E}+2$ & $6.01 \mathrm{E}+2$ & $3.77 \mathrm{E}+3$ & $2.71 \mathrm{E}+3$ & $3.76 \mathrm{E}+3$ & $<4 \mathrm{E}+2$ & $5.51 \mathrm{E}+2$ & - \\
\hline $1^{\text {st }}$ Post-burn leach & $2.36 \mathrm{E}+6$ & $5.25 \mathrm{E}+4$ & $<2 \mathrm{E}+3$ & $3.18 \mathrm{E}+3$ & $6.50 \mathrm{E}+4$ & $5.37 \mathrm{E}+4$ & - & $5.37 \mathrm{E}+3$ & $2.37 \mathrm{E}+3$ & - \\
\hline \multirow[t]{3}{*}{$2^{\text {nd }}$ Post-burn leach } & $1.95 \mathrm{E}+5$ & $5.54 \mathrm{E}+3$ & $<2 \mathrm{E}+2$ & $1.20 \mathrm{E}+3$ & $8.76 \mathrm{E}+2$ & $<5 \mathrm{E}+2$ & $2.85 \mathrm{E}+4$ & - & $1.12 \mathrm{E}+3$ & $<1 \mathrm{E}+5$ \\
\hline & \multicolumn{10}{|c|}{ Compact Fraction $^{\text {b }}$} \\
\hline & Ag-110m & Ce-144 & Cs-134 & Cs-137 & Eu-154 & Eu-155 & Ru-106 & Sb-125 & Sr-90 & Zr-95 \\
\hline Deconsolidation & $2.22 \mathrm{E}-2$ & $<3 \mathrm{E}-7$ & $<2 \mathrm{E}-7$ & $1.68 \mathrm{E}-6$ & $1.30 \mathrm{E}-4$ & $1.5 \mathrm{E}-4$ & $1.5 \mathrm{E}-5$ & - & $1.39 \mathrm{E}-6$ & - \\
\hline 1st Pre-burn leach & $1.65 \mathrm{E}-3$ & $5.7 \mathrm{E}-8$ & $<4 \mathrm{E}-8$ & $9.74 \mathrm{E}-8$ & $2.47 \mathrm{E}-5$ & $2.69 \mathrm{E}-5$ & - & $<3 \mathrm{E}-6$ & $1.16 \mathrm{E}-7$ & $<2 \mathrm{E}-6$ \\
\hline 2nd Pre-burn leach & $1.07 \mathrm{E}-4$ & $1 . \mathrm{E}-8$ & $6 . \mathrm{E}-9$ & $3.06 \mathrm{E}-8$ & $4.38 \mathrm{E}-6$ & $4.40 \mathrm{E}-6$ & $5.7 \mathrm{E}-8$ & $<3 \mathrm{E}-7$ & $3.38 \mathrm{E}-8$ & - \\
\hline 1st Post-burn leach & $7.93 \mathrm{E}-3$ & $2.4 \mathrm{E}-7$ & $<6 \mathrm{E}-8$ & $1.6 \mathrm{E}-7$ & $7.55 \mathrm{E}-5$ & $8.75 \mathrm{E}-5$ & 一 & 4.E-6 & $1.45 \mathrm{E}-7$ & - \\
\hline 2nd Post-burn leach & $6.55 \mathrm{E}-4$ & 3.E-8 & $<9 \mathrm{E}-9$ & $6.10 \mathrm{E}-8$ & $1.0 \mathrm{E}-6$ & $<7 \mathrm{E}-7$ & $4.3 \mathrm{E}-7$ & 一 & $6.88 \mathrm{E}-8$ & $<6 \mathrm{E}-7$ \\
\hline Process Totals & $3.25 \mathrm{E}-2$ & 7.E-7 & $<3 \mathrm{E}-7$ & $2.0 \mathrm{E}-6$ & $2.4 \mathrm{E}-4$ & $2.7 \mathrm{E}-4$ & $1.6 \mathrm{E}-5$ & $6 . \mathrm{E}-6$ & $1.75 \mathrm{E}-6$ & $<2 \mathrm{E}-6$ \\
\hline Particle equivalent & $1.34 \mathrm{E}+2$ & 3.E-3 & $<1 \mathrm{E}-3$ & $8.4 \mathrm{E}-3$ & $9.7 \mathrm{E}-1$ & $1.1 \mathrm{E}+0$ & $6.6 \mathrm{E}-2$ & 3.E-2 & $7.22 \mathrm{E}-3$ & $<9 \mathrm{E}-3$ \\
\hline
\end{tabular}

Table 4. Uranium and plutonium inventory in the deconsolidation and leach solutions from Compact 4-1-1 expressed as total mass ( $\mu \mathrm{g})$ and compact fraction (based on calculated inventories [Sterbentz 2013]).

\begin{tabular}{|c|c|c|c|c|c|c|}
\hline & \multicolumn{6}{|c|}{ Mass $(\mu \mathrm{g})$} \\
\hline & U-234 & U-235 & $\mathrm{U}-236$ & $\mathrm{U}-238$ & Pu-239 & Pu-240 \\
\hline Deconsolidation & $<3 \mathrm{E}-2$ & $1.74 \mathrm{E}+0$ & $6.60 \mathrm{E}-2$ & $6.25 \mathrm{E}+0$ & $1.79 \mathrm{E}-1$ & $<9 \mathrm{E}-2$ \\
\hline Pre-burn leach 1 & $<3 \mathrm{E}-2$ & $1.59 \mathrm{E}-1$ & $<9 \mathrm{E}-3$ & $1.37 \mathrm{E}+0$ & $9.20 \mathrm{E}-2$ & $<9 \mathrm{E}-2$ \\
\hline Pre-burn leach 2 & $<3 \mathrm{E}-2$ & $<1 \mathrm{E}-1$ & $<9 \mathrm{E}-3$ & $2.70 \mathrm{E}-1$ & $<1 \mathrm{E}-1$ & $<9 \mathrm{E}-2$ \\
\hline Post-burn leach 1 & $<3 \mathrm{E}-2$ & $<1 \mathrm{E}-1$ & $<9 \mathrm{E}-3$ & $6.03 \mathrm{E}-1$ & $<1 \mathrm{E}-1$ & $<9 \mathrm{E}-2$ \\
\hline \multirow[t]{3}{*}{ Post-burn leach 2} & $<3 \mathrm{E}-2$ & $<1 \mathrm{E}-1$ & $<9 \mathrm{E}-3$ & $2.98 \mathrm{E}-1$ & $<1 \mathrm{E}-1$ & $<9 \mathrm{E}-2$ \\
\hline & \multicolumn{6}{|c|}{ Compact Fraction } \\
\hline & U-234 & $\mathrm{U}-235$ & U-236 & U-238 & Pu-239 & Pu-240 \\
\hline Deconsolidation & $<2 \mathrm{E}-5$ & $1.01 \mathrm{E}-4$ & $2.62 \mathrm{E}-6$ & $9.21 \mathrm{E}-6$ & $2.13 \mathrm{E}-5$ & $<2 \mathrm{E}-5$ \\
\hline Pre-burn leach 1 & $<2 \mathrm{E}-5$ & $9.20 \mathrm{E}-6$ & $<4 \mathrm{E}-7$ & $2.02 \mathrm{E}-6$ & $1.09 \mathrm{E}-5$ & $<2 \mathrm{E}-5$ \\
\hline Pre-burn leach 2 & $<2 \mathrm{E}-5$ & $<6 \mathrm{E}-6$ & $<4 \mathrm{E}-7$ & $3.98 \mathrm{E}-7$ & $<1 \mathrm{E}-5$ & $<2 \mathrm{E}-5$ \\
\hline Post-burn leach 1 & $<2 \mathrm{E}-5$ & $<6 \mathrm{E}-6$ & $<4 \mathrm{E}-7$ & $8.89 \mathrm{E}-7$ & $<1 \mathrm{E}-5$ & $<2 \mathrm{E}-5$ \\
\hline Post-burn leach 2 & $<2 \mathrm{E}-5$ & $<6 \mathrm{E}-6$ & $<4 \mathrm{E}-7$ & $4.39 \mathrm{E}-7$ & $<1 \mathrm{E}-5$ & $<2 \mathrm{E}-5$ \\
\hline Process totals & $<1 \mathrm{E}-4$ & $1.27 \mathrm{E}-4$ & $4.05 \mathrm{E}-6$ & $1.30 \mathrm{E}-5$ & $<7 \mathrm{E}-5$ & $<1 \mathrm{E}-4$ \\
\hline Particle equivalent & $<4 \mathrm{E}-1$ & $5.25 \mathrm{E}-1$ & $1.67 \mathrm{E}-2$ & $5.35 \mathrm{E}-2$ & $<3 \mathrm{E}-1$ & $<4 \mathrm{E}-1$ \\
\hline
\end{tabular}


The uranium data in Table 4 indicate that there were no exposed kernels during the DLBL process, indicating no particles with failed TRISO or failed SiC layers. The U-235 total is equivalent to approximately $50 \%$ of the inventory in a single particle. However, this is most likely due to a combination of background contamination in the hot cell as well as the low predicted inventory of U-235 ( $0.17 \mathrm{~g})$ relative to the predicted inventory of U-238 (0.68 g) in Compact 4-1-1, making the U-235 data more sensitive to contributions from contamination. The U-238 inventory in the solutions is above detection limits and is extremely low (total compact fraction of $1.28 \times 10^{-5}$, or $\sim 5 \%$ of a single particle inventory, in all solutions combined).

The total quantity of $\mathrm{Ag}-110 \mathrm{~m}$ found outside of the $\mathrm{SiC}$ layer was $3.3 \%$ of the compact inventory, equivalent to the inventory in 134 Compact 4-1-1 particles, clearly indicating release through intact coatings. Note that $12.5 \%$ of the total Capsule 4 inventory of Ag- $110 \mathrm{~m}$ was measured outside of the compacts on the various capsule components (Demkowicz et al. 2013; Harp, Demkowicz, and Ploger 2012).

Total Eu-154 found outside of the SiC layer was $2.4 \times 10^{-4}$, equivalent to the inventory in $\sim 1$ particle, and is likely indicative of release through intact coatings. There is good agreement between Eu-154 and Eu-155 results. The Sr-90 and Ce-144 inventories were much lower, amounting to a compact fraction of only $1.76 \times 10^{-6}$ and $7 \times 10^{-7}$, respectively, indicating very limited release through intact coatings. Similarly the Cs-134 and Cs-137 inventories were very low. The Cs-134 inventory was lower than Cs-137, and in most solutions was below detection limits. The Cs-137 levels are more likely to be influenced by hot cell contamination than Cs-134.

Note that there is a similar trend in the measured activities in the various DLBL solutions for many of the fission products including Eu-154, Eu-155, Ce-144, and Sr-90. In particular, the inventory in the solutions tends to decrease dramatically with each successive leach step before the burn (deconsolidation $>1^{\text {st }}$ pre-burn leach $>2^{\text {nd }}$ pre-burn leach), followed by a jump in inventory in the first post-burn leach solutions and again a decrease with the second post-burn leach solution. The increase in inventory in the first post-burn leach solution is believed to be due to the oxidation of carbide phases, which had limited solubility in nitric acid.

\section{PARTICLE INSPECTION AND GAMMA COUNTING \\ 3.1 Visual Inspection}

Details of the equipment and procedures for visual particle inspection and gamma spectrometry of individual particles are given in Appendix B. Because no grab samples of particles were taken between deconsolidation-leach-burn-leach steps, all particles inspected show the exterior silicon carbide layer that was exposed following the final burn step.

All particles were essentially spheroidal, but some particles had irregular white markings on the $\mathrm{SiC}$ surface that appeared to have some raised surface relief. Some particles had greater than approximately $25 \%$ white surface, but most had only occasional freckles. The surfaces resembled hard water deposits. Inspection of particles revealed that as much as approximately $15 \%$ of the particles viewed had some degree of white surface character as shown in Figure 6 and Figure 7, but no obvious evidence of cracks or other mechanical damage in the $\mathrm{SiC}$ was observed. The distinct dark lines and smears observed in particles from Compact 6-3-2 (Demkowicz et al. 2012) were not common. No apparent fissures were observed. 


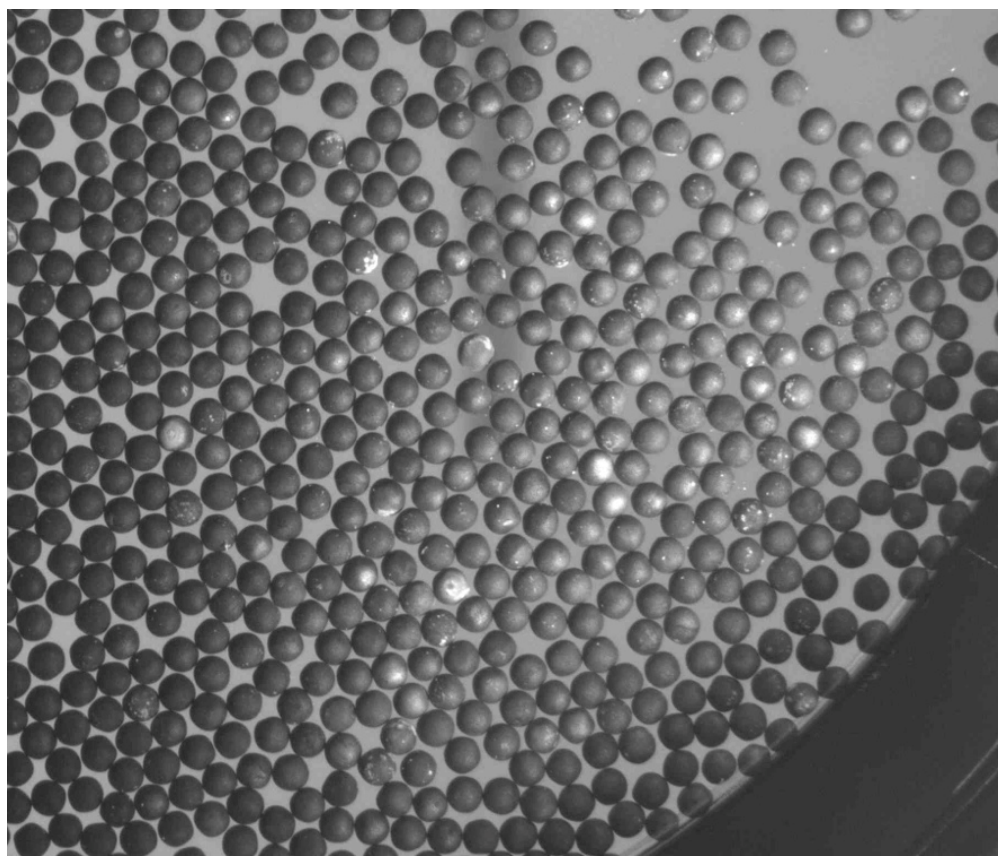

Figure 6. Photograph of irradiated AGR-1 Compact 4-1-1 particles following the second post-burn leach. Note certain particles with white surface markings.

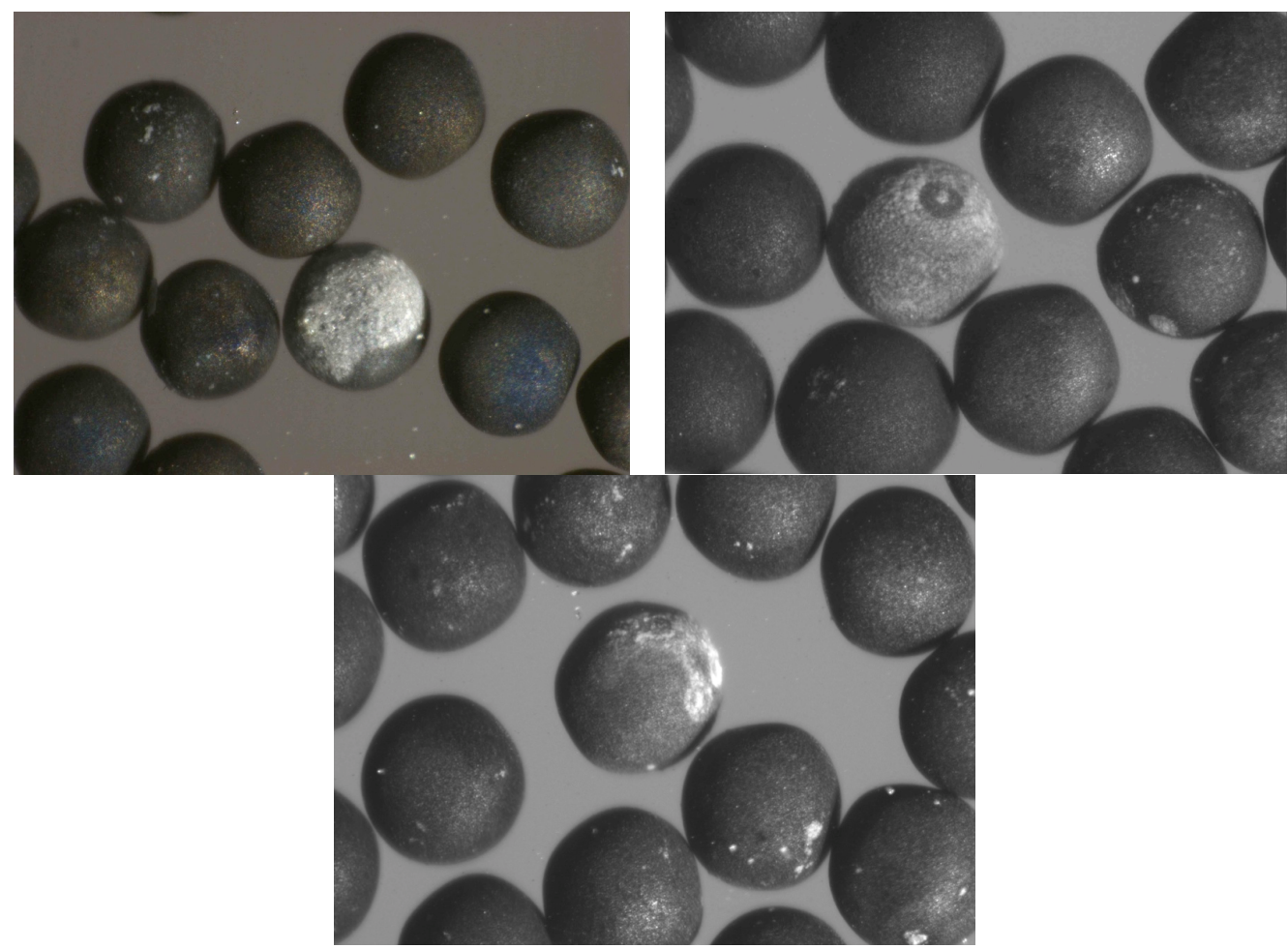

Figure 7. Several specific examples of irradiated AGR-1 Compact 4-1-1 particles with conspicuous white surface markings. 


\subsection{Particle Gamma Counting}

A total of 61 particles from Compact 4-1-1 were gamma counted following the second post-burn leach. Individual particles were selected using the inspection system described in Appendix B. This included 59 particles placed in individual glass vials, and two particles that were inadvertently placed in a single vial together (discovered after review of the gamma data). The count times used were either 2 or 12 hours. The gamma counting was performed between February 7, 2011 and April 28, 2011. Details of the gammacounting equipment and procedure are given in Appendix B.

Table 5 provides the decay-corrected activity of each isotope measured in the particles (all activity values are decay-corrected to November 7, 2009, 12:00 GMT, one day after the end of the AGR-1 irradiation, as discussed in Section 2). No Ru-103 activity was detected in numerous particles and the MDA was used to calculate the decay-corrected activities in the table instead (values in gray text and preceded by "<"). Due to the short half-life of Ru-103 ( $t_{1 / 2}=39.2$ days) it had decayed sufficiently such that the remaining activity was near the detection limit, and the uncertainties on the measured values were high.

Table 5. Decay corrected activities (in $\mathrm{Bq}$ ) for isotopes measured by gamma counting of particles from irradiated Compact 4-1-1. Values in gray indicate the MDA for cases in which no activity was detected. ${ }^{\text {a }}$

\begin{tabular}{|c|c|c|c|c|c|c|c|c|c|c|}
\hline & $10 \mathrm{~m}$ & & & & & & & & & $\mathrm{Zr}-95$ \\
\hline & & $4.35 \mathrm{E}+7$ & $.77 \mathrm{E}+6$ & $4.39 \mathrm{E}+6$ & $1.73 \mathrm{E}+5$ & & $2.35 \mathrm{E}+7$ & & & 4.13E+7 \\
\hline & & & $.77 \mathrm{E}+6$ & & & & & & & \\
\hline & & & & & & & & & & $99 \mathrm{E}+7$ \\
\hline & & & & & & & & & & $4.44 \mathrm{E}+7$ \\
\hline & & & & & & & & & & $5.34 \mathrm{E}+7$ \\
\hline & & & & & & & & & & $7 \mathrm{E}+7$ \\
\hline & & & & & & & & & & $98 \mathrm{E}+7$ \\
\hline & & & & & & & & & & $85 \mathrm{E}+7$ \\
\hline & & & & & & & & & & \\
\hline & & & & & & & & & & $0 \mathrm{E}+7$ \\
\hline & & & & & & & & & & $3 \mathrm{E}+7$ \\
\hline & & & & & & & & & & \\
\hline & & & & & & & & & & \\
\hline & & $\mathrm{E}+7$ & $6.20 \mathrm{E}+6$ & $2 \mathrm{E}+6$ & $1.63 \mathrm{E}+5$ & & & & & $5.74 \mathrm{E}+7$ \\
\hline & & & & & & & & & & \\
\hline & & & & & & & & & & \\
\hline & & & & $6 \mathrm{E}+6$ & $1.93 \mathrm{E}+5$ & & & & & $4 \mathrm{E}+7$ \\
\hline & & & & & & & & & & $9 \mathrm{E}+7$ \\
\hline & & & & & & & & & & $7 \mathrm{E}+7$ \\
\hline & & & & & & & & & & \\
\hline & & & & & & & & & & $22 \mathrm{E}+7$ \\
\hline & & & & & & & & & & $1 \mathrm{E}+7$ \\
\hline & & & & & & & & & & \\
\hline & & & & & & & & & & $1 \mathrm{E}+1$ \\
\hline & & & & & $2.17 \mathrm{E}+5$ & & & & & $78 \mathrm{E}+7$ \\
\hline & & & & & $1.94 \mathrm{E}+5$ & & & & & $30 \mathrm{E}+7$ \\
\hline & & & & & & & & & & $9.08 \mathrm{E}+7$ \\
\hline & & & & & $1.89 \mathrm{E}+5$ & & & & & $4.90 \mathrm{E}+7$ \\
\hline AGR1-411-037 & $8.91 \mathrm{E}+4$ & $4.93 \mathrm{E}+7$ & $7.00 \mathrm{E}+6$ & $4.81 \mathrm{E}+6$ & $1.79 \mathrm{E}+5$ & $1.12 \mathrm{E}+5$ & $5 . \mathrm{E}+7$ & $1.43 \mathrm{E}+7$ & $2.29 \mathrm{E}+5$ & $4.84 \mathrm{E}+7$ \\
\hline
\end{tabular}


Table 5. (continued).

\begin{tabular}{|c|c|c|c|c|c|c|c|c|c|c|}
\hline Particle No. & $\mathrm{g}-110 \mathrm{~m}$ & Ce-144 & Cs-134 & Cs-137 & Eu-154 & $\mathrm{Eu}-155$ & $\mathrm{Ru}-103$ & Ru-106 & $\mathrm{Sb}-125$ & Zr-95 \\
\hline AGR1-411-038 & $45 \mathrm{E}+4$ & $72 \mathrm{E}+7$ & $6.83 \mathrm{E}+6$ & $4.65 \mathrm{E}+6$ & $1.75 \mathrm{E}+5$ & $9.11 \mathrm{E}+4$ & $3.1 \mathrm{E}+7$ & $1.38 \mathrm{E}+7$ & $2.22 \mathrm{E}+5$ & $4.50 \mathrm{E}+7$ \\
\hline AGR1-411-039 & & $4.93 \mathrm{E}+7$ & $8.25 \mathrm{E}+6$ & $5.20 \mathrm{E}+6$ & $2.04 \mathrm{E}+5$ & $1.0 \mathrm{E}+5$ & $<6 . \mathrm{E}+7$ & $1.54 \mathrm{E}+7$ & $2.10 \mathrm{E}+5$ & $4.41 \mathrm{E}+7$ \\
\hline AGR1-411-040 & $.02 \mathrm{E}+4$ & $.23 \mathrm{E}+7$ & $5.88 \mathrm{E}+6$ & $4.43 \mathrm{E}+6$ & $1.58 \mathrm{E}+5$ & $1.1 \mathrm{E}+5$ & $<6 . \mathrm{E}+7$ & $1.25 \mathrm{E}+7$ & $2.14 \mathrm{E}+5$ & $5.84 \mathrm{E}+7$ \\
\hline AGR1-411-041 & $9.45 \mathrm{E}+4$ & $4.87 \mathrm{E}+7$ & $7.66 \mathrm{E}+6$ & $5.01 \mathrm{E}+6$ & $1.93 \mathrm{E}+5$ & $0,5 F+4$ & $<3 . \mathrm{E}+7$ & $1.41 \mathrm{E}+7$ & $2.45 \mathrm{E}+5$ & $4.53 \mathrm{E}+7$ \\
\hline AGR1-411-042 & & & $6.89 \mathrm{E}+6$ & & $1.81 \mathrm{E}+5$ & & $<3 . \mathrm{E}+7$ & $1.34 \mathrm{E}+7$ & $1.83 \mathrm{E}+5$ & $4.52 \mathrm{E}+7$ \\
\hline AGR1-411-043 & & & $7.01 \mathrm{E}+6$ & & & & 3.E+7 & & $2.28 \mathrm{E}+5$ & $5.55 \mathrm{E}+7$ \\
\hline AGR1-411-044 & & & $7.03 \mathrm{E}+6$ & & & $1.17 \mathrm{E}+5$ & & & $2.06 \mathrm{E}+5$ & \\
\hline 045 & & & $6.03 \mathrm{E}+6$ & $4.44 \mathrm{E}+6$ & & & $<4$.E +7 & & & $5.37 \mathrm{E}+7$ \\
\hline AGR1-411-046 & & & $7.23 \mathrm{E}+6$ & & & & & & $2.19 \mathrm{E}+5$ & $5.27 \mathrm{E}+7$ \\
\hline AGR1-411-047 & & & & & & & & & & \\
\hline AGR1-411-048 & $8.19 \mathrm{E}+4$ & $5.15 \mathrm{E}+7$ & $7.49 \mathrm{E}+6$ & $5.08 \mathrm{E}+6$ & $1.97 \mathrm{E}+5$ & $1.20 \mathrm{E}+5$ & $3.2 \mathrm{E}+7$ & $1.36 \mathrm{E}+7$ & $1.98 \mathrm{E}+5$ & $4.96 \mathrm{E}+7$ \\
\hline AGR1-4 & $5.0 \mathrm{E}+04$ & $4.82 \mathrm{E}+7$ & $6.20 \mathrm{E}+6$ & $4.40 \mathrm{E}+6$ & $1.59 \mathrm{E}+5$ & $1.1 \mathrm{E}+5$ & $<7 . \mathrm{E}+7$ & $1.20 \mathrm{E}+7$ & $1.84 \mathrm{E}+5$ & $4.79 \mathrm{E}+7$ \\
\hline AGR1-411-050 & & & & & & & & & & $4.62 \mathrm{E}+7$ \\
\hline AGR1-411-051 & $.49 \mathrm{E}+4$ & $5.56 \mathrm{E}+7$ & $7.17 \mathrm{E}+6$ & $5.09 \mathrm{E}+6$ & $1.88 \mathrm{E}+5$ & $1.2 \mathrm{E}+5$ & $<4$.E +7 & $1.45 \mathrm{E}+7$ & $2.57 \mathrm{E}+5$ & $5.70 \mathrm{E}+7$ \\
\hline AGR1-411-052 & $9.19 \mathrm{E}+4$ & $5.10 \mathrm{E}+7$ & $7.84 \mathrm{E}+6$ & $5.12 \mathrm{E}+6$ & $1.99 \mathrm{E}+5$ & $1.45 \mathrm{E}+5$ & $2.7 \mathrm{E}+7$ & $1.42 \mathrm{E}+7$ & $1.82 \mathrm{E}+5$ & $4.61 \mathrm{E}+7$ \\
\hline AGR1-411-053 & $4.9 \mathrm{E}+4$ & & $6.30 \mathrm{E}+6$ & $4.70 \mathrm{E}+6$ & $1.68 \mathrm{E}+5$ & $1.21 \mathrm{E}+5$ & & $1.26 \mathrm{E}+7$ & $2.26 \mathrm{E}+5$ & $5.74 \mathrm{E}+7$ \\
\hline AGR1-411-054 & $9.50 \mathrm{E}+4$ & $4.98 \mathrm{E}+7$ & $8.20 \mathrm{E}+6$ & $5.20 \mathrm{E}+6$ & $2.06 \mathrm{E}+5$ & & $<8 . \mathrm{E}+7$ & $1.53 \mathrm{E}+7$ & $2.31 \mathrm{E}+5$ & $4.69 \mathrm{E}+7$ \\
\hline AGR1-411-055 & $5.59 \mathrm{E}+4$ & $5.00 \mathrm{E}+7$ & $6.47 \mathrm{E}+6$ & $4.59 \mathrm{E}+6$ & $1.68 \mathrm{E}+5$ & $9.77 \mathrm{E}+4$ & $<3 . \mathrm{E}+7$ & $1.24 \mathrm{E}+7$ & $2.01 \mathrm{E}+5$ & $5.17 \mathrm{E}+7$ \\
\hline AGR1-411-056 & $6.13 \mathrm{E}+4$ & $4.59 \mathrm{E}+7$ & $5.43 \mathrm{E}+6$ & $4.02 \mathrm{E}+6$ & $1.46 \mathrm{E}+5$ & $9.6 \mathrm{E}+4$ & $<4$.E +7 & $1.15 \mathrm{E}+7$ & $2.01 \mathrm{E}+5$ & $4.97 \mathrm{E}+7$ \\
\hline AGR1-411-057 & $8.2 \mathrm{E}+4$ & $4.60 \mathrm{E}+7$ & $6.93 \mathrm{E}+6$ & $4.63 \mathrm{E}+6$ & $1.75 \mathrm{E}+5$ & $1.07 \mathrm{E}+5$ & 3.E+7 & $1.29 \mathrm{E}+7$ & $2.08 \mathrm{E}+5$ & $4.32 \mathrm{E}+7$ \\
\hline AGR1-411-058 & $8.26 \mathrm{E}+4$ & $5.60 \mathrm{E}+7$ & $8.18 \mathrm{E}+6$ & $5.51 \mathrm{E}+6$ & $2.07 \mathrm{E}+5$ & $1.24 \mathrm{E}+5$ & $<7 . \mathrm{E}+7$ & $1.48 \mathrm{E}+7$ & $2.0 \mathrm{E}+5$ & $5.40 \mathrm{E}+7$ \\
\hline AGR1-411-059 & $7.74 \mathrm{E}+4$ & $4.66 \mathrm{E}+7$ & $7.05 \mathrm{E}+6$ & $4.66 \mathrm{E}+6$ & $1.82 \mathrm{E}+5$ & $1.13 \mathrm{E}+5$ & $2.8 \mathrm{E}+7$ & $1.27 \mathrm{E}+7$ & $1.85 \mathrm{E}+5$ & $4.51 \mathrm{E}+7$ \\
\hline AGR1-411-060 & $5.53 \mathrm{E}+4$ & $4.91 \mathrm{E}+7$ & $6.40 \mathrm{E}+6$ & $4.51 \mathrm{E}+6$ & $1.66 \mathrm{E}+5$ & $1.11 \mathrm{E}+5$ & $<4$.E +7 & $1.18 \mathrm{E}+7$ & $1.89 \mathrm{E}+5$ & $4.98 \mathrm{E}+7$ \\
\hline AGR1-411-061 & $6.20 \mathrm{E}+4$ & $4.65 \mathrm{E}+7$ & $5.50 \mathrm{E}+6$ & $4.05 \mathrm{E}+6$ & $1.47 \mathrm{E}+5$ & $9.1 \mathrm{E}+4$ & $<7 . \mathrm{E}+7$ & $1.20 \mathrm{E}+7$ & $1.88 \mathrm{E}+5$ & $5.04 \mathrm{E}+7$ \\
\hline AGR1-411-062 & $6.65 \mathrm{E}+4$ & $4.60 \mathrm{E}+7$ & $6.70 \mathrm{E}+6$ & $4.51 \mathrm{E}+6$ & $1.72 \mathrm{E}+5$ & $1.14 \mathrm{E}+5$ & $<6 . \mathrm{E}+7$ & $1.22 \mathrm{E}+7$ & $1.91 \mathrm{E}+5$ & $4.46 \mathrm{E}+7$ \\
\hline AGR1-411-063 & 8.E+4 & $5.48 \mathrm{E}+7$ & $7.54 \mathrm{E}+6$ & $5.24 \mathrm{E}+6$ & $1.98 \mathrm{E}+5$ & $1.17 \mathrm{E}+5$ & $3.6 \mathrm{E}+7$ & $1.39 \mathrm{E}+7$ & $2.49 \mathrm{E}+5$ & $5.40 \mathrm{E}+7$ \\
\hline AGR1-411-064 & $6.28 \mathrm{E}+4$ & $4.99 \mathrm{E}+7$ & $7.04 \mathrm{E}+6$ & $4.82 \mathrm{E}+6$ & $1.79 \mathrm{E}+5$ & $1.08 \mathrm{E}+5$ & $4.7 \mathrm{E}+7$ & $1.29 \mathrm{E}+7$ & $1.76 \mathrm{E}+5$ & $4.88 \mathrm{E}+7$ \\
\hline AGR1-411-065 & $7.21 \mathrm{E}+4$ & $4.90 \mathrm{E}+7$ & $7.24 \mathrm{E}+6$ & $4.78 \mathrm{E}+6$ & $1.86 \mathrm{E}+5$ & $8.7 \mathrm{E}+4$ & $<8 . \mathrm{E}+7$ & $1.35 \mathrm{E}+7$ & $2.11 \mathrm{E}+5$ & $4.72 \mathrm{E}+7$ \\
\hline AGR1-411-066 & $8.06 \mathrm{E}+4$ & $6.48 \mathrm{E}+7$ & $9.13 \mathrm{E}+6$ & $6.20 \mathrm{E}+6$ & $2.37 \mathrm{E}+5$ & $1.41 \mathrm{E}+5$ & $5.3 \mathrm{E}+7$ & $1.77 \mathrm{E}+7$ & $2.53 \mathrm{E}+5$ & $6.19 \mathrm{E}+7$ \\
\hline AGR1-411-067 & $6.47 \mathrm{E}+4$ & $4.86 \mathrm{E}+7$ & $6.70 \mathrm{E}+6$ & $4.62 \mathrm{E}+6$ & $1.69 \mathrm{E}+5$ & $1.11 \mathrm{E}+5$ & $<3 . \mathrm{E}+7$ & $1.26 \mathrm{E}+7$ & $1.98 \mathrm{E}+5$ & $4.79 \mathrm{E}+7$ \\
\hline AGR1-411-068 & $6.64 \mathrm{E}+4$ & $5.07 \mathrm{E}+7$ & $6.24 \mathrm{E}+6$ & $4.59 \mathrm{E}+6$ & $1.65 \mathrm{E}+5$ & $1.05 \mathrm{E}+5$ & $<7 . \mathrm{E}+7$ & $1.29 \mathrm{E}+7$ & $2.13 \mathrm{E}+5$ & $5.35 \mathrm{E}+7$ \\
\hline Average $^{c}$ & $7.40 \mathrm{E}+4$ & $4.92 \mathrm{E}+7$ & $6.85 \mathrm{E}+6$ & $4.71 \mathrm{E}+6$ & $1.77 \mathrm{E}+5$ & $1.05 \mathrm{E}+5$ & $4.38 \mathrm{E}+7$ & $1.33 \mathrm{E}+7$ & $2.06 \mathrm{E}+5$ & $4.90 \mathrm{E}+7$ \\
\hline $\mathrm{SD}$ & $1.6 \mathrm{E}+4$ & $3.9 \mathrm{E}+6$ & $8.5 \mathrm{E}+5$ & $4.1 \mathrm{E}+5$ & $2.0 \mathrm{E}+4$ & $1.5 \mathrm{E}+4$ & $1.7 \mathrm{E}+7$ & $1.3 \mathrm{E}+6$ & $2.0 \mathrm{E}+4$ & $5.5 \mathrm{E}+6$ \\
\hline \multicolumn{11}{|c|}{$\begin{array}{l}\text { a. Measured activity data taken from AL Report No. } 93239 \text { (2011) } \\
\text { b. Particle AGR1-411-035 was in fact two particles inadvertently loaded into a single vial. The values from these two particles have not been } \\
\text { included in the averages and standard deviations reported in the table. }\end{array}$} \\
\hline
\end{tabular}

Figure 8 shows the distribution of Ce-144 activities of 61 particles from Compact 4-1-1, normalized to the mean. Note the single vial that was inadvertently loaded with two particles (normalized activity of 1.84). In addition, there was one particle (AGR1-411-066) with a Ce-144 activity that was 30\% larger than the mean. The activity of other key isotopes (Cs-134, Cs-137, Eu-154, Ru-106, and Zr-95) is greater than the mean by a similar amount, indicating that this particle apparently was an AGR-1 particle that simply had a larger-than-average kernel. 


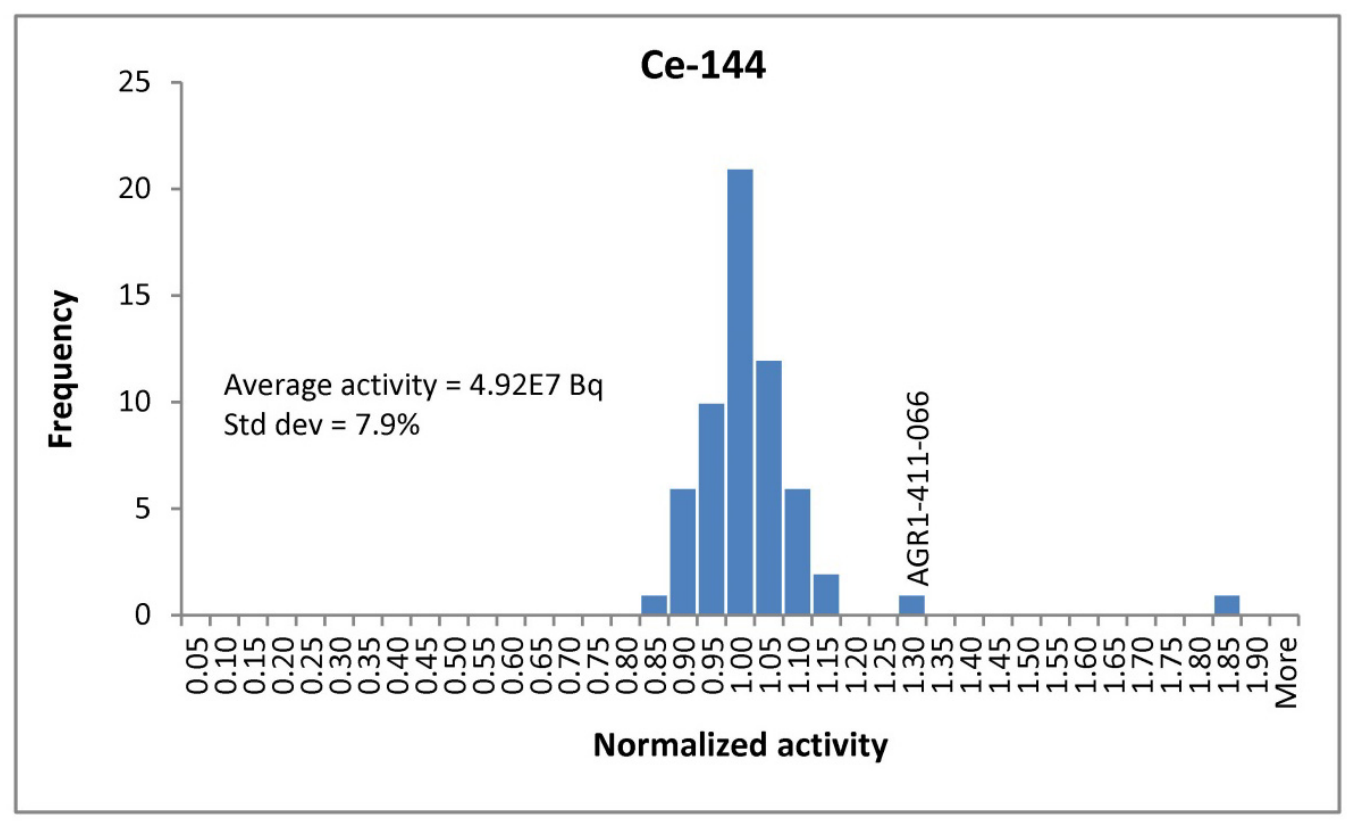

Figure 8. Normalized Ce-144 activity distribution for 61 particles from irradiated AGR-1 Compact 4-1-1. Note: Average activity and standard deviation shown on the figure do not include the double particle at 1.84 .

For each isotope, $X$, the measured inventory in each particle $\left(A_{i}^{X}\right)$ was compared with the value predicted by physics calculations (Sterbentz 2013). The predicted activity in each particle was determined by dividing the predicted activity for Compact 4-1-1 $\left(A_{411(\text { calc })}^{X}\right)$ by the average number of particles per AGR-1 Variant 3 compact $(4,126)$. A normalization was then applied to this value to minimize the particle-to-particle variation in starting fissile content (the result of variation in as-fabricated kernel characteristics such as diameter, density, and stoichiometry) and burnup. For most isotopes, this was accomplished by dividing by the ratio of the measured Cs-137 activity in particle $i\left(A_{i}^{C s 137}\right)$ to the average measured Cs-137 activity for all $n$ particles measured $\left(\sum_{i=1}^{n}\left(\frac{1}{n}\right) A_{i}^{C s 137}\right)$. The result is a ratio of measured to calculated isotope activity, normalized for variations in fissile content and burnup as shown in Equation (2) This ratio represents an estimate of the fraction of the original inventory that was retained in the particle. It is, however, subject to errors due to the biases in the predicted inventory in the compact.

$\frac{\left[A_{i}^{X} /\left(\frac{A_{411(\text { calc })}^{X}}{4126}\right)\right]}{A_{i}^{C S 137} / \sum_{i=1}^{n}\left(\frac{1}{n}\right) A_{i}^{C S 137}}$

Cs-137 activity was used to normalize the values because it has high activity, is easy to quantify with low uncertainty, is generated as a relatively linear function of burnup, and is well retained in particles with intact SiC. In the case of Cs-137, Ce-144 activity was used in Equation (2) (instead of Cs-137) to normalize the values for variation in fissile content and burnup.

Table 6 lists the average measured-to-calculated activity ratio for several isotopes in Compact 4-1-1. These are the average of the individual values calculated for each particle. The average measured-to-calculated activity ratio for several isotopes (including Cs-134, Cs-137, and Ce-144) is very close to 1.0, indicating good agreement with the predicted values from Sterbentz 2013. The ratio for $\mathrm{Ag}-110 \mathrm{~m}$ is also close to 1.0 and will be addressed in further detail below. For the remaining fission products in Table 6, the measured-to-calculated ratios were significantly below 1.0. The main potential causes for such a deviation would be (a) a bias in the calculated activity of the compact or (b) significant 
release of the isotopes from the particles during irradiation. Based on the inventory of fission products found in the Capsule 4 components (Harp, Demkowicz, and Ploger 2012), as well as the inventory found outside of the $\mathrm{SiC}$ layer based on the DLBL results (Table 3), it is clear that average release of these isotopes (Eu-154, Eu-155, Ru-103, Ru-106, Sb-125, and Zr-95) from the individual particles was significantly less than $1 \%$. Therefore, release from the particles cannot be the explanation for the low measured-to-calculated ratios in Table 6 . The conclusion is that the discrepancy is primarily due to errors in the calculated fission product inventories. The values in Table 6 are in reasonably good agreement (within $10 \%$ or less) with measured-to-calculated values for the intact compact based on gamma-scanning (Harp 2013) for all isotopes except Ag-110m and Eu-155. (Values for these isotopes were not reported in Harp 2013.)

Table 6. Average ratio of measured-to-calculated activities.

\begin{tabular}{|l|c|c|c|}
\hline \multicolumn{1}{|c|}{ Isotope } & Avg & SD & CV $^{\mathrm{a}}$ \\
\hline Ag-110m & 1.02 & 0.18 & $18 \%$ \\
\hline Ce-144 & 0.94 & 0.06 & $6 \%$ \\
\hline Cs-134 & 1.00 & 0.06 & $6 \%$ \\
\hline Cs-137 & 0.99 & 0.06 & $6 \%$ \\
\hline Eu-154 & 0.85 & 0.03 & $4 \%$ \\
\hline Eu-155 & 0.70 & 0.09 & $13 \%$ \\
\hline Ru-106 & 0.83 & 0.03 & $4 \%$ \\
\hline Sb-125 & 0.58 & 0.05 & $13 \%$ \\
\hline Zr-95 & 0.89 & 0.11 & \\
\hline a. CV = coefficient of variation & & & \\
\hline
\end{tabular}

Figure 9 shows the distribution of the Ce-144 measured-to-calculated activity ratios for the 61 particles. Note that the double particle and the large kernel are now part of the main distribution, since the ratio of Cs-137 to Ce-144 activities were normal.

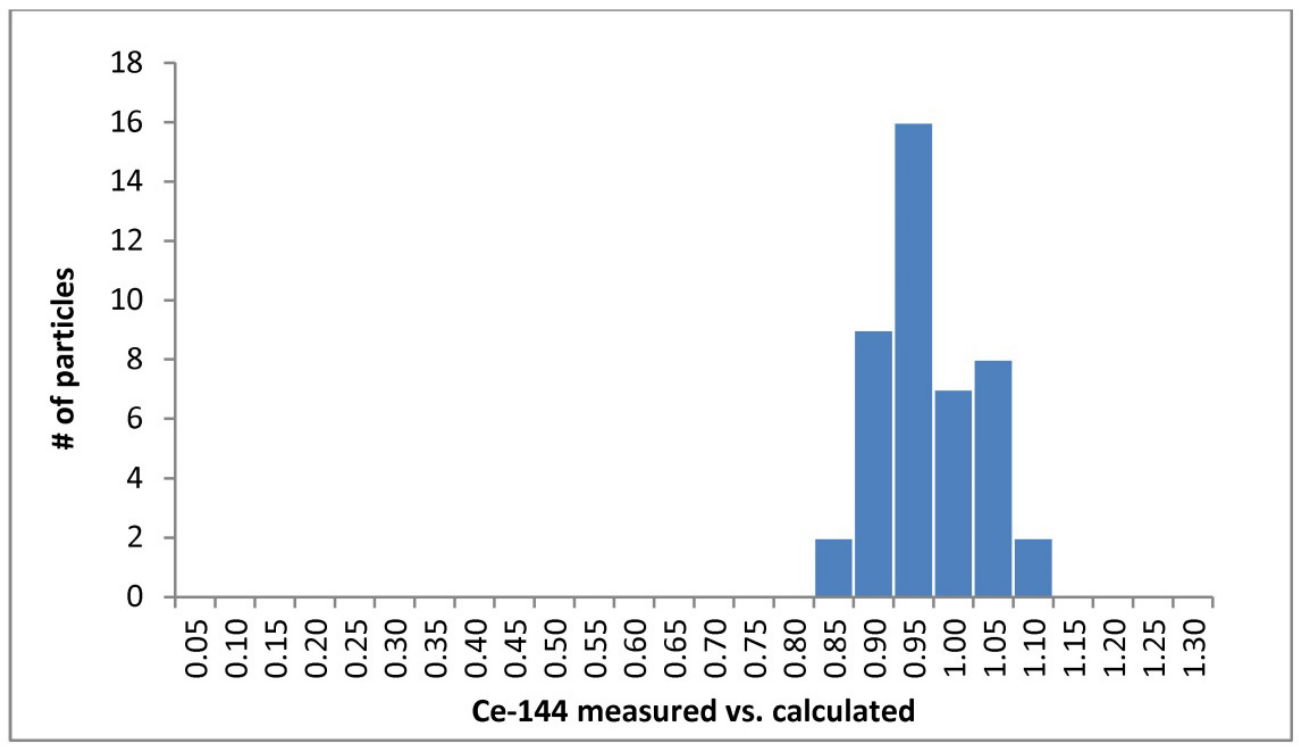

Figure 9. Distribution of Ce-144 measured-to-calculated activity ratios for 61 particles from irradiated AGR-1 Compact 4-1-1. 
The distribution of Ag-110m measured-to-calculated activity ratios is presented in Figure 10. Note that for Compact 4-1-1, this calculation includes both the double particle and the large kernel, since Equation $\left(2 \frac{\left[A_{i}^{X} /\left(\frac{A_{411(\text { calc })}^{X}}{4126}\right)\right]}{A_{i}^{\text {CS137 }} / \sum_{i=1}^{n}\left(\frac{1}{n}\right) A_{i}^{C S 137}}\right.$ () effectively normalizes the values. The distribution of values in Figure 10 is centered on a value of approximately 1.0 (actual mean is 1.02) and has broad range, with a standard deviation of 0.18 , a maximum of 1.42 , and a minimum of 0.68 . The reason for this is not immediately clear. One possible explanation is that the predicted Ag-110m inventory for Compact 4-1-1 is significantly lower than it should be, and therefore the ratios in Figure 10 are shifted too high and the distribution in reality reflects significant Ag- $110 \mathrm{~m}$ release from many of the particles. However, available AGR-1 PIE data indicate that the predicted Ag-110m compact inventory is reasonably accurate (a total Ag-110m mass balance for Capsule 4, including Ag-110m remaining in the compacts after irradiation as well as found in all of the capsule components, accounts for $93 \%$ of the predicted inventory [Demkowicz et al. 2013]). Gamma counting of the intact compacts suggests that this compact released very little of its Ag-110m inventory, ${ }^{a}$ while the DLBL data (Table 3) indicate that approximately $3.3 \%$ of the total compact Ag-110m inventory was retained in the compact outside of the SiC layers. The conclusion is that on average there was relatively low release of silver from the particles in this compact, and that the data presented in Figure 10 are indicative of a large distribution of Ag-110m activity in the particles due to irradiation conditions.

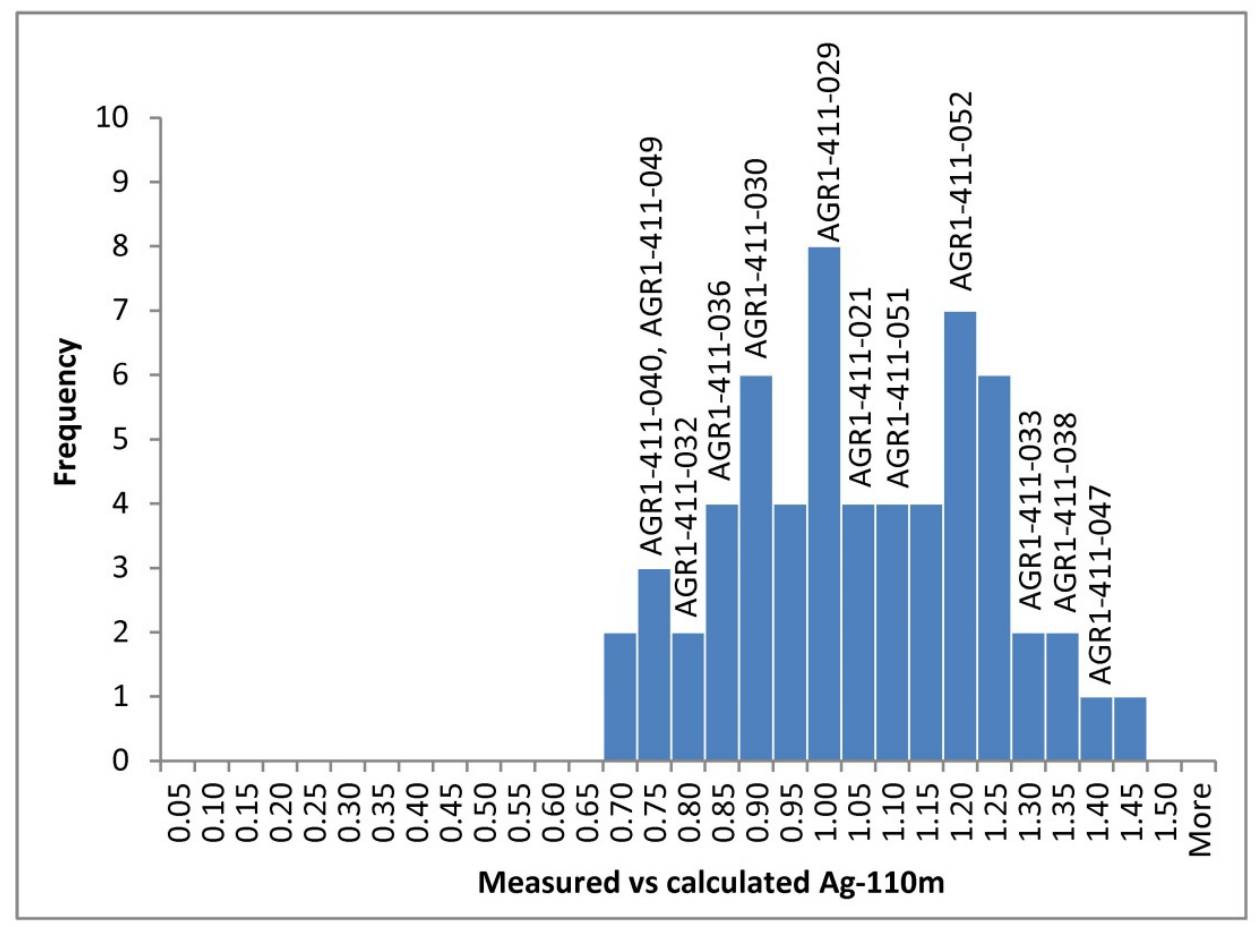

Figure 10. Distribution of measured-to-calculated Ag-110m activity ratios for AGR-1 Compact 4-1-1, normalized by the Cs-137 activity to account for variations in fissile content and burnup. Labels indicate the location of specific particles in the distribution.

Several particles were selected for microanalysis based on their measured Ag-110m inventory. These included three particles each with low and high measured-to-calculated Ag-110m ratios, and six particles

\footnotetext{
a While Compact 4-1-1 was not gamma scanned, the overall trend from the scanned compacts in Capsule 4 suggests that silver
} release from Compact 4-1-1 was very low (Harp 2013). 
with ratios near the mean. The locations of the specific particles in the overall distribution are shown in Figure 10. Preparation and analysis of these particles is discussed in Section 4. While one objective of this approach was to determine if differences in silver retention are correlated with various particle microstructural characteristics, it should be noted that in the case of Compact 4-1-1 it appears that most of the variation in $\mathrm{Ag}-110 \mathrm{~m} \mathrm{M} / \mathrm{C}$ ratio among the particles is due to a large range of inventories generated in the particles and not to large differences in silver retention behavior, as discussed above. This is notably different from the silver retention behavior of particles from other compacts (for example, Compact 6-3-2, as described in Demkowicz et al. 2012).

The distributions of the measured-to-calculated activity ratios of other measured fission products (Eu-154, Eu-155, Ru-106, Sb-125, Zr-95) to Cs-137 all had normal appearance with no conspicuous outliers. The Eu-154 measured-to-calculated activity ratio distribution is shown in Figure 11 as an example. The average value is 0.85 , as shown in Table 6 .

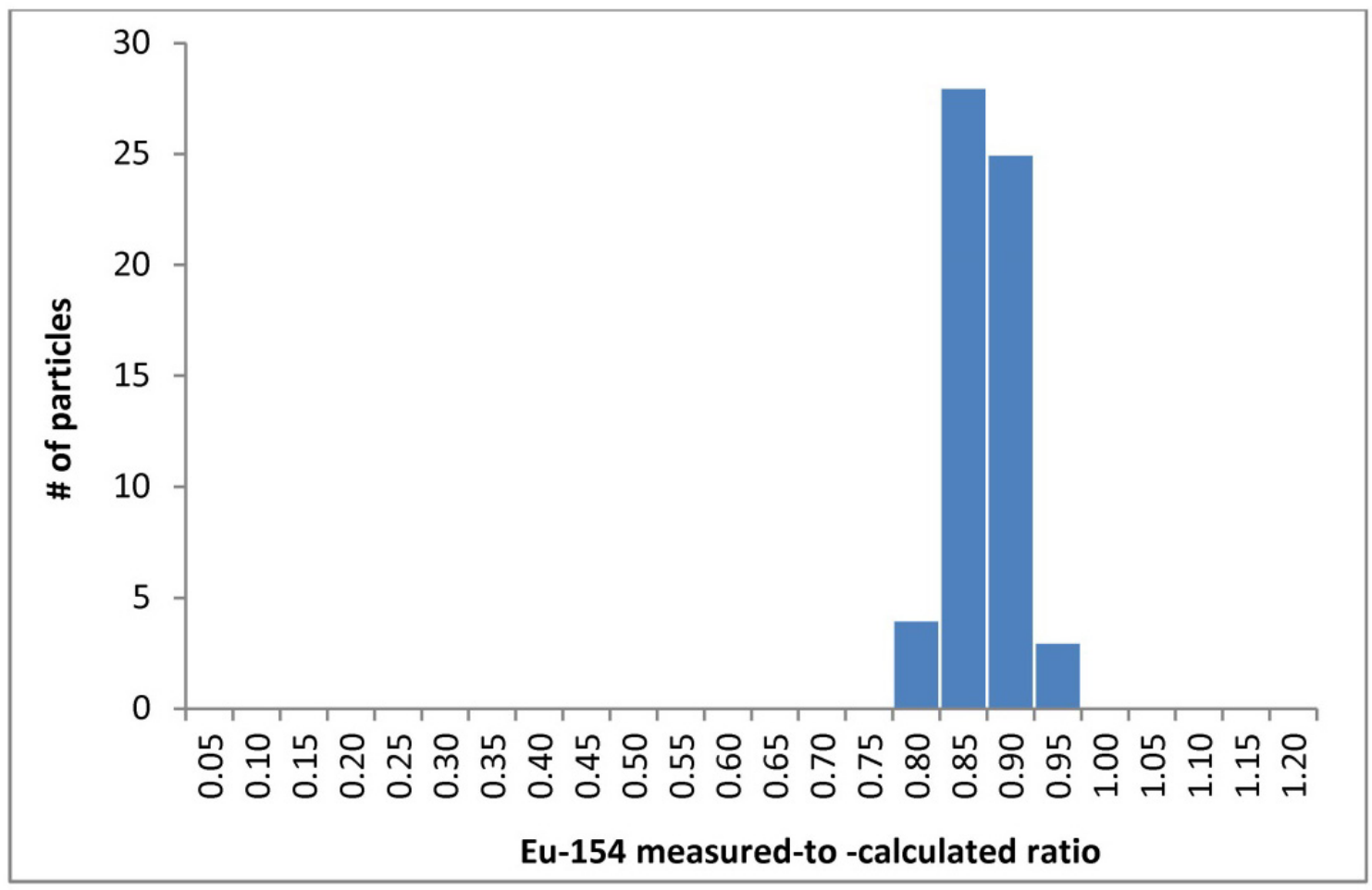

Figure 11. Distribution of Eu-154 measured-to-calculated activity ratios of 61 particles from irradiated AGR-1 Compact 4-1-1.

\section{MICROSCOPY}

\subsection{Sample Preparation and Ceramography}

Deconsolidated, burned-back particles from Compact 4-1-1 were loaded into cylindrical mounts and encapsulated with Buehler EpoHeat epoxy at the MFC AL. A total of ten mounts were prepared, as various problems were encountered and the sample preparation approach was modified during development of these mounts. The preparation of several mounts was unsatisfactory for a variety of reasons, including problems with epoxy curing or poor results during grinding and polishing, and these will not be discussed in detail in this report. Selected Compact 4-1-1 mounts are listed in Table 7 along with details on the particles (including identifiers from Table 5 and the Ag-110m M/C activity ratios) and mount characteristics. All mounts were pneumatically transferred to the Hot Fuel Examination Facility 
(HFEF) for surface preparation and ceramography. Except for highly radioactive Mount U3, all of these mounts were intended as candidates for additional studies at the MFC Electron Microscopy Laboratory (EML) if successfully prepared and if warranted by particle features. Although ceramography was completed on four mounts, only Mount 120T was sent to EML for further analysis.

Table 7. Compact 4-1-1 particle mounts. The Ag-110m measured-to-calculated (M/C) activity ratio is listed for each particle that was gamma counted.

\begin{tabular}{|c|c|c|c|c|}
\hline $\begin{array}{l}\text { Mount } \\
\text { ID }\end{array}$ & $\begin{array}{l}\text { Particle Numbers } \\
\text { (AGR1-411-0\#\#) }\end{array}$ & $\mathrm{Ag}-110 \mathrm{~m} \mathrm{M} / \mathrm{C}$ & Primary Purpose & Status \\
\hline $120 \mathrm{~T}$ & $\begin{array}{l}21 \\
29 \\
30\end{array}$ & $\begin{array}{l}1.04 \\
0.95 \\
0.88\end{array}$ & $\begin{array}{l}\text { Microstructure studies, } \\
\text { grinding/polishing for } \\
\text { flatter TRISO layers }\end{array}$ & $\begin{array}{l}\text { Successfully prepared, } \\
\text { ceramography complete, } \\
\text { transferred to EML. }\end{array}$ \\
\hline $121 \mathrm{~T}$ & $\begin{array}{l}36 \\
51 \\
52\end{array}$ & $\begin{array}{l}0.82 \\
1.09 \\
1.17\end{array}$ & $\begin{array}{l}\text { Microstructure studies, } \\
\text { grinding/polishing for } \\
\text { flatter TRISO layers }\end{array}$ & $\begin{array}{l}\text { Successfully prepared, } \\
\text { ceramography complete, } \\
\text { transferred to AL for } \\
\text { further processing. }\end{array}$ \\
\hline $127 \mathrm{~T}$ & $\begin{array}{l}32 \\
40 \\
49 \\
\end{array}$ & $\begin{array}{l}0.77 \\
0.74 \\
0.74 \\
\end{array}$ & $\begin{array}{l}\text { Microstructural influences } \\
\text { on Ag-110m release }\end{array}$ & $\begin{array}{l}\text { Successfully prepared, } \\
\text { ceramography complete. }\end{array}$ \\
\hline $128 \mathrm{~T}$ & $\begin{array}{l}33 \\
38 \\
47 \\
\end{array}$ & $\begin{array}{l}1.29 \\
1.33 \\
1.36 \\
\end{array}$ & $\begin{array}{l}\text { Microstructural influences } \\
\text { on Ag- } 110 \mathrm{~m} \text { retention }\end{array}$ & $\begin{array}{l}\text { SiC damage in } \\
\text { preparation, } \\
\text { ceramography complete. }\end{array}$ \\
\hline U3 & $\begin{array}{l}\text { Not gamma } \\
\text { counted }^{\mathrm{a}}\end{array}$ & N/A & $\begin{array}{l}\text { Optical characterization of } \\
\text { TRISO-layer behavior on } \\
128 \text { random particles }\end{array}$ & $\begin{array}{l}\text { Examined at six levels for } \\
\text { internal particle } \\
\text { morphology. }\end{array}$ \\
\hline
\end{tabular}

All Compact 4-1-1 mounts had an interior that tapered to a 19-mm (0.75-inch) cylinder in the bottom portion, as shown in Figure 12. The annular groove was added to prevent axial sliding of epoxy during pneumatic transfers between the HFEF Containment Box preparation cell and the Metallographic Loading Cell. Stainless steel was initially used as a mount material in conjunction with a series of thin narrow steps around the base exterior, which were primarily intended to avoid grinding on the full $6.4-\mathrm{mm}$ (0.25-inch) wall thickness of steel. Stainless steel was abandoned in favor of softer Micarta (a laminar composite based on thermosetting plastic) for all mounts listed in Table 7 after particles were sometimes found recessed into the mount above the steps in earlier mounts. Glass-backed, double-sided adhesive tape was employed to hold the particles in place, but the thin tape used through Mount 121T tended to deform inward. Thick double-sided tape that adhered better to the glass and that resisted deformation was used on subsequent mounts. Incomplete epoxy curing was observed on early mounts; consequently, a furnace cure $\left(90\right.$ minutes at $\left.55^{\circ} \mathrm{C}\right)$ was implemented at $\mathrm{AL}$ for all of the mounts listed in Table 7 . While 128 randomly selected particles were poured into Mount U3 without concern over placement, a narrow funnel was used to place individual particles close to a plastic orientation marker in the remaining mounts. This facilitated identifying the gamma-counted particles at HFEF during examination (relative to post-loading photographs taken at AL) and limited the mount area that had to be covered by stage movements during microscopy. 


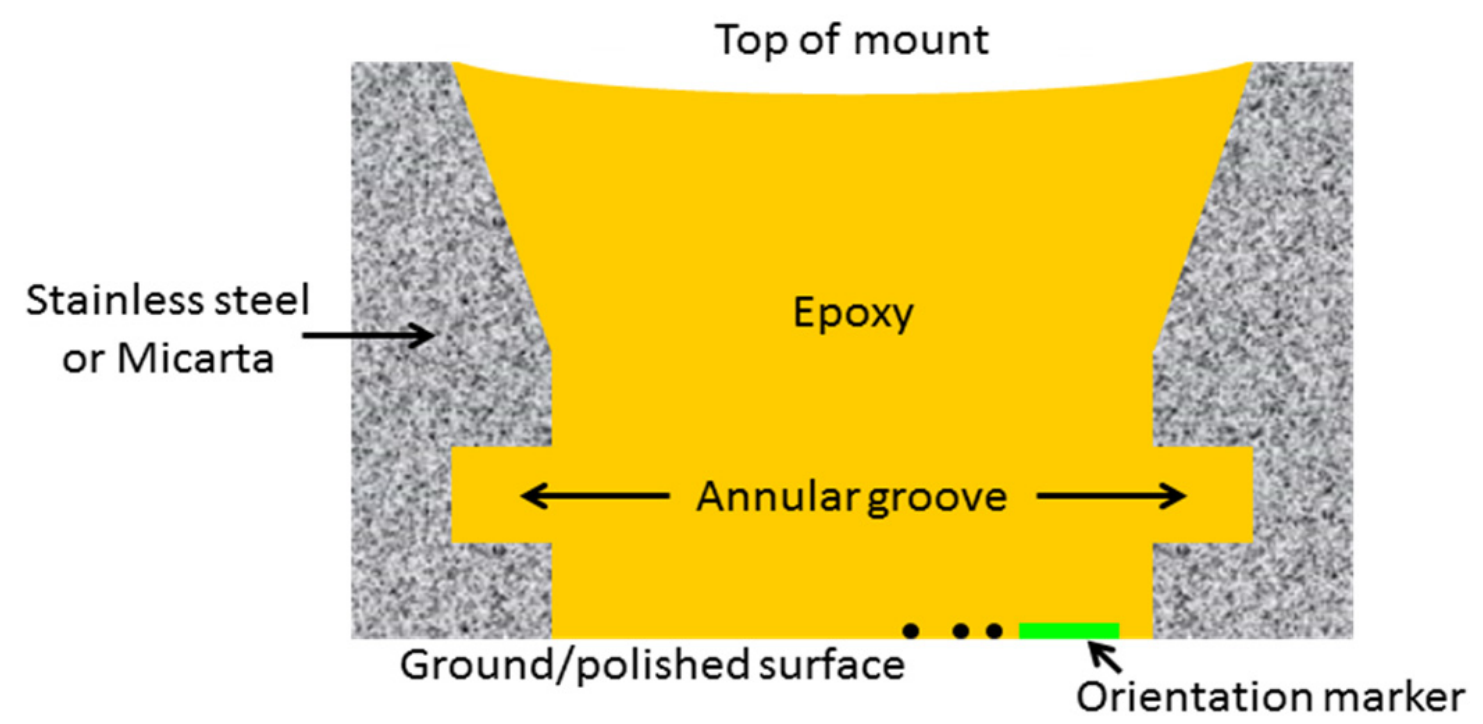

Figure 12. Cross-sectional diagram through center of typical particle mount. (Shallow, narrow steps at peripheral base of steel mounts are not shown.)

As discussed in Section 3.2 and presented in Table 7, Compact 4-1-1 particles were typically selected for mounting according to Ag-110m gamma activity (excepting Mount U3). Release and retention of metallic fission products may be influenced by subtle $\mathrm{SiC}$ microstructural features such as grain orientation, which often cannot be revealed by optical microscopy (ceramography) and thus must be studied with electron microscopic methods. Slight rounding of SiC edges and relief of the adjacent IPyC periphery was observed during electron microscopy of Mount 48T, which contained three particles from Compact 6-3-2 (Van Rooyen et al. 2012). Numerous combinations of grinding discs, polishing cloths, and polishing compounds were tested on mounts with surrogate TRISO particles to achieve improvements in these regards. Optical microscopy results indicated that coarse grinding with Struers MD-Piano 600-grit diamond discs and fine grinding with MD-Piano 1200-grit diamond discs were still appropriate. However, better flatness was achieved on the surrogate mounts when an MD-Dur polishing cloth was used for the 3- $\mu \mathrm{m}$ diamond suspension instead of an MD-Dac cloth. An MD-Nap polishing cloth was maintained for the 1- $\mu \mathrm{m}$ diamond suspension. An MD-Chem cloth was still used for the final polish, but the $0.25-\mu \mathrm{m}$ diamond suspension was replaced with $0.04-\mu \mathrm{m}$ colloidal silica. The revised preparation sequence was implemented for Mounts 120T, 121T, 127T, and 128T. A foam-tipped swab was used to smooth eyedropper-applied back-potting epoxy on Mounts $127 \mathrm{~T}$ and 128T before vacuum impregnation, which reduced the thickness of surplus epoxy that had to be ground away before reaching the particle surface.

Mount U3 examinations were limited to optical microscopy, so the last two polishing steps were not essential. However, it was ground and polished at six levels to more thoroughly investigate internal morphologies than possible with a single cross-sectioned elevation. Distances between planes were controlled with a dial indicator-based gauge that measured the mount height at its center. Further information on preparation of this mount is provided in connection with ceramographic results in Section 4.1.4.

Ceramographic investigations on all mounts in Table 7 were aimed at conspicuous behavior of TRISO layers during irradiation, such as fractures in TRISO layers and delaminations between them. These studies were conducted on a Leitz metallograph using a 6.6-megapixel Leaf-Volare camera, and results are presented below. Particles are classified according to an internal morphology scheme (see Appendix C) developed for analyzing fuel particles exposed in cross-sectioned AGR-1 fuel compacts (Ploger et al. 2012). Type A particles exhibit a continuous gap between the buffer and IPyC layers in the plane of polish, Type B particles show bonding between the buffer and IPyC layers along the entire 
interface, and Type AB particles display partial debonding between these layers. These three basic particle types are subdivided according to whether the buffer stayed intact or fractured. 


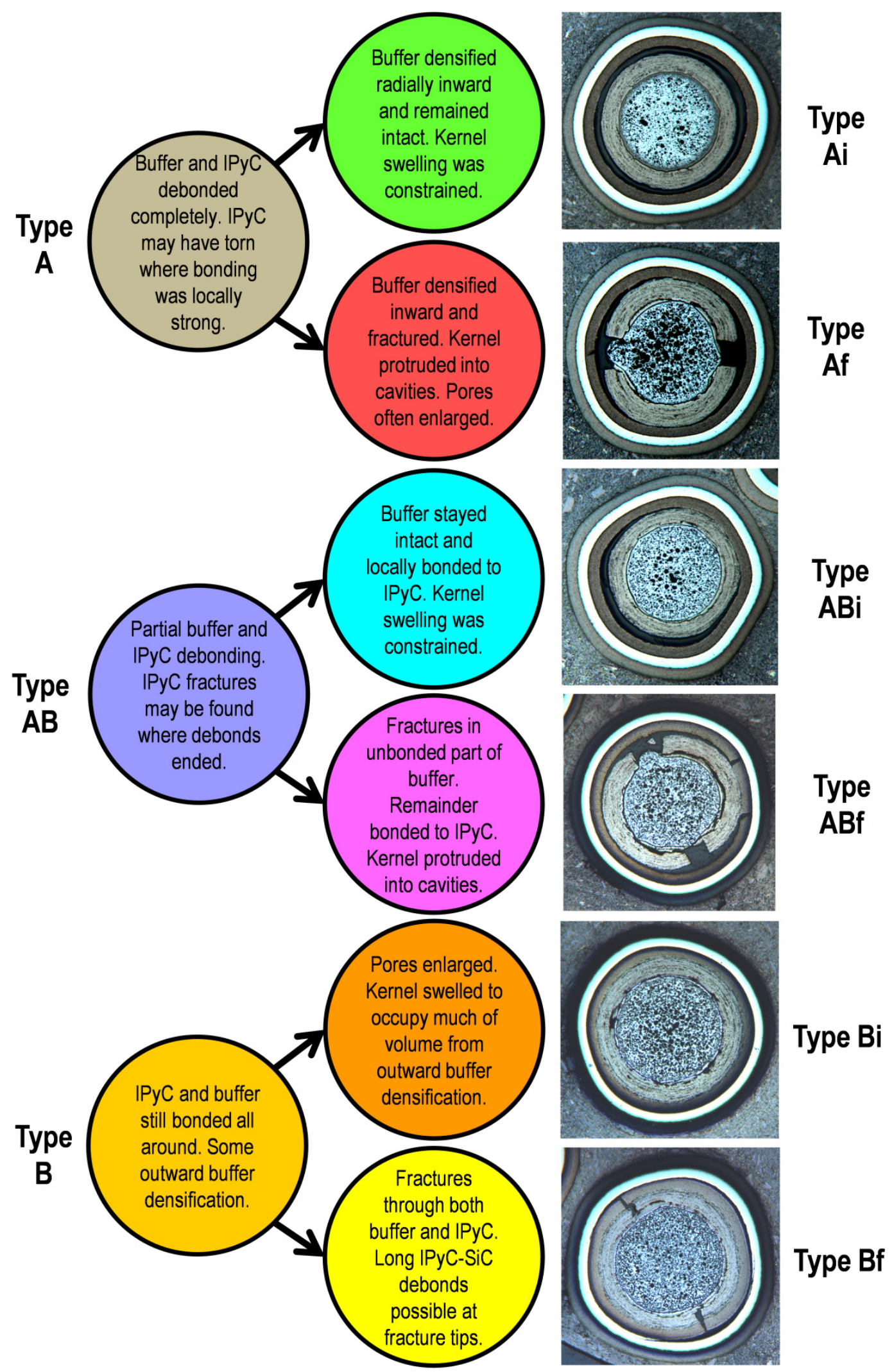

Figure C-1 presents representative examples of all six characteristic morphologies. 


\subsubsection{Mounts 120T and 121T}

Mount 120T was loaded with particles AGR1-411-021, AGR1-411-029, and AGR1-411-030, while Mount 121T was loaded with particles AGR1-411-036, AGR1-411-051, and AGR1-411-052. All of these particles retained approximately average Ag-110m inventories and they were selected for these developmental mounts because the primary intention was to confirm that flatter TRISO layers could be prepared on irradiated particles (see Figure 10 for graphical representation of the measured-to-calculated ratio of $\mathrm{Ag}-110 \mathrm{~m}$ in the particles loaded on these mounts). Coarse grinding progressed gradually at 2-minute intervals under $20 \mathrm{~N}$ of force. Both mounts were coated with epoxy by eyedropper after a periscope examination suggested that one kernel was becoming exposed in each mount (the metallograph was not available for confirmation). However, a vacuum impregnation was mistakenly not performed, so neither mount was properly back-potted at this time. After curing and grinding off surplus epoxy, metallographic examination revealed that no kernels had yet been exposed and that a later back-pot would be needed to stabilize kernels. This was done when periscope examination suggested that coarse grinding was approaching midplane in both mounts (the metallograph again was unavailable for a firm determination). After removal of surplus epoxy, both mounts then were finely ground and polished in anticipation that particles were sufficiently close to midplane for ceramography. This proved valid for Mount 120T, but Mount 121T would have benefitted from slightly deeper grinding. This is one reason why Mount $120 \mathrm{~T}$ was ultimately chosen for transfer to EML while Mount $121 \mathrm{~T}$ was instead returned to $\mathrm{AL}$ and processed to obtain the $\mathrm{SiC}$ shells for subsequent experiments. However, as shown below, Mount 120T also displayed a wider range of characteristic particle morphologies than Mount 121T.

4.1.1.1 Particle AGR1-411-021 (Mount 120T). Particle AGR1-411-021 is displayed after final polishing in Figure 13. The buffer and IPyC layers debonded along much of the interface, which apparently was driven by buffer densification during irradiation. The buffer tore at isolated positions during debonding, leaving small amounts of buffer attached to the IPyC. Another prominent feature is buffer fracturing, which occurred in tangential, circumferential, and radial directions in this particle. The combination of partial buffer-IPyC debonding and buffer fracturing is classified as a Type ABf particle (see Appendix C), which was found in 142 of the 981 particles (14\%) classified in AGR-1 compact cross sections (Ploger et al. 2012). 


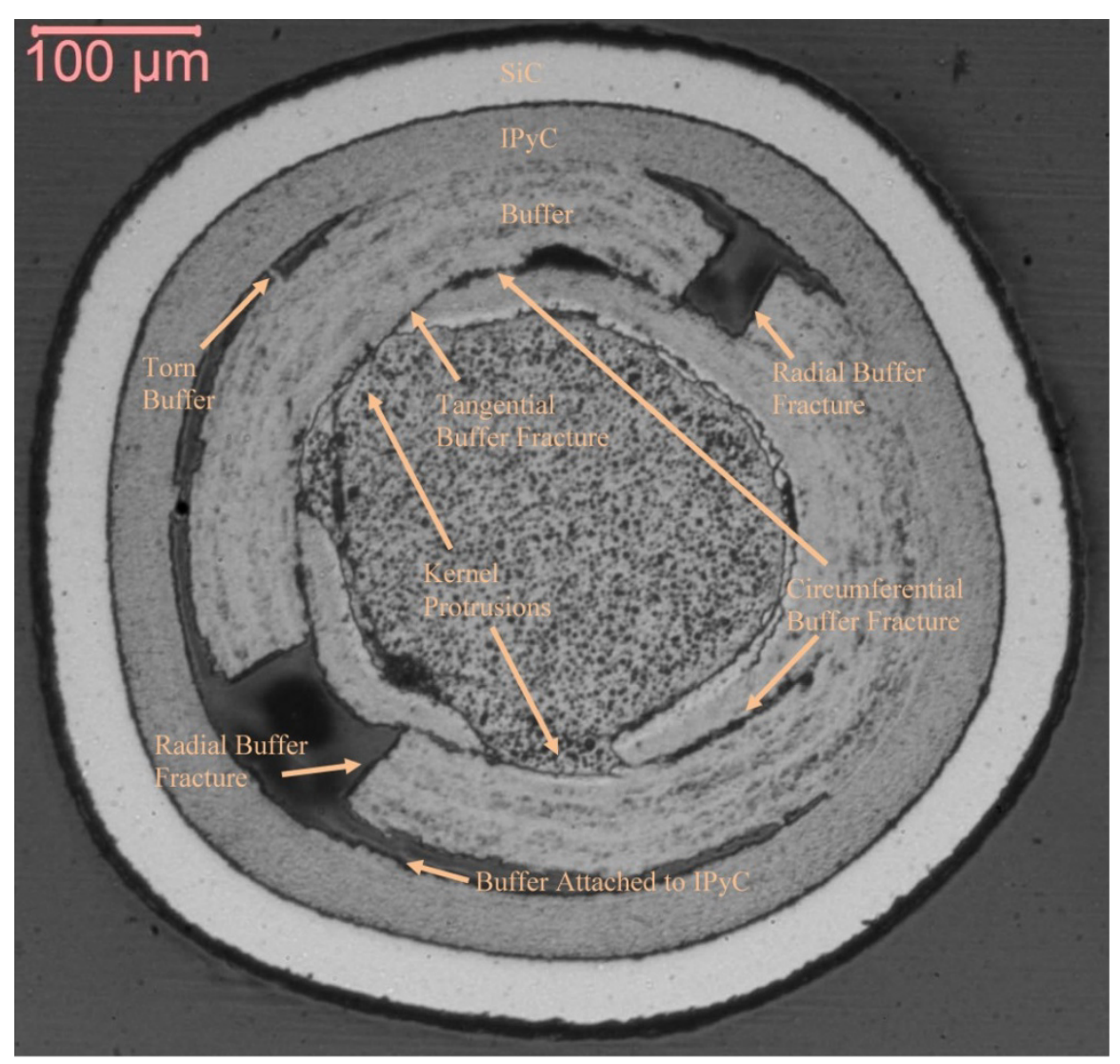

Figure 13. Partial buffer-IPyC debonding and buffer fracturing in Type ABf particle AGR1-411-021.

The cavity between radial buffer fracture surfaces at the lower left of Figure 13 is appreciably wider than the cavity at the upper right, which suggests that the lower left buffer fracture happened earlier. The wide cavity may be related to the extensive buffer-IPyC debonding on both sides of this fracture, but whether the buffer fracture predated the buffer-IPyC debonding cannot be determined from the end-state configuration. Nevertheless, the relatively short buffer-IPyC debond at the upper right (within an otherwise-bonded region) likely was induced by stress concentrated at the tip of the buffer fracture. Such buffer fractures within regions where the buffer was still bonded to the IPyC layer often were accompanied by IPyC tears or fractures in AGR-1 compact cross sections (Ploger et al. 2012), so the absence of IPyC damage in this situation is unusual. This may reflect the superior resistance to IPyC damage observed in cross sections of Variant 3 Compact 4-1-3 (Ploger et al. 2012).

Buffer fractures in AGR-1 compact cross sections often were followed by asymmetrical kernel swelling into the buffer fracture cavities (Ploger et al. 2012), and such kernel protrusions are evident in Figure 13 where the inner portion of the buffer separated. However, pieces of inner buffer blocked the kernel from protruding into both fracture cavities, although the buffer fragment at the lower left was bowed outward - evidently in response to pressure from the expanding kernel. 
4.1.1.2 Particle AGR1-411-029 (Mount 120T). Two views of particle AGR1-411-029 are provided in Figure 14. This Type Ai particle shows essentially complete debonding along the visible buffer-IPyC interface and an intact buffer, which was the most common of the six characteristic morphologies (53\%) in AGR-1 compact cross sections (Ploger et al. 2012). One noteworthy feature is the bright ring in the buffer adjacent to the kernel. This reaction layer is termed a uranium carbide "skin" and was created during particle fabrication (Hunn et al. 2005). This reaction layer may be somewhat brittle, at least after irradiation, because fractures are evident along the left side of the interface, especially in the higher magnification view (b). Figure 14(b) also reveals minor sample preparation damage on the SiC periphery. However, the kernel and all of the TRISO layers appear to be equally well-focused, so extra grinding/polishing relief of the softer buffer and IPyC layers seems to have been minimal.
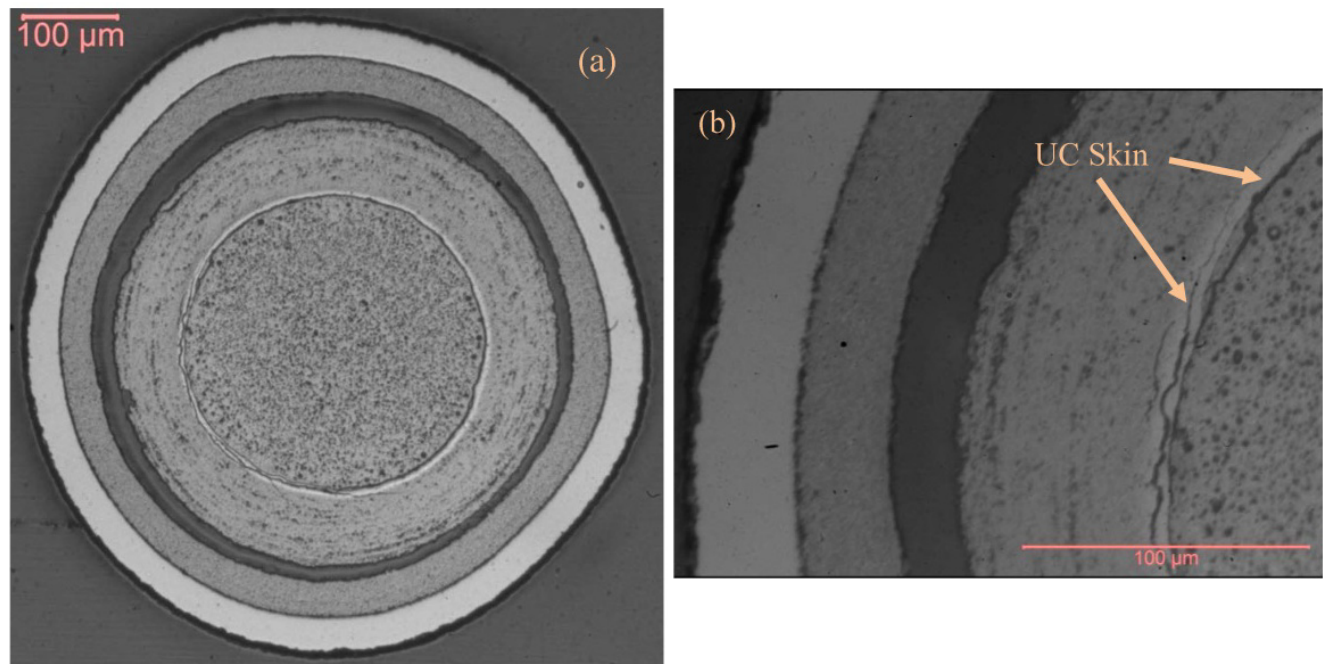

Figure 14. Full cross section (a) and higher magnification of TRISO layers (b) in Type Ai particle AGR1-411-029.

4.1.1.3 Particle AGR1-411-030 (Mount 120T). Particle AGR1-411-030 is shown in Figure 15. The buffer and IPyC layers partially debonded and the buffer stayed intact in this Type ABi particle. This characteristic morphology was found in 19\% of the classified particles in AGR-1 compact cross sections (Ploger et al. 2012). Residual buffer-IPyC bonding is seen only at the right side. Higher magnification view (b) confirms that the bonding is more than just point contact along the interface. This view also displays minor grinding damage on the outside of the $\mathrm{SiC}$ layer. As in Figure 14, the kernel and all of the TRISO layers are sharply focused, so any extra relief of softer layers during surface preparation appears minimal. 

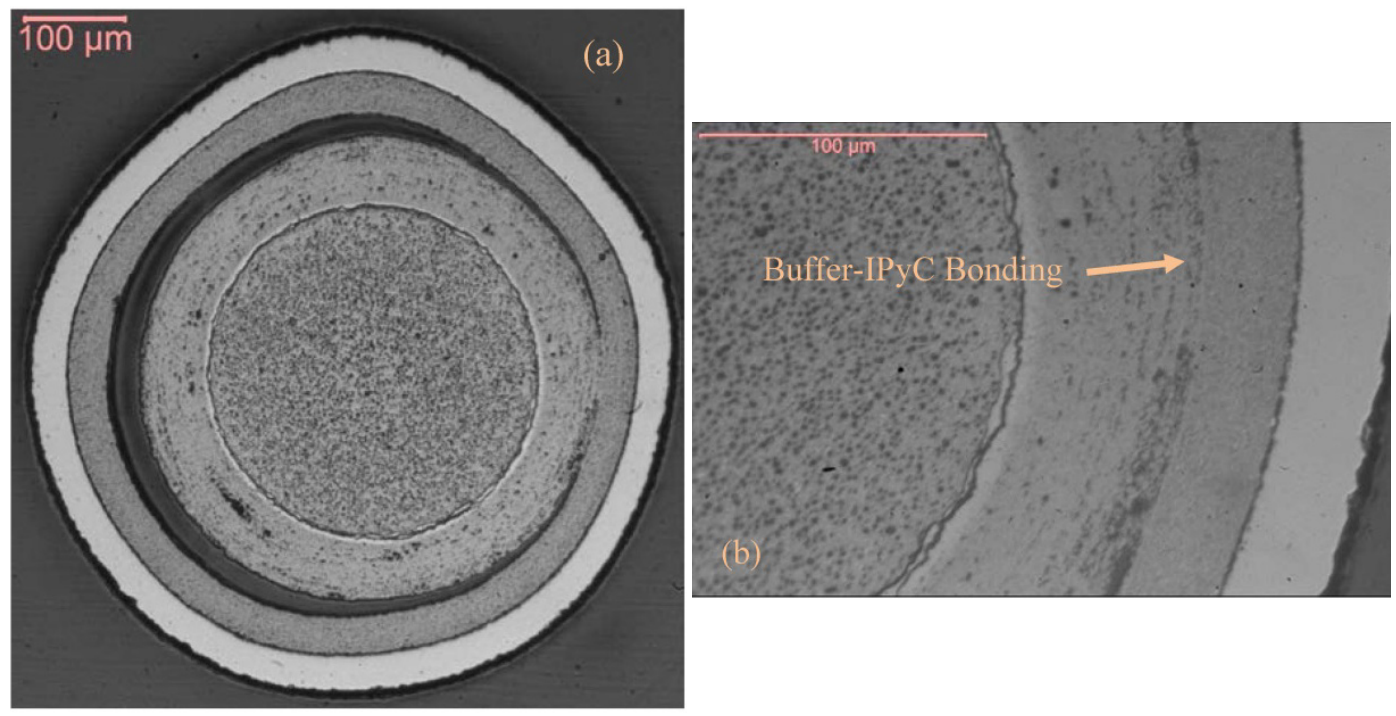

Figure 15. Full cross section (a) and higher magnification of TRISO layers (b) in Type ABi particle AGR1-411-030.

4.1.1.4 Particle AGR1-411-036 (Mount 121T). Another Type ABi particle is presented in Figure 16, in this case from Mount 121T. Although a buffer-IPyC gap opened around most of the circumference, a thin layer of buffer frequently remained attached to the IPyC so separation generally occurred by buffer tearing rather than interfacial debonding. The particle silhouette can be discerned through thin epoxy at the upper right of this image. Because the particle edge was not in the plane of polish, particle AGR1-411-036 definitely was not ground to midplane.

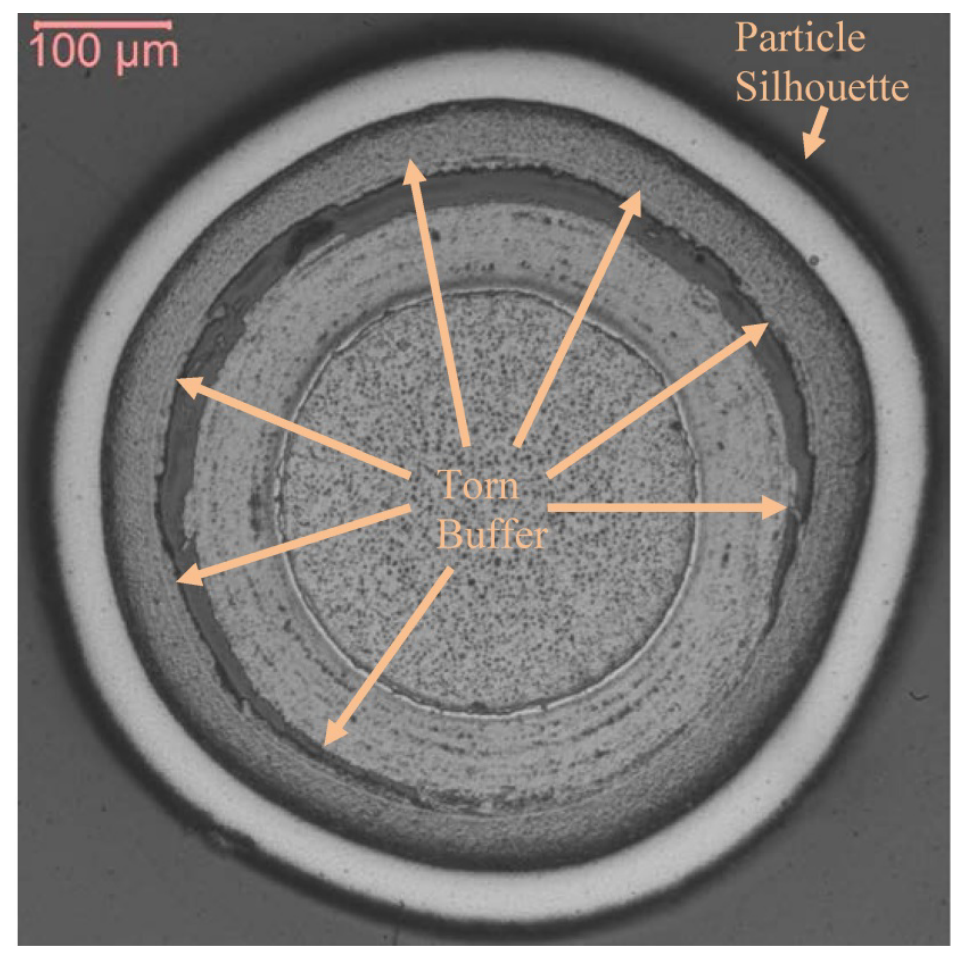

Figure 16. Extensive buffer tearing in Type ABi particle AGR1-411-036. 
4.1.1.5 Particle AGR1-411-051 (Mount 121T). Particle AGR1-411-051 (a Type Ai particle) is displayed in Figure 17. Buffer-IPyC separation in this particle occurred by a mixture of buffer tearing and interfacial debonding. As with particle AGR1-411-036, this particle was not ground all the way to midplane. The darker IPyC periphery in Figure 17(a) suggests extra relief there from preferential grinding and polishing, but this effect is largely a lighting artifact according to the even layer focus in Figure 17(b).
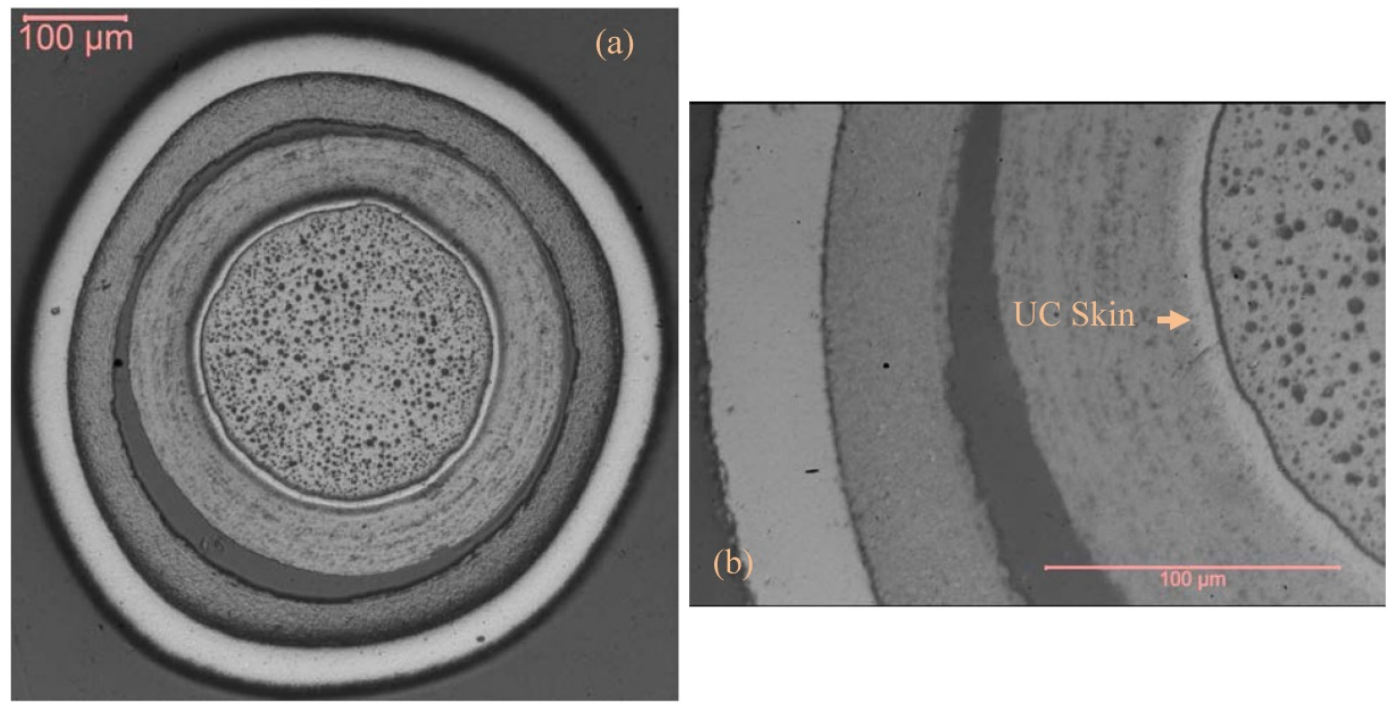

Figure 17. Cross-sectional (a) and higher magnification (b) views of Type Ai particle AGR1-411-051.

\subsubsection{Particle AGR1-411-052 (Mount 121T). Particle AGR1-411-052 (another Type Ai} particle) is shown in Figure 18. Buffer remnants are rare along the IPyC interior, so the radial gap opened overwhelmingly in this particle by interfacial debonding. In spite of the complete debonding observed in the cross-section, the buffer and kernel appear concentric with the IPyC and SiC layers. As with the other two particles in Mount 121T, this particle was not ground all the way to midplane.

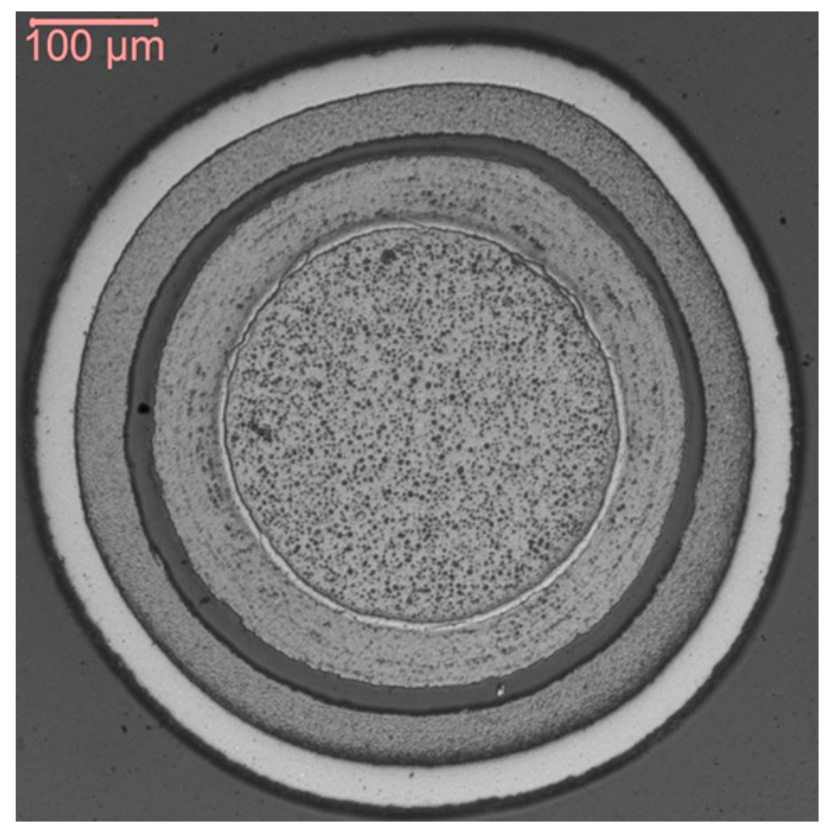

Figure 18. Type Ai particle AGR1-411-052 with very little buffer attached to the IPyC layer. 


\subsubsection{Mounts 127T and 128T}

Mount 127T was loaded with particles AGR1-411-032, AGR1-411-040, and AGR1-411-049 (low Ag-110m M/C ratio). Mount 128T was loaded with particles AGR1-411-033, AGR1-411-038, and AGR1-411-047 (high Ag-110m M/C ratio). Grinding was conducted on one mount at a time in a staggered sequence. Coarse grinding progressed gradually at 2-minute intervals under $20 \mathrm{~N}$ of force with the intention of barely exposing kernels in each set of three particles before a single back-pot to stabilize the kernels, followed by coarse grinding to approach midplane. This strategy worked for Mount 127T, but difficulty was subsequently encountered on Mount $128 \mathrm{~T}$ because of an unexpected combination of morphologies among its particles. As discussed below, the kernel and buffer in particle AGR1-411-047 were displaced vertically from the midplane of the other layers so additional grinding was needed to contact this kernel. Meanwhile, the buffer in particle AGR1-411-038 appeared under periscope examination to have fractured and the buffer fracture evidently resulted in poor lateral support for this kernel. In the absence of back-pot stabilization, the kernel in particle AGR1-411-038 fell out during the last 2-minute grinding interval that exposed the kernel in particle AGR1-411-047.

After both mounts were back-potted, the 600-grit disc was cleaned to remove abrasive fragments. The cleaning appeared to be successful because no major scratches were observed by periscope while surplus back-pot epoxy was ground off both mounts. Mount 127T was then ground with the same disc until periscope examination suggested it was close enough to midplane for a metallograph check. Mount 128T then was ground to midplane proximity during which the buffer was dislodged from particle AGR1-411-038. The metallograph examination revealed that both mounts needed additional coarse grinding to reach the edges of the particle silhouettes. All particles were in good condition at this point, with the exception of the missing kernel and buffer in particle AGR1-411-038 (Mount 128T). The deeper scratches seen in the epoxy did not appear unusual for coarsely-ground surfaces, but the 600-grit disc was cleaned again as a precaution before continuing toward midplane on Mount 127T. No damage was evident by periscope on Mount 127T after coarse grinding, although SiC cracks were seen later during ceramography on one side of particle AGR1-411-032. However, extensive SiC damage was conspicuous by periscope after the final 2-minute grinding interval on Mount 128T. It now appears likely that a SiC fragment from Mount 127T particle AGR1-411-032 contaminated the disc and triggered the avalanche of damage on Mount 128T. The source of the damage on Mount 127T particle AGR1-411-032 is unknown, but the possibility that a kernel fragment from Mount 128T particle AGR1-411-038 escaped the disc cleaning procedures cannot be discounted.

Mount $127 \mathrm{~T}$ was finely ground and polished successfully despite the $\mathrm{SiC}$ fractures on particle AGR1-411-032. Mount 128T was back-potted again to stabilize SiC fragments before fine grinding and polishing. No attempt was made to grind beyond the SiC damage in Mount 128T due to the likelihood of freeing more $\mathrm{SiC}$ fragments and creating additional damage. Furthermore, as discussed below, some $\mathrm{SiC}$ regions in the Mount 128T particles appeared to be in adequate condition after final polishing for electron microscopy. All particles in Mounts 127T and 128T appear ground very close to midplane of the $\mathrm{SiC}$ layers.

4.1.2.1 Particle AGR1-411-032 (Mount 127T). As shown in Figure 19, particle AGR1-411-032 debonded completely along the visible buffer-IPyC interface and the buffer fractured. This Type Af morphology was found in $8 \%$ of the classified particles from AGR-1 compact cross sections (Ploger et al. 2012). Buffer fragments on the left side of this figure likely moved during grinding before back-pot stabilization because fracture surfaces do not match. However, this buffer appeared deformed through the periscope shortly after becoming exposed, so the buffer probably fractured in-pile. If so, buffer fractures most likely happened late during irradiation and did not open into substantial cavities because no asymmetric kernel swelling is evident. In any case, the unfractured buffer portion provided sufficient lateral support to hold the kernel before back-potting. Rotation of the kernel and buffer before back-potting also is a possibility for this particle (another reason for performing an early back-pot shortly after grinding through the IPyC layer, rather than waiting until kernels become exposed). Exterior $\mathrm{SiC}$ 
fractures are found along the lower left of Figure 19 (perhaps from merely a single impact), but what the impacting object consisted of is not clear. One small shard of $\mathrm{SiC}$ appears to be missing. This missing shard is suspected of triggering the extensive $\mathrm{SiC}$ damage on Mount 128T. Incidentally, while Figure 19 suggests that the kernel and all TRISO layers were in even focus, temporary vibration problems on the metallograph over the period when ceramography was conducted on Mounts 127T and 128T prevented the acquisition of high magnification images for confirming planarity at coating interfaces.

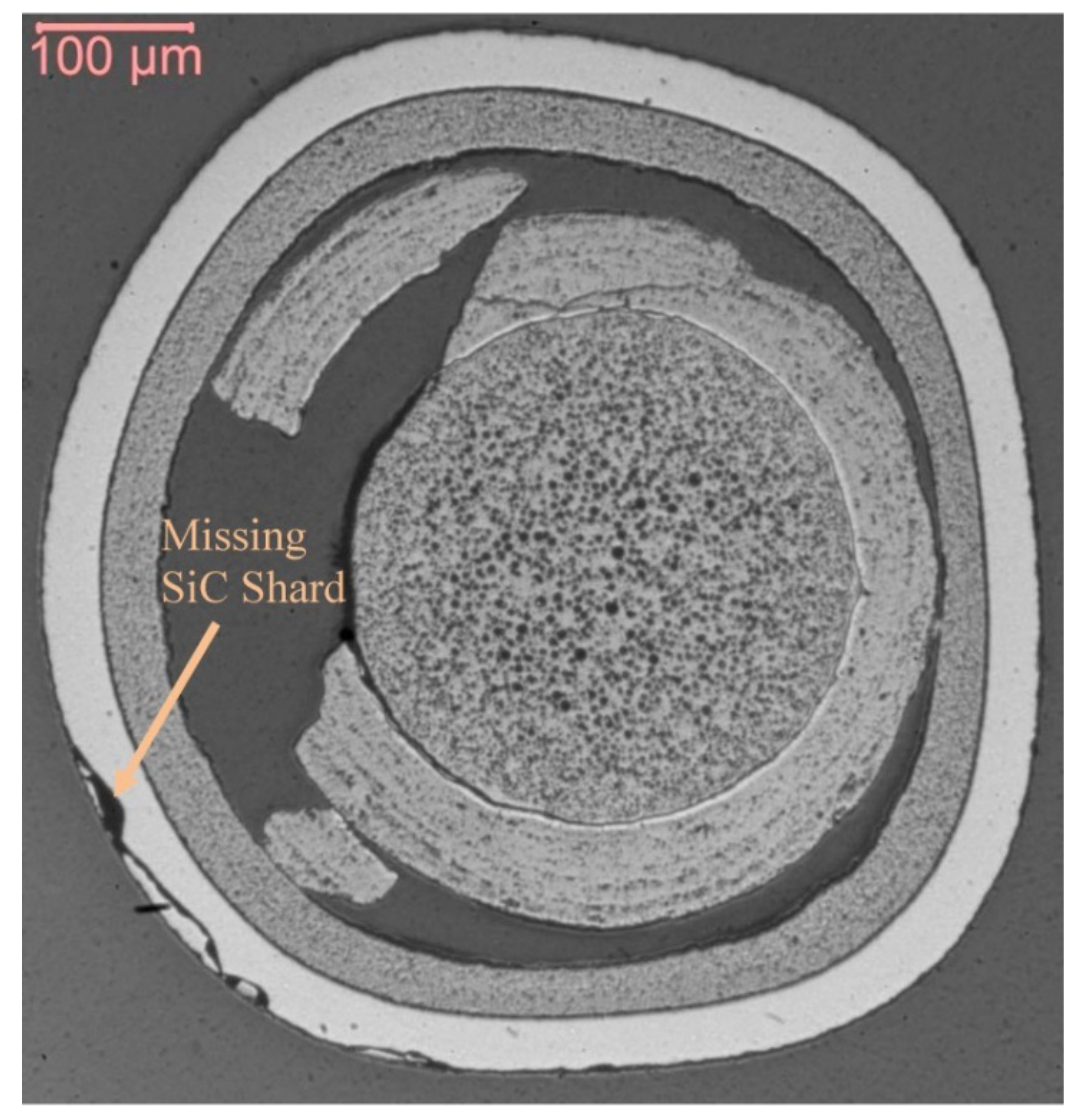

Figure 19. Type Af particle AGR1-411-032 in which buffer fragments moved before back-potting.

\subsubsection{Particle AGR1-411-040 (Mount 127T). As displayed in Figure 20, particle}

AGR1-411-040 exhibits an intact buffer and no buffer-IPyC debonding. Such Type Bi particles were seen in less than 5\% of the classified particles in AGR-1 compact cross sections (Ploger et al. 2012). With strong bonding along the entire buffer-IPyC interface, the buffer was forced to contract radially outward as it densified. While buffers shrank inward onto the kernels in Type A and Type AB particles, outward buffer densification of Type B buffers imposed little or no constraint on kernel expansion during irradiation. Unconstrained kernel swelling often was accompanied by pore enlargement in AGR-1 compact cross sections, especially near kernel centers (Ploger et al. 2012). Similar enlarged kernel pores clearly formed in particle AGR1-411-040. There is a narrow gap between the kernel and buffer in Figure 20. This gap is absent at isolated positions where remnants of the uranium carbide "skin" is still present, so most of this reaction layer may have broken out during grinding, along with a portion of buffer near the top of the image. Any large fragments of uranium carbide probably were abrasive and could conceivably have been responsible for dislodging the missing portion of buffer. 


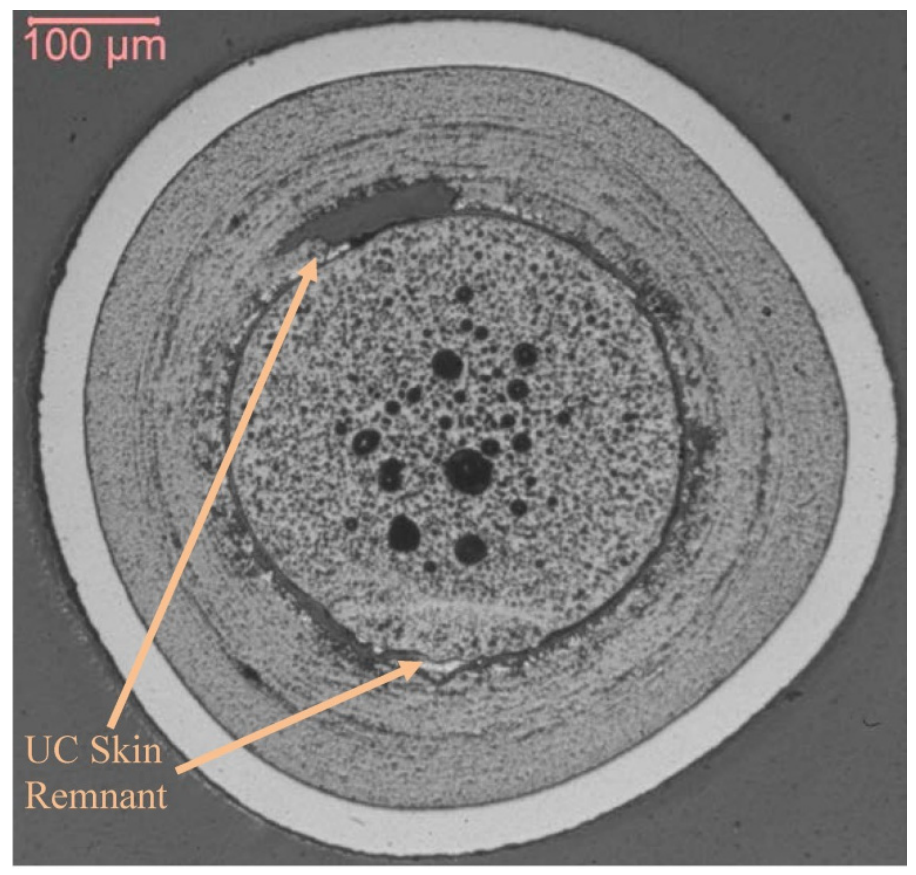

Figure 20. Type Bi particle AGR1-411-040 with full buffer-IPyC bonding and enlarged kernel pores.

4.1.2.3 Particle AGR1-411-049 (Mount 127T). The most notable feature of Type Ai particle AGR1-411-049 in Figure 21 is the unusually wide buffer-IPyC gap. This gap width, along with the relatively small kernel diameter (compared to Figure 18, for example) indicates that the kernel and buffer are not concentric with the SiC and IPyC layers and were vertically displaced from the midplane of the outer layers before back-potting. This displacement exaggerates the thickness of the buffer-IPyC gap in the plane of polish.

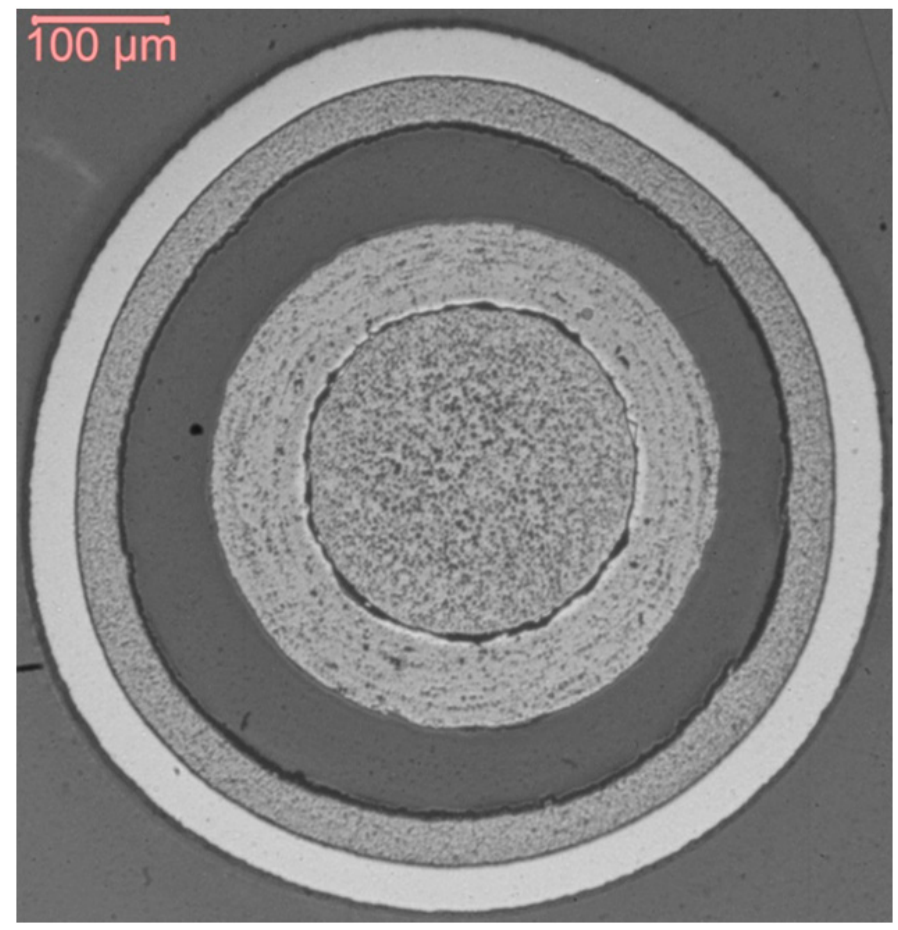

Figure 21. Type Ai particle AGR1-411-049 with exaggerated buffer-IPyC gap. 
4.1.2.4 Particle AGR1-411-033 (Mount 128T). Figure 22 presents particle AGR1-411-033, a rare Type Bi morphology of the sort already discussed for particle AGR1-411-040 (Figure 20). Considerable pore enlargement again is evident, along with local interlinkage of the largest pores (partially filled by epoxy during the last back-pot). Unlike particle AGR1-411-040 in Figure 20, much of the uranium carbide "skin" survived grinding. The kernel and inner layers are in good condition after polishing removed scratches in them, but the $\mathrm{SiC}$ is extensively shattered. The regional concentration of the deep $\mathrm{SiC}$ fracture networks suggests that relatively few impacts by hard debris could still produce extensive damage in brittle $\mathrm{SiC}$. Despite the large number of $\mathrm{SiC}$ cracks in Figure 22, the second back-pot on Mount 128T was able to hold most of the $\mathrm{SiC}$ shards in place during fine grinding with a 1200-grit disc. Isolated unfractured $\mathrm{SiC}$ regions might still be suitable for electron microscopy studies.

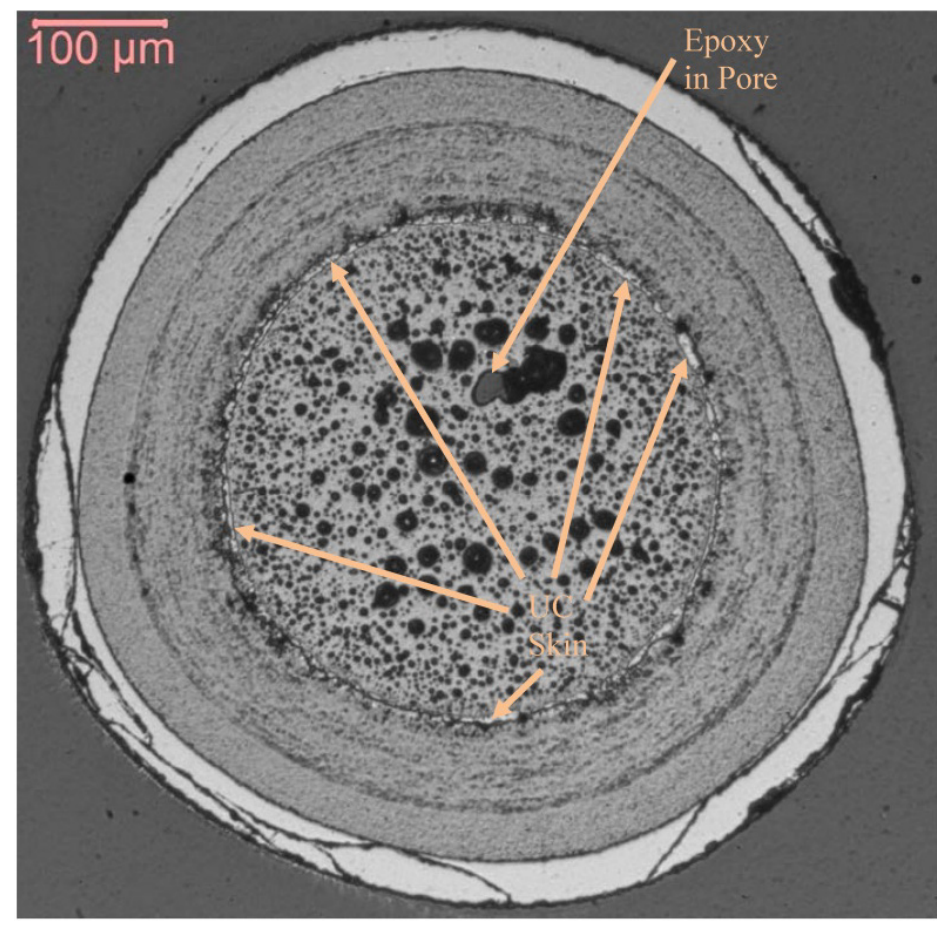

Figure 22. Type Bi particle AGR1-411-033 with $\mathrm{SiC}$ fractured by debris impacts during grinding.

4.1.2.5 Particle AGR1-411-038 (Mount 128T). Particle AGR1-411-038, which lost its kernel before the first back-pot and its buffer during later grinding, is shown in Figure 23. A faint boundary between epoxy added during the first and second back-pots can be traced where the buffer exterior was present during the initial back-pot. There is a short break in this otherwise circular boundary at the upper left of Figure 23 where the back-pot boundary proceeds radially to the IPyC interior on both sides of the break. Something blocked the first back-potting epoxy from filling the buffer-IPyC gap here, either a buffer fragment or kernel protrusion that stayed in place when the remainder of the kernel was lost. Both interpretations support the early periscope indication of a fractured buffer in particle AGR1-411-038. If so, it would have had a Type Af morphology. Crack networks in the SiC layer appear confined to three azimuthal regions, which suggest a small number of impacts by one or more hard debris fragments during the last coarse grinding interval on Mount 128T. Some cracks are also present in the upper portion of the IPyC layer. 


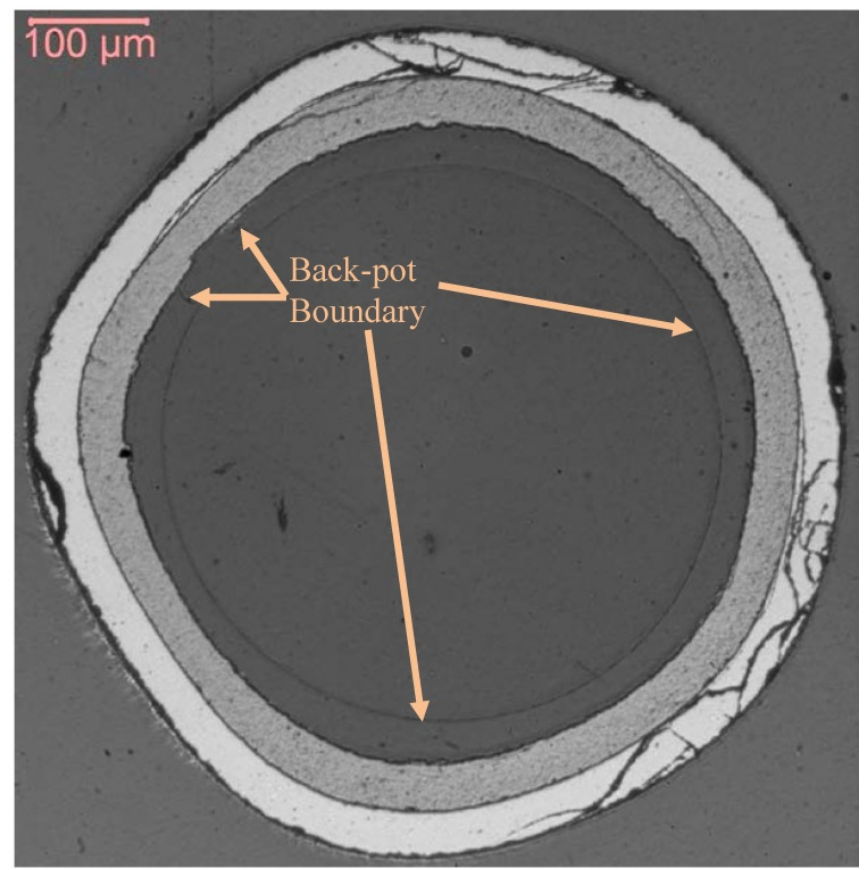

Figure 23. Particle AGR1-411-038 after losing kernel and buffer during preparation of Mount 128T.

4.1.2.6 Particle AGR1-411-047 (Mount 128T). As with Type Ai particle AGR1-411-049 in Figure 21, particle AGR1-411-047 exhibits an exaggerated buffer-IPyC gap in Figure 24 because the kernel and buffer were displaced vertically from the SiC and IPyC midplane before back-potting. As discussed above, an extra two minutes of coarse grinding was needed to expose the kernel in this particle, during which the kernel was dislodged from particle AGR1-411-038. Particle AGR1-411-047 apparently suffered more impacts from hard debris than the other two particles in Mount 128T. Only the upper left portion of the $\mathrm{SiC}$ and IPyC layers is suitable for electron microscopy.

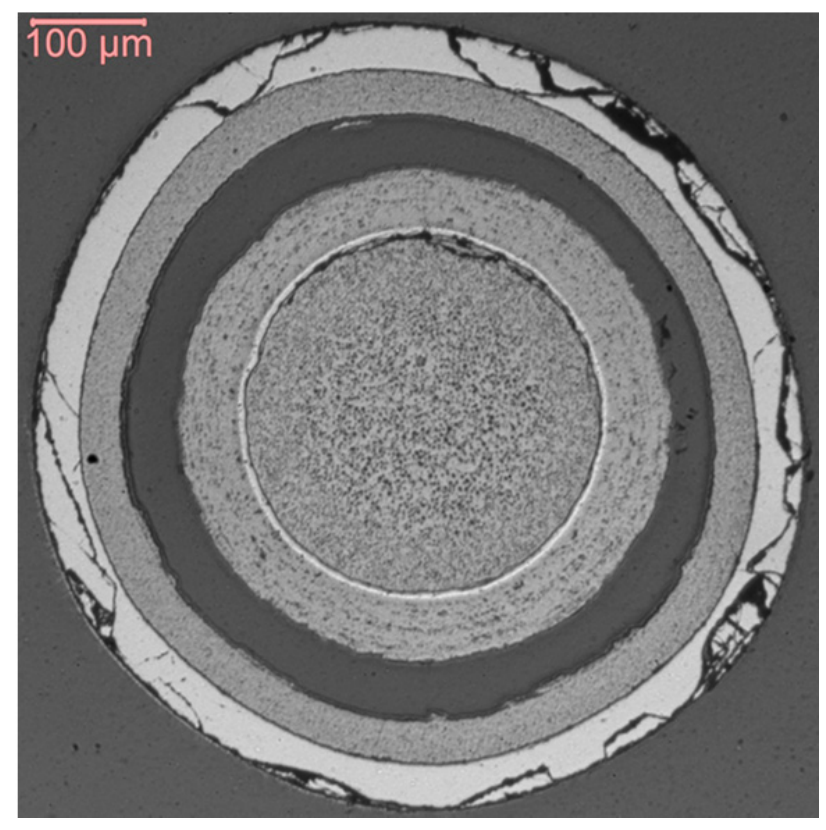

Figure 24. Type Ai particle AGR1-411-047 with exaggerated buffer-IPyC gap thickness. 


\subsubsection{Particle Internal Morphology Correlation with Ag-110m Behavior}

A total of 12 particles deconsolidated from Compact 4-1-1 were studied with ceramography. These particles included examples of five of the six characteristic morphologies in Appendix C. Particles in Mounts $120 \mathrm{~T}$ and $121 \mathrm{~T}$ yielded approximately average inventories of Ag-110m during individual gamma counts, while Mount 127T particles had lower-than-average Ag-110m inventories and Mount 128T particles had higher-than-average Ag-110m inventories. Ceramography was unable to uncover any relationship between Ag-110m behavior and internal morphology. For example, Mounts 127T and 128T each included one Type Ai particle, one Type Af particle, and one Type Bi particle.

\subsubsection{Mount U3}

Particles in Mount U3 were concentrated on one side of the epoxied cavity as they were poured onto the adhesive tape. Bubbles formed among closely grouped particles where gas was trapped when the epoxy was poured. Furthermore, this mount had to be stored for over a year during a facility shutdown before it could be prepared, and appreciable embrittlement of epoxy occurred adjacent to the particles from radiation damage. As soon as grinding with a 600-grit disc opened the bubbles, an attempt was made to fill them by vacuum-impregnating epoxy (back-potting). Unfortunately, this epoxy was not able to infiltrate the embrittled epoxy residue, so clustered particles still were not held firmly in place. Approximately twenty particles were quickly lost from the partially back-potted regions shown in Figure 25. Several additional particles were dislodged as grinding progressed with a 1200 -grit disc through the six levels that were examined on the metallograph, along with some buffers and kernels from particles whose $\mathrm{SiC}$ and IPyC layers were retained. Each level examined first received a 3- $\mu \mathrm{m}$ diamond polish, which was adequate to reveal characteristic morphologies in images of individual particles.

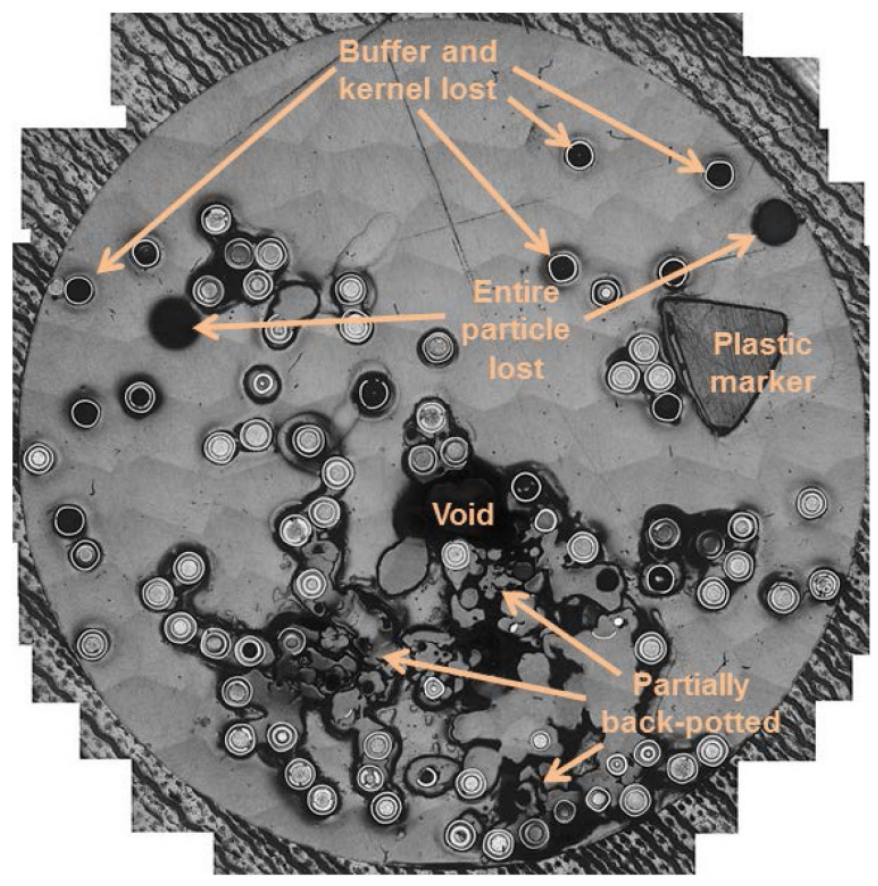

Figure 25. Montage of Mount U3 at the final level examined. 
Early grinding established that Mount U3 particles were not held at a consistent elevation by the adhesive tape as the epoxy cured. More particles became exposed with additional grinding, so latter levels had more particles with cross-sectioned kernels that are required to determine morphology. However, some of the early particles became dislodged or lost their buffers and kernels before reaching the final level. Kernels were never reached in some particles, and only 72 of the approximately 100 particles that were retained within Mount U3 could be classified at one or more levels. As an overall consequence of these difficulties, the 72 particles were classified at $\sim 4$ levels on average.

Morphological results from the 72 particles and all six levels are displayed in Figure 26. For comparison, single-level results from Compact 4-1-3 (extracted from Ploger et al. 2012) and from the sixth level of Mount U3 are presented in Figure 27. The charts in Figure 27 are quite similar, in part because the AGR-1 irradiation conditions (temperature and neutron exposure) were virtually identical for Compacts 4-1-1 and 4-1-3. Little difference is found between the randomly staggered particles in the compact cross sections and in the similar elevations in the Mount U3 array. Both charts in Figure 27 are significantly different from the multi-level results in Figure 26. Most prominently, Figure 26 shows fewer Type Ai particles (complete buffer-IPyC debonding) and correspondingly more Type ABi particles (partial buffer-IPyC debonding) than in Figure 27. Similarly, fewer Type Af particles and more Type ABf particles are found in Figure 26 than in Figure 27. Both trends indicate that localized buffer-IPyC bonding can be missed with only a single cross section, so multiple cross sections are necessary to more accurately differentiate between Type A and Type AB particles.

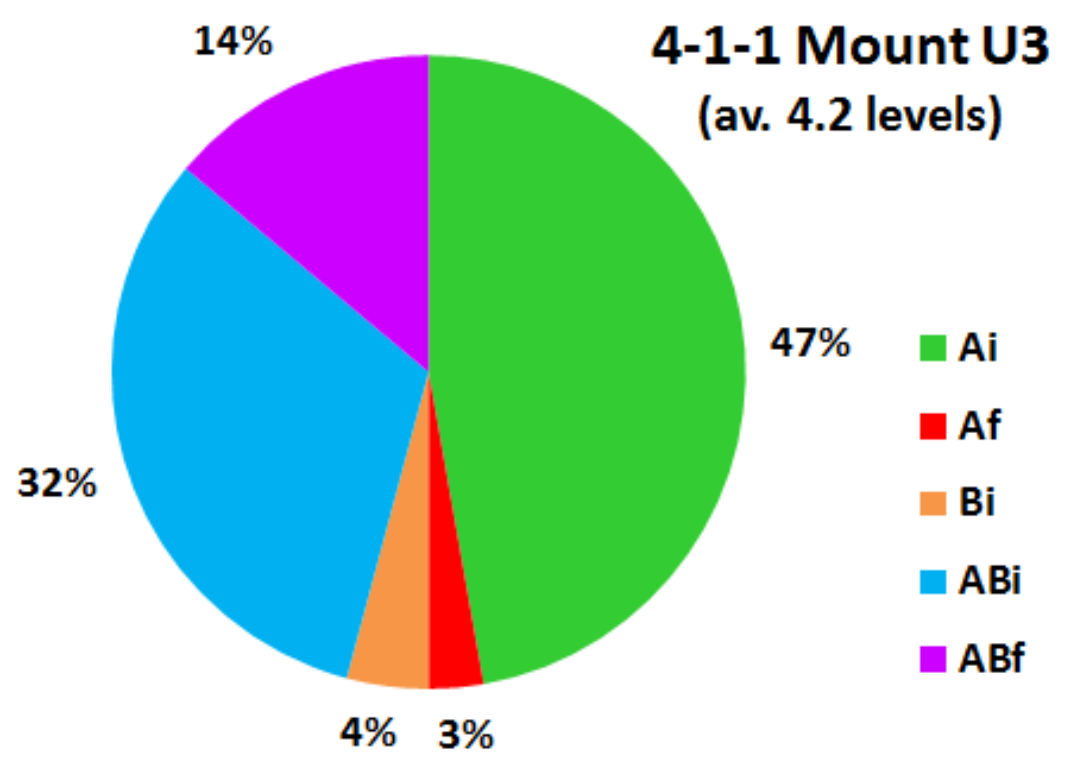

Figure 26. Multi-level results on morphology classification from 72 particles, where "i" signifies an intact buffer and "f" indicates a fractured buffer. 

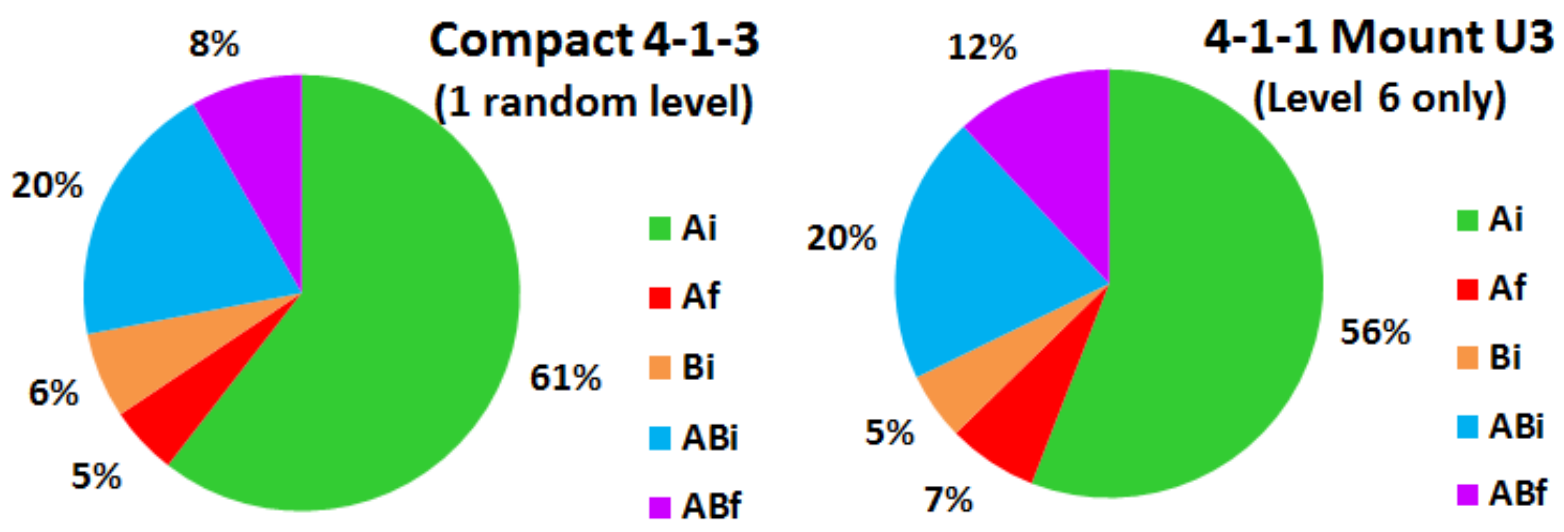

Figure 27. Single level morphology results from 157 particles in Compact 4-1-3 cross sections (left) and 59 particles at deepest level in Mount U3 (right).

Along with fractured buffers, the Mount U3 particles were checked for other anomalies: IPyC fractures, (both through-layer cracks and partial thickness tears), debonds between the IPyC and $\mathrm{SiC}$ layers, and fractures in the SiC layer. No such anomalies were detected in any of the Mount U3 particles at any level. This result is similar to findings from Compact 4-1-3, where only two IPyC tears were detected among 157 particles (Ploger et al. 2012).

\subsection{Additional Processing of Mount 121T}

Following the ceramographic examination described in Section 4.1.1, Mount 121T was transferred back to the Analytical Laboratory to remove the particles from the epoxy mount and obtain the SiC shells for subsequent experiments. The steps performed began in October 2011 by oxidation of the epoxy in the Hot Cell 5 muffle furnace. This was done by heating the mount in the furnace at $400^{\circ} \mathrm{C}$ in air for 2 hours to eliminate any volatile organics, then increasing the temperature to $750^{\circ} \mathrm{C}$ for approximately 40 hours. The result of the oxidation was a small amount of ash and a clean stainless steel mount that was rinsed with $16 \mathrm{M}$ nitric acid, and the ash was leached while heating for several hours to remove any residual kernel material. The solution was decanted three times to leave a heel that was later filtered. A final leach with $8 \mathrm{M}$ nitric acid was performed before filtration of the solids through a 0.45 micron filter. Inspection of the filter showed the three discrete $\mathrm{SiC}$ shell hemispheres remaining. A final leach cycle was performed on the SiC shells involving three heated $8 \mathrm{M}$ nitric acid leaches followed by drying, to completely remove any residual surface contamination on the shells. The shells were placed in a glass $\mathrm{V}$-vial of the type used for gamma counting and measured on Detector A in the B-wing counting room.

The measured activity in the shells is given in Table 8, decay-corrected to 12:00 GMT November 7, 2009. The activities in the three hemispheric shells were multiplied by a factor of 2 to estimate the total inventory in the intact $\mathrm{SiC}$ shells for the three particles. ${ }^{\mathrm{b}}$ The adjusted values were then compared to the original inventory in the three particles based on particle gamma counting (Table 5) to calculate the average fraction of the original particle inventory present in the shells. These values are also provided in Table 8 . The data indicate that on average 15\% of the particle Ag- $110 \mathrm{~m}$ inventory and $0.99 \%$ of the Ru-106 inventory remain in the SiC. The calculated fractions for the remaining isotopes are all less than $0.4 \%$. Agreement between the fractions calculated for the two cesium isotopes and the two europium isotopes is very good.

b This involves the implicit assumption that the $\mathrm{SiC}$ hemispheres represent precisely $50 \%$ of the total $\mathrm{SiC}$ volume from the original particles. This is only an approximation, and based on the discussion in Section 4.1.1, it is clear that the particles were not ground precisely to the particle midplane. No attempt has been made to adjust the values for any deviation from this assumption. 
Table 8. Decay-corrected activity measured and fraction of original particle inventory found in three $\mathrm{SiC}$ hemispheric shells from Compact 4-1-1 particles.

\begin{tabular}{|l|c|c|}
\hline \multicolumn{1}{|c|}{ Isotope } & $\begin{array}{c}\text { Activity } \\
(\mathrm{Bq})\end{array}$ & Particle fraction \\
\hline Ag-110m & $1.9 \mathrm{E}+04$ & $1.5 \mathrm{E}-01$ \\
\hline Ce-144 & $5.6 \mathrm{E}+04$ & $7.1 \mathrm{E}-04$ \\
\hline Co-60 & $6.0 \mathrm{E}+02$ & NA $^{\mathrm{a}}$ \\
\hline Cs-134 & $4.5 \mathrm{E}+03$ & $4.1 \mathrm{E}-04$ \\
\hline Cs-137 & $3.5 \mathrm{E}+03$ & $4.6 \mathrm{E}-04$ \\
\hline Eu-154 & $9.3 \mathrm{E}+02$ & $3.3 \mathrm{E}-03$ \\
\hline Eu-155 & $7.2 \mathrm{E}+02$ & $3.8 \mathrm{E}-03$ \\
\hline Ru-106 & $2.1 \mathrm{E}+05$ & $9.9 \mathrm{E}-03$ \\
\hline Sb-125 & $5.6 \mathrm{E}+02$ & $1.7 \mathrm{E}-03$ \\
\hline a. Predicted activity of Co-60 in the particles was not determined.
\end{tabular}

\subsection{Electron Microscopy}

Electron microscopic examination was initially planned on Mounts 127T and 128T. Mount 120T was prepared to investigate a suitable preparation technique for EBSD measurements as part of the advanced microscopy objectives. Transport of Mounts 127T and 128T from HFEF to EML, however, has not been completed due to issues with radiation control, and therefore it was decided to initially perform basic scanning electron microscopy (SEM) examinations on Mount 120T. The basic SEM examinations were followed by high resolution transmission examination, the results of which are reported separately (van Rooyen et al. 2014). This report includes the following detailed results:

1. Precipitate distribution

2. Qualitative precipitate composition

3. IPyC-SiC interlayer thickness

4. IPyC-SiC interlayer integrity and/or corrosion attack.

The distribution and position of the precipitates in the coating layers are of interest as this may provide insight into the transport behavior of some fission products. Three measurements were performed and the results are presented here: the SiC-IPyC interlayer thickness, the positioning of the precipitates away from this interlayer, and the number of precipitates in each region analyzed. Precipitates in the coating layers around the entire particle cross-sectional circumference were identified based on the light contrast areas on SEM images. SEM-energy dispersive x-ray spectroscopy (EDS) analysis was used to identify features such as Pd-rich precipitates in selected areas of the particle cross sections. The precipitate distribution around the particle circumference was investigated using an image montage. The description and detail of this methodology was already described in a previous report (van Rooyen et al. 2012a) and conference paper (van Rooyen et al. 2012b). 
All of the analysis presented here was performed using a JEOL 7000F SEM. The EDS and wavelength dispersive $x$-ray spectroscopy (WDS) data were collected using the Oxford Instruments INCA suite, version 4.09. Detector calibration was performed in November 2011 by the Oxford Instruments service engineers during the preventative maintenance visit. All records of calibration are held in the EML as part of the maintenance records.

\subsubsection{Sem Examination of Particle Agr1-411-021}

Figure 28 shows an optical micrograph of particle AGR1-411-021 and a montage of SEM images showing randomly distributed precipitate clusters along the IPyC-SiC interface. The precipitate clusters along the interface are encircled in blue in Figure 28. A higher magnification micrograph of the blue encircled precipitate clusters is shown in Figure 28(c). The location of the precipitates does not appear to be significantly correlated with the kernel deformation and buffer fracture.

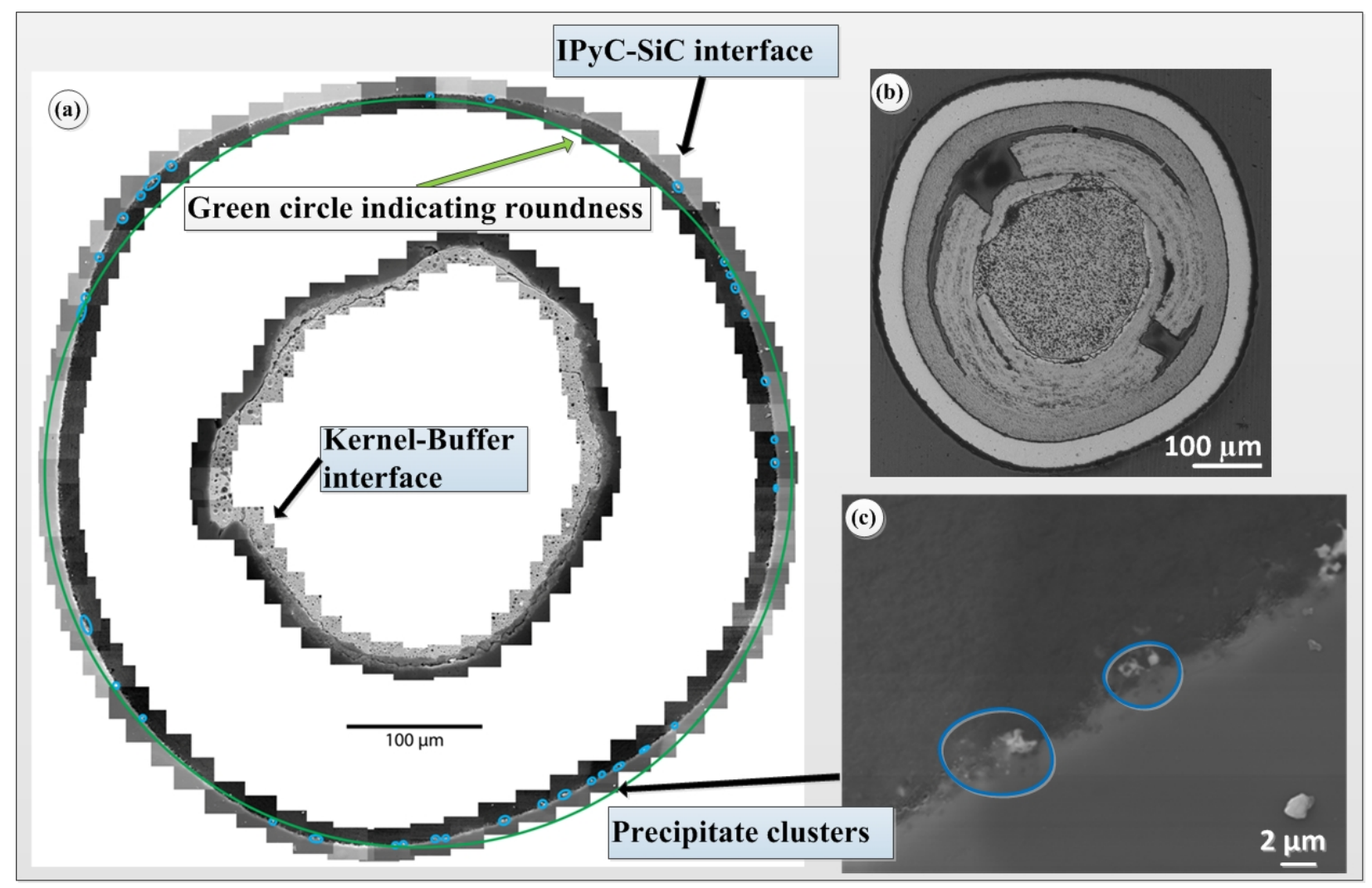

Figure 28. SEM image montage (a) of particle AGR1-411-021 showing randomly distributed precipitates marked by blue circles. Inset image (b) shows an optical micrograph of the particle and the image in (c) shows an example of the precipitate clusters (encircled in blue).

Results of measuring the distance of visible precipitates from the IPyC-SiC interface are presented in Table 9 and Figure 29 (measurement methodology has been presented in van Rooyen et al. 2012a). The precipitates in the SiC layer of AGR1-411-021 were at an average distance of $9.3 \mu \mathrm{m}$ from the IPyC-SiC interface but with a maximum distance of $17.5 \mu \mathrm{m}$ The measurements in the IPyC revealed that the average distance is $2.7 \mu \mathrm{m}$ from the IPyC-SiC interface with a maximum distance of $16.4 \mu \mathrm{m}$, suggesting that the interface and/or SiC-layer acts as an initial barrier to the transport of these precipitates. Note that because of variation in the dimensions of the as-fabricated particles and uncertainties in the proximity of the final polished plane to the actual particle mid-plane, there is the possibility of a bias in the distances measured on the polished cross-sections. Rough estimates place this bias in the range of $0-5 \%$ of the measured value. 
No significant differences are noted in the distance of precipitates from the interface in the IPyC layer in particle AGR1-411-021 compared with particle AGR1-632-034 from lower burnup (11.3\% FIMA) Compact 6-3-2 (van Rooyen et al. 2012a). The average and maximum penetration of precipitates in the $\mathrm{SiC}$ layer are slightly larger for AGR1-411-021, with a maximum of $\sim 18 \mu \mathrm{m}$ vs. $\sim 15 \mu \mathrm{m}$ for particle AGR1-632-034 (van Rooyen et al. 2012b). A larger coated particle sample set will be needed before more definitive conclusions can be drawn relative to the effect of operating conditions (time, burnup, temperature) on precipitate penetration in the layers.

Table 9. Distance of precipitates from the IPyC-SiC interlayer of particle AGR1-411-021.

\begin{tabular}{|l|c|}
\hline \multicolumn{2}{|c|}{ Distance of Precipitates into the SiC from the Interface $(\boldsymbol{\mu m})$} \\
\hline Average & 9.3 \\
\hline Maximum & 17.5 \\
\hline & Distance of Precipitates in the IPyC from the Interface $(\boldsymbol{\mu m})$ \\
\hline Average & 2.7 \\
\hline Maximum & 16.4 \\
\hline
\end{tabular}

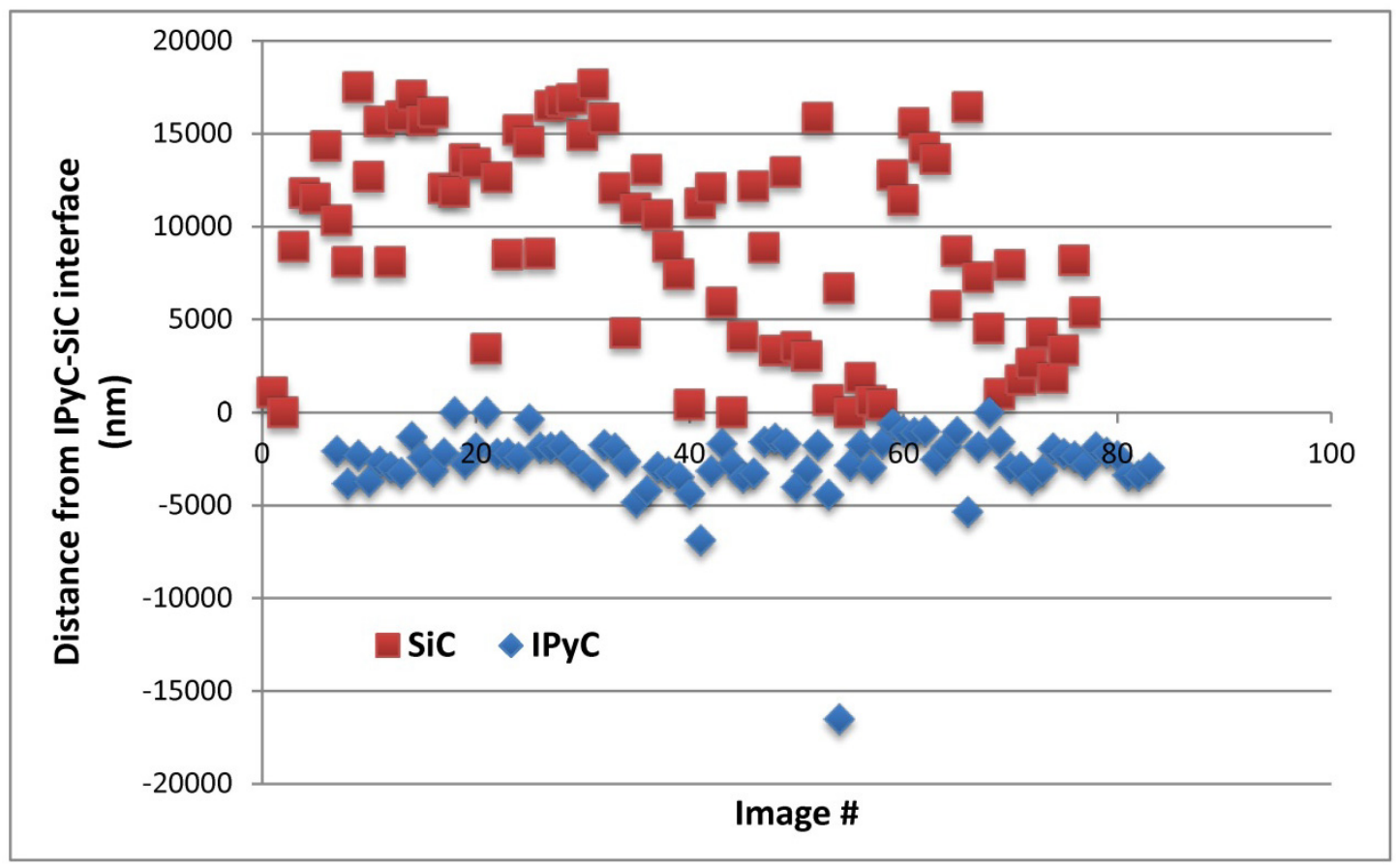

Figure 29. Precipitate position as a function of the maximum distance away from the IPyC-SiC interlayer in particle AGR1-411-021 for each image acquired. Positive displacement represents distance into the $\mathrm{SiC}$ layer; negative displacement indicates distance into the IPyC layer. 
The IPyC-SiC interlayer thickness for AGR1-411-021 varies from 2.1 to $6.5 \mu \mathrm{m}$ with an average thickness of $3.7 \mu \mathrm{m}$ (Table 10 and Figure 30). By comparison, the IPyC-SiC interlayer thickness for AGR1-632-034 varies from 0.7 to $3.7 \mu \mathrm{m}$, with an average thickness of $1.7 \mu \mathrm{m}$ (van Rooyen et al. 2012a). It is not yet clear whether this difference in thickness is significant for fission product transport or the formation of precipitates, nor whether it is significantly influenced by sample preparation techniques. A more detailed comparison of deviations in interlayer thickness for different particles from the same compact, as well as comparison of values for particles from different compacts, will be presented in a separate report (van Rooyen et al. 2015).

Table 10. IPyC SiC interlayer thickness measurements for particle AGR1-411-021.

\begin{tabular}{|c|c|}
\hline \multicolumn{2}{|c|}{$\begin{array}{c}\text { IPyC-SiC Interlayer Thickness } \\
(\mu \mathrm{m})\end{array}$} \\
\hline Average & 3.7 \\
\hline Maximum & 6.5 \\
\hline Minimum & 2.1 \\
\hline
\end{tabular}

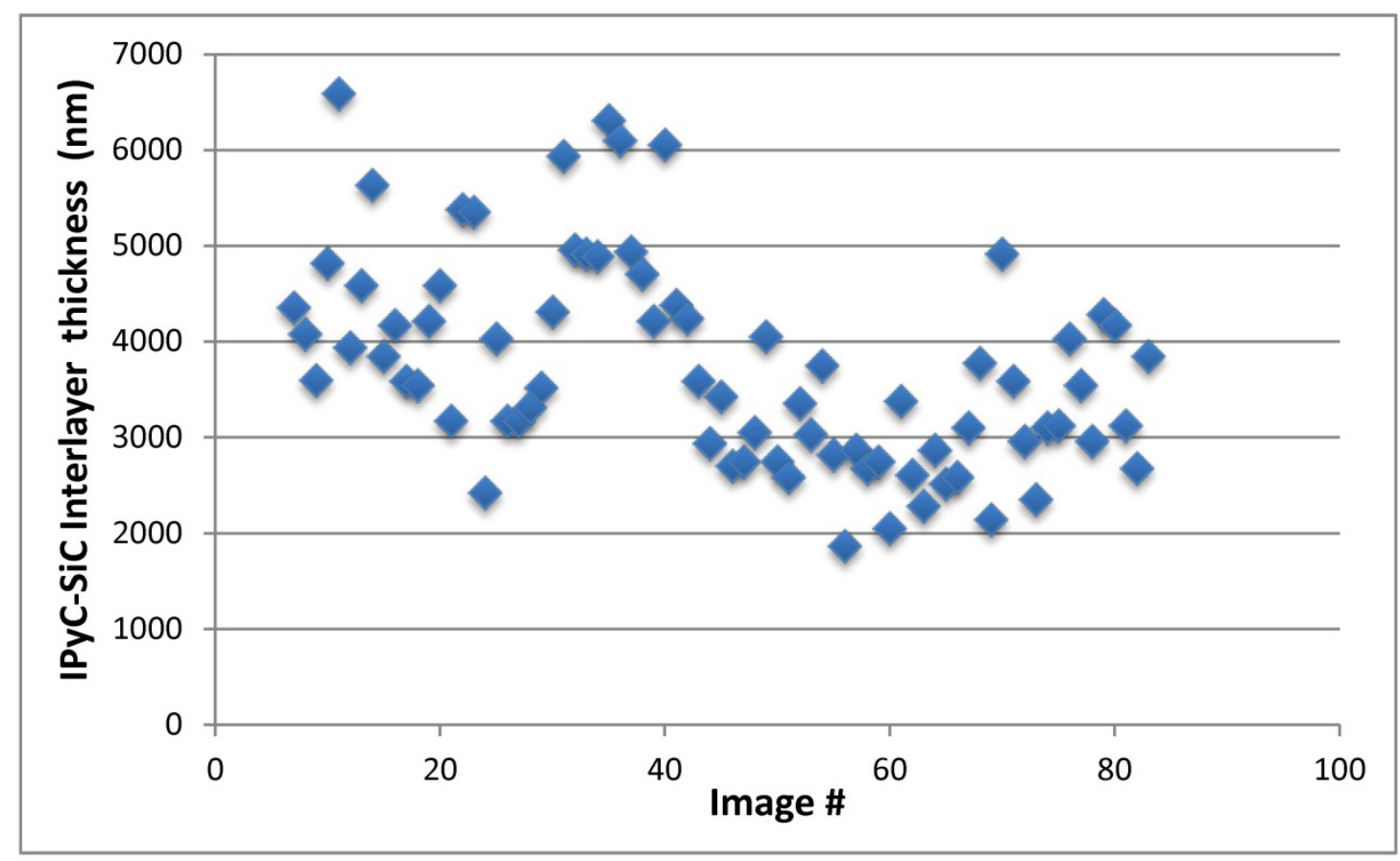

Figure 30. IPyC-SiC interlayer thickness measured from SEM montage of particle AGR1-411-021.

Behavior of the fuel kernel in particle AGR1-411-021 is shown in Figure 31, including protrusion of the kernel into the void created by the fractured buffer, and fracture of the kernel. Pd-rich precipitates are identified along the IPyC-SiC interface using EDS mapping as shown in Figure 32. No EDS analysis for Cs was completed for particle AGR1-411-021 as the main focus was on the identification of Pd. No significant corrosion of the $\mathrm{SiC}$ layer was observed in any of the areas examined on the circumference as shown by typical examples in Figure 33. 


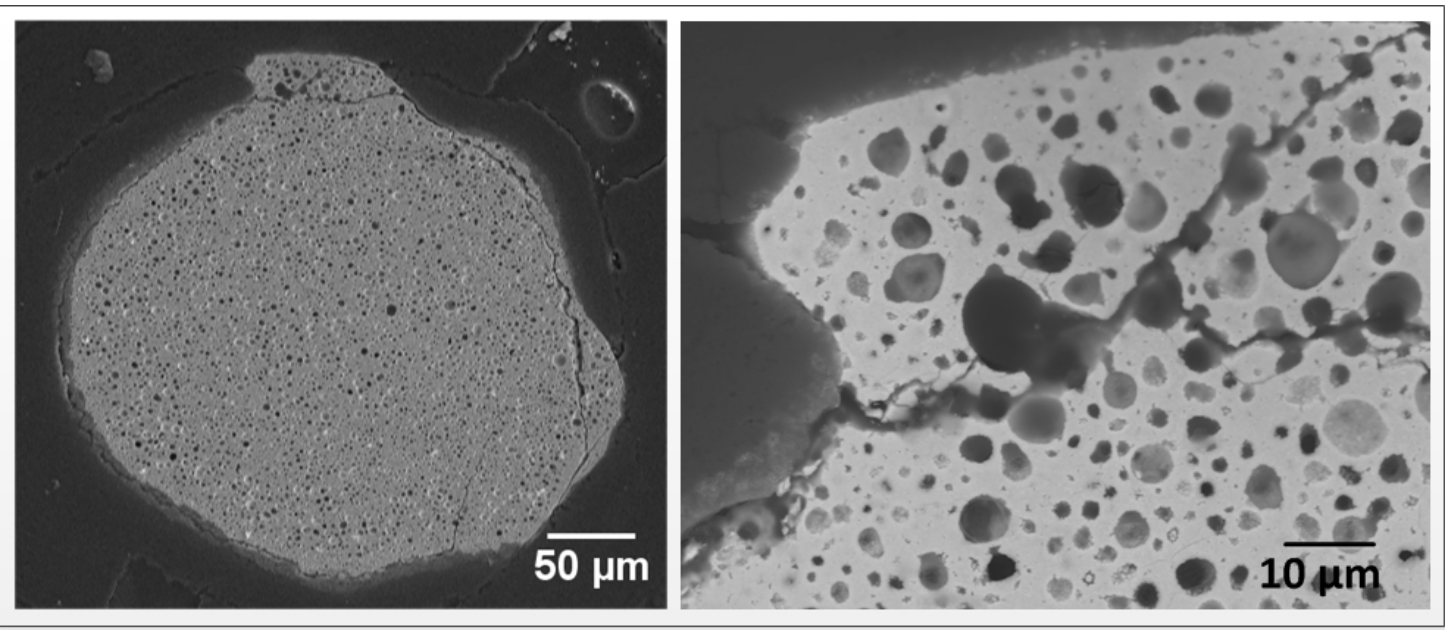

Figure 31. Secondary electron (left) and backscattered electron (right) images of particle AGR1-411-021 fuel kernel.

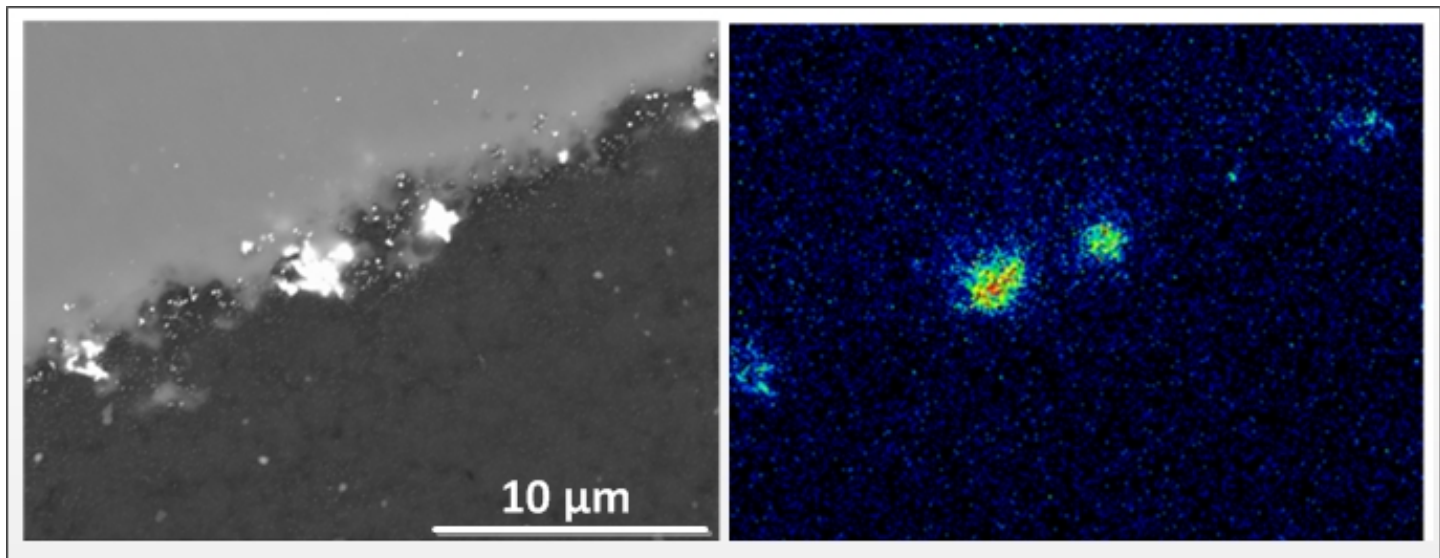

Figure 32. SEM micrograph (left) and corresponding PdL $\alpha 1$ EDS map (right) showing presence of Pd-rich precipitates at the IPyC-SiC interface for particle AGR1-411-021.

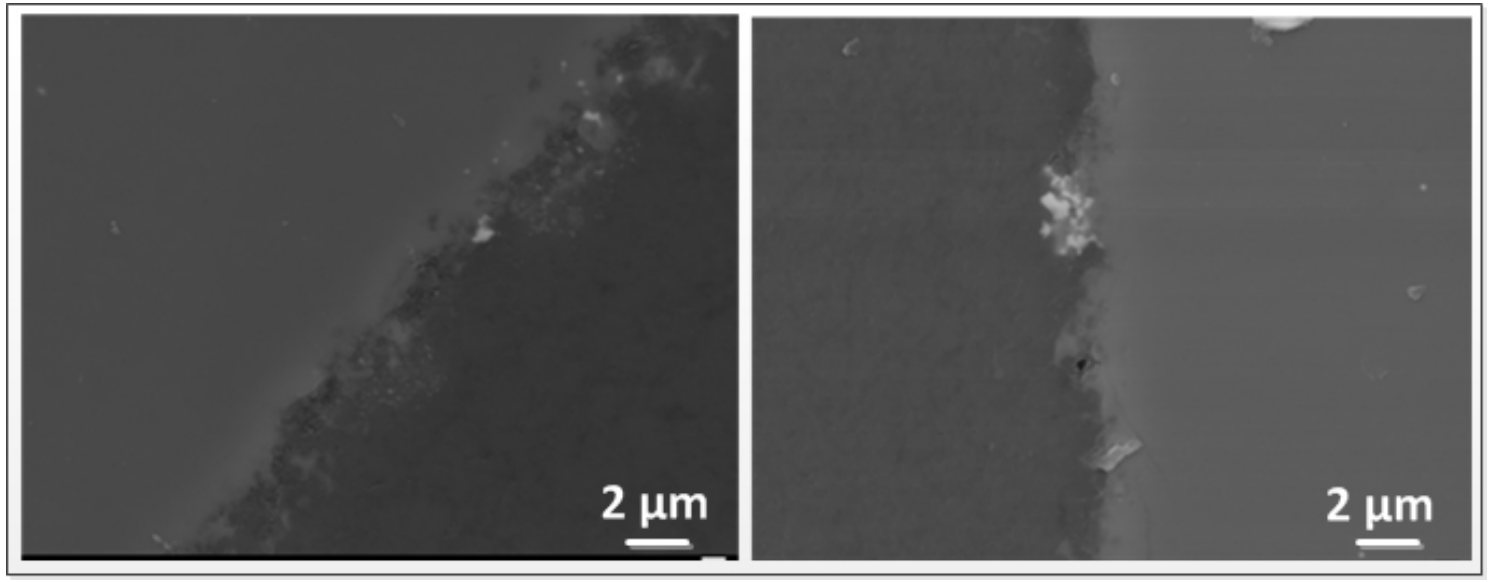

Figure 33. SEM micrographs showing Pd-rich precipitates at the IPyC-SIC interface of particle AGR1-411-021, but no significant corrosion of the SiC layer. 


\subsubsection{SEM Examination of Particle AGR1-411-030}

The precipitate distribution for particle AGR1-411-030 is shown in Figure 34. This precipitate cluster pattern indicates a higher density at the bottom of the figure where the distance from the fuel kernel is lowest, suggesting that proximity of the kernel to the IPyC-SiC interface has a significant effect on fission product precipitation along the interface. This behavior will need to be confirmed with more data from additional particles. No detailed measurements were made on the distance of precipitates in the $\mathrm{SiC}$ and IPyC layers from the IPyC-SiC interlayer, as the images collected for these measurements also contain a significant amount of loose surface contamination that can be mistaken for precipitates within the layers (see Figure 35) and could strongly bias the measurements. However, for the qualitative precipitate cluster distribution montage (Figure 34) only the main Pd clusters were considered, and this figure is therefore representative of the macro cluster distribution. No significant corrosion of the $\mathrm{SiC}$ layer was observed in any of the areas investigated along the circumference, with typical examples of the IPyC-SiC interface shown in Figure 35. Regions of porosity were observed in the buffer and SiC layers, as highlighted in Figure 36.

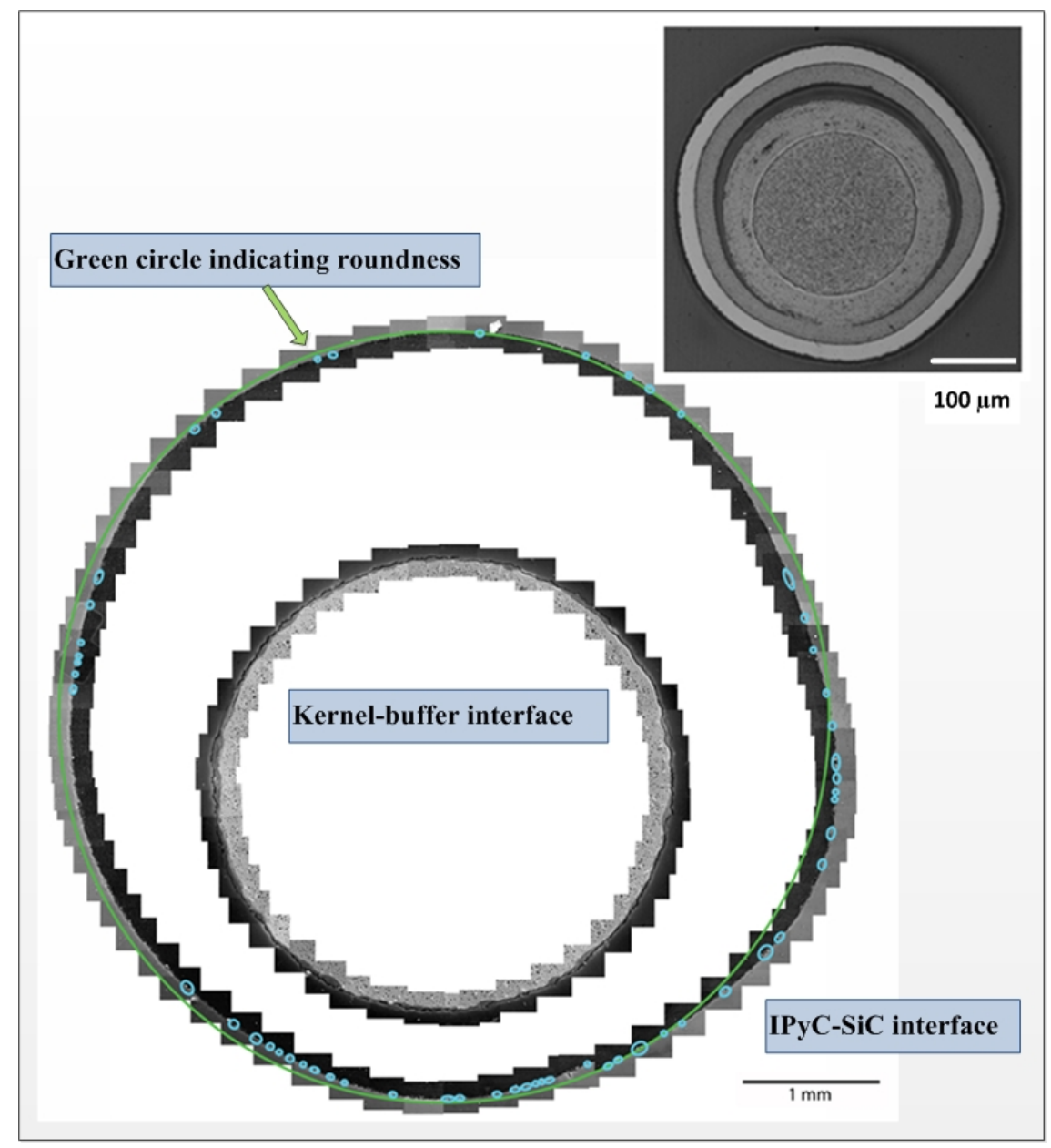

Figure 34. Particle AGR1-411-030 SEM image montage showing precipitate clusters (indicated by blue circles). These precipitate clusters appear to be located at the bottom where the kernel is the closest to the IPyC-SiC layer interface (note that the positioning of the inner montage showing the kernel-buffer interface relative to the IPyC-SiC montage is approximate). Inset image at upper right is an optical micrograph of the particle cross-section. 


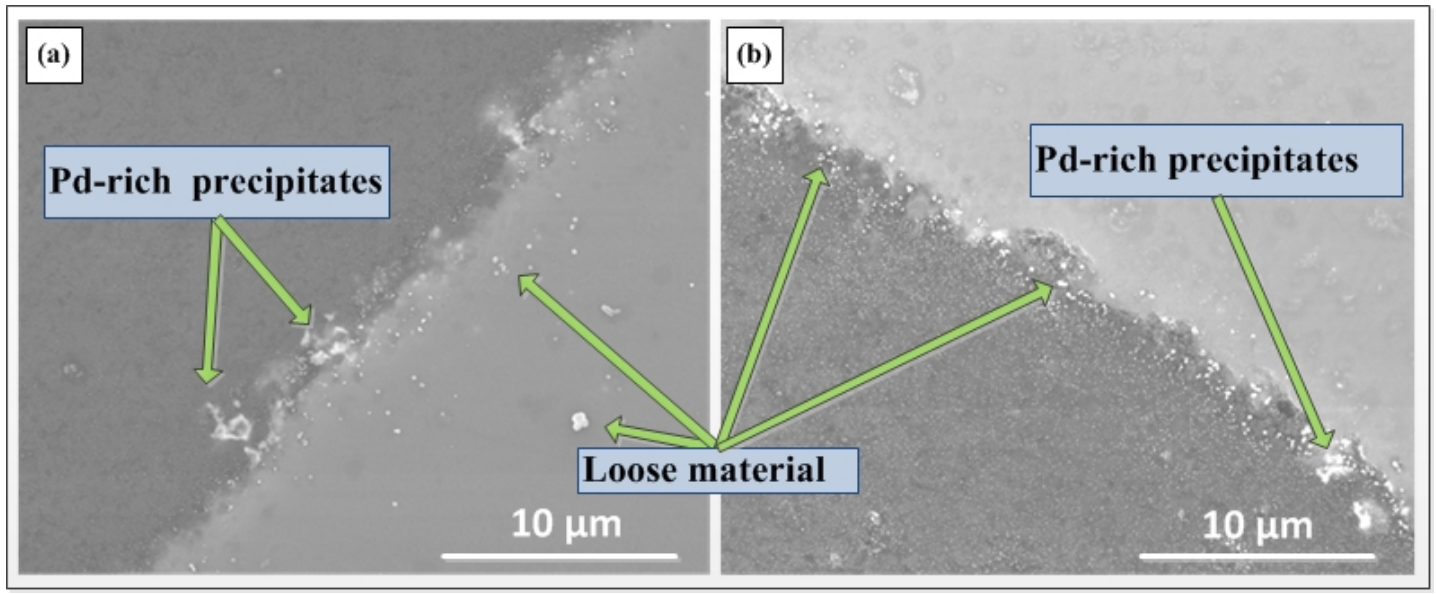

Figure 35. Particle AGR1-411-030 micrographs showing the presence of loose debris on the surface making detailed quantification of the location of Pd precipitates impractical.

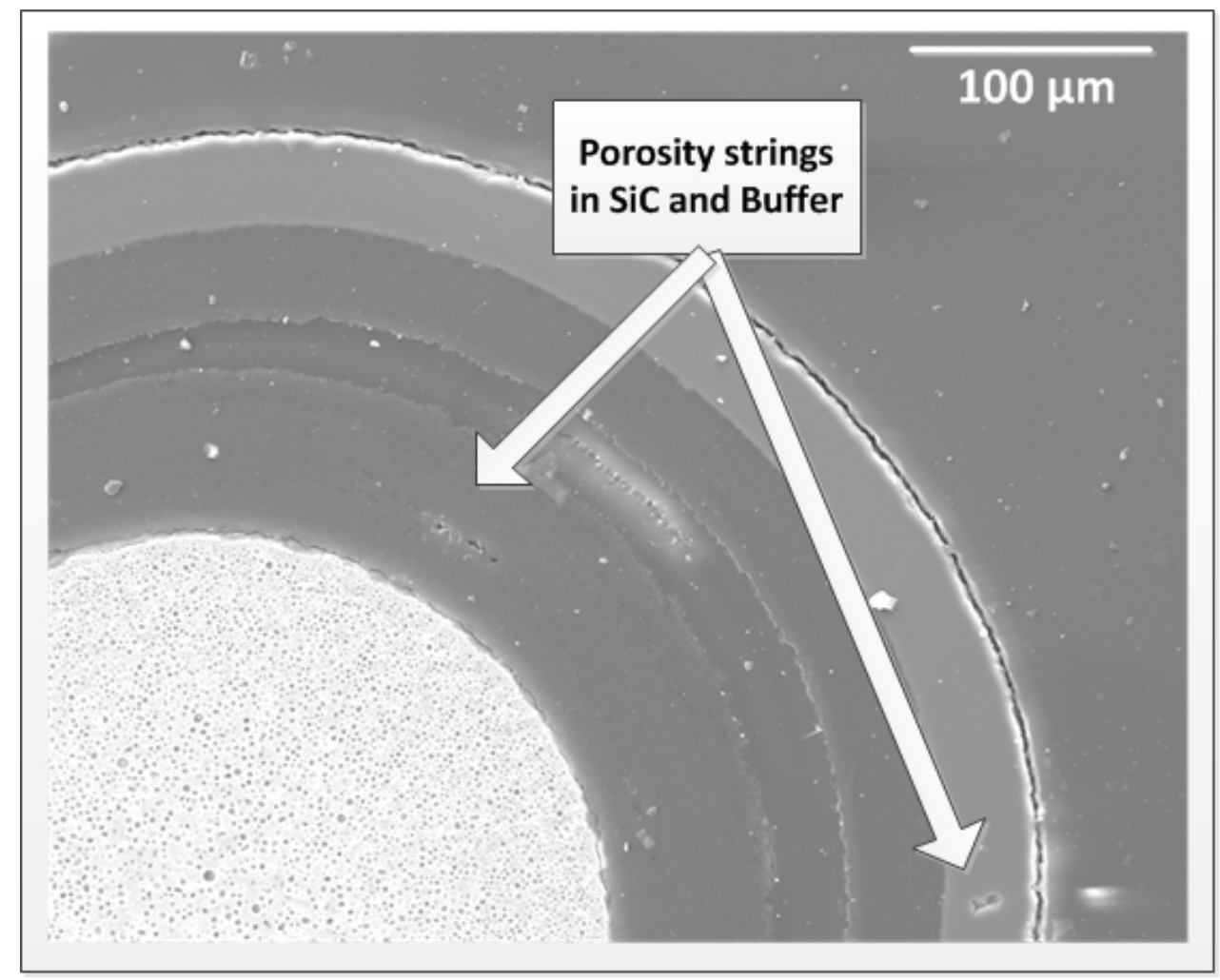

Figure 36. Porosity (indicated by arrows) observed in the buffer and SiC layers of particle AGR1-411-030.

\subsubsection{SEM Examination of Particle AGR1-411-029}

The SEM examination of AGR1-411-029 revealed one main difference compared with those of AGR1-411-021 and AGR1-411-030, namely the presence of cesium-containing crystallites on the fuel kernel cross section (Figure 37(a) and Figure 38). 


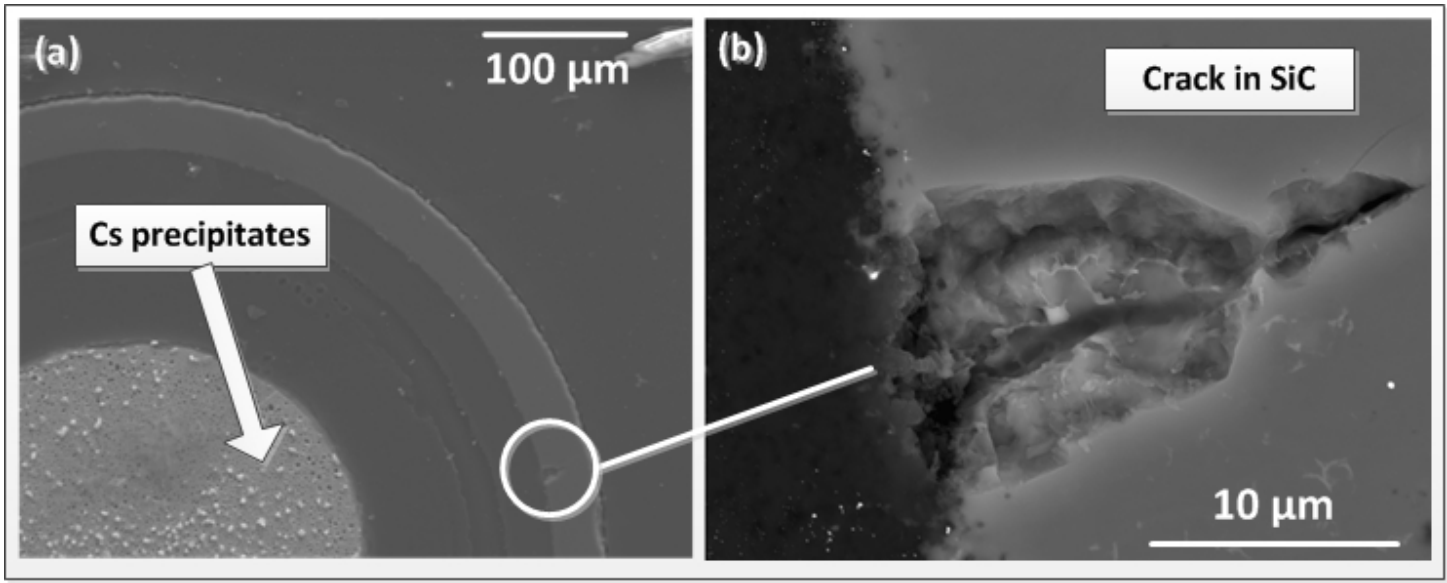

Figure 37. SEM microgaphs of particle AGR1-411-029 showing Cs-containing crystallites on the fuel cross section (a) and a crack in $\mathrm{SiC}$ layer (b).
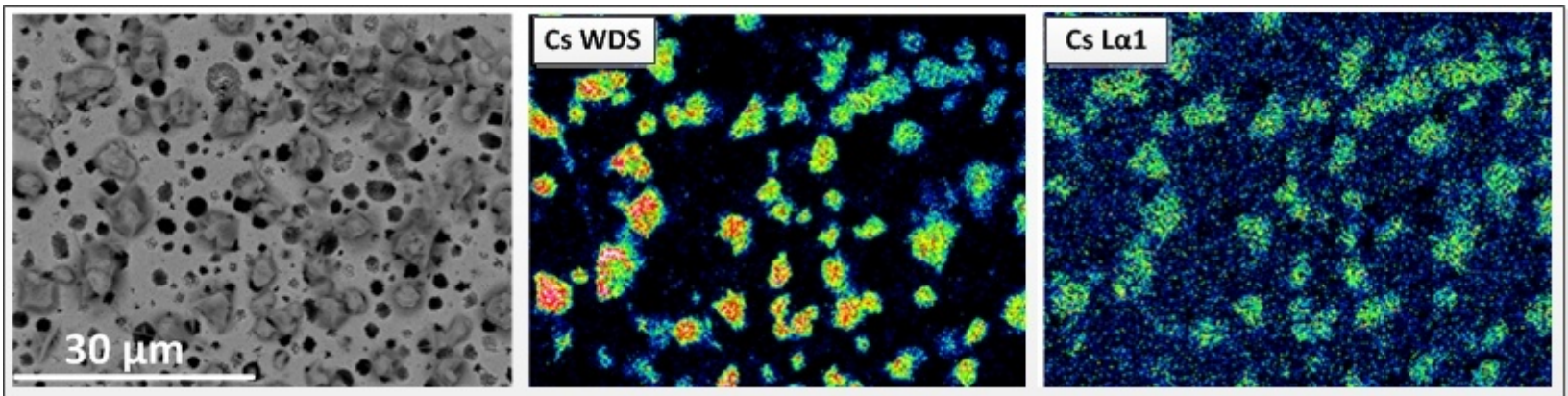

Figure 38. Micrograph (left) and Cs WDS (middle) and EDS (right) maps of the particle AGR1-411-029 fuel kernel cross section, indicating the presence of cesium-containing crystallites.

The cesium-containing crystallites apparently formed during the decontamination process at EML, as they were not visible immediately after sample preparation at HFEF (Figure 14). These crystallites most probably formed after the rinsing process in the EML glove box where water could have infiltrated the fuel kernel porosity. After the rinsing process the water will evaporate, resulting in precipitation of cesium-containing crystallites on the surface. Although this needs to be verified, it seems that the material in question is concentrated on one side of the mount, which may be the result of the angle and positioning of the mount during the rinsing process.

The $\mathrm{SiC}$ crack observed in Figure 37 may have been caused by sample handling or preparation techniques after ceramography, as this crack was not observed during the ceramography examination as shown in Figure 14.

No SEM image montage was completed on this sample to map the distribution of precipitates at the IPyC-SiC interface. No corrosion is observed on the IPyC-SiC interface in the areas examined. 


\subsubsection{Electron Microscopy Conclusions}

Although the three particles all had $\mathrm{Ag}-110 \mathrm{~m} \mathrm{M} / \mathrm{C}$ ratios near the average of particles gamma counted, the microscopic examination revealed differences in the layer and kernel characteristics. This basic SEM examination showed that there is a trend for higher Pd-rich precipitate concentration at the IPyC-SiC interface in the region where the kernel is closest to the interface, in the case when the kernel is not concentric with the SiC layer (particle AGR1-411-030). However, the location of the precipitates does not appear to be significantly correlated with the kernel deformation and buffer fracture for particle AGR1-411-021. This trend needs to be verified with a larger statistical sample to make any meaningful conclusions.

The precipitates in the SiC layer of AGR1-411-021 were at an average distance of $9.3 \mu \mathrm{m}$ from the IPyC-SiC interface but with a maximum distance of $17.5 \mu \mathrm{m}$. The measurements in the IPyC revealed that the average distance is $2.7 \mu \mathrm{m}$ from the IPyC-SiC interface with a maximum distance of $16.4 \mu \mathrm{m}$, suggesting that the interface and/or SiC-layer acts as an initial barrier to the transport of these precipitates.

No significant differences are noted between the distance of precipitates from the IPyC-SiC interface in the IPyC layer of particle AGR1-411-021 compared with particle AGR1-632-034 from a lower burnup (11.3\% FIMA) compact (particle AGR1-632-034). The average and maximum penetration of precipitates in SiC are slightly larger for particle AGR1-411-021 with a maximum of $\sim 18 \mu \mathrm{m}$ vs the $\sim 15 \mu \mathrm{m}$ for particle AGR1-632-034. A larger coated particle sample set will be needed before more definitive conclusions can be drawn relative to the effect of operating conditions (time, burnup, temperature) on precipitate penetration in the layers.

The IPyC-SiC interlayer thickness for AGR1-411-021 varies from 2.1 to $6.5 \mu \mathrm{m}$ with an average thickness of $3.7 \mu \mathrm{m}$ and is slightly thicker compared to AGR1-632-034 with an average thickness of $1.7 \mu \mathrm{m}$. It is not yet clear whether this difference in thickness is significant for fission product transport or the formation of precipitates, or if it is affected by sample preparation techniques.

No significant corrosion was observed on the IPyC-SiC interface in any of the areas examined on the circumference of all three particles.

The SEM examination of AGR1-411-029 revealed the presence of cesium-containing crystallites on the fuel kernel cross section that were not present on particles AGR1-411-021 and AGR1-411-030.

\section{RESULTS SUMMARY}

The key findings from destructive PIE of Compact 4-1-1 are as follows:

- No particles with failed TRISO coatings or defective SiC were observed, based on the DLBL results.

- Silver release from the particles appears to have been relatively low. Approximately $3.3 \%$ of the predicted compact Ag-110m inventory was found in the compact outside of the SiC during DLBL analysis. The Ag-110m measured-to-calculated activity ratio distribution in 61 gamma-counted particles was fairly broad, but centered on a value of 1.02. The interpretation is that there was a large distribution of Ag-110m inventories in the individual particles in the compact, but that the particles did not release a significant quantity of silver.

- The fraction of the predicted compact Eu-154 inventory found in the compact outside of the SiC was $2.4 \times 10^{-4}$, or approximately the equivalent inventory from one particle. Because there were no exposed kernels during the DLBL process, this level represents some release of europium through intact coating layers.

- Release of Sr-90 and Ce-144 from the particles was extremely low. The total compact fraction found in the compact outside of the SiC layers was $1.8 \times 10^{-6}(\mathrm{Sr}-90)$ and $7 \times 10^{-7}(\mathrm{Ce}-144)$. 
- Cesium inventory in the compact outside of the SiC layers was also very low: the compact fraction for Cs-134 and Cs-137 were both $<2 \times 10^{-6}$.

- The morphology of kernel, buffer, and IPyC layer in the deconsolidated Compact 4-1-1 particles examined is generally similar to that observed during ceramography of AGR-1 compact cross sections. Specifically, some particles exhibited a gap between the buffer and IPyC layers driven by buffer densification and subsequent buffer-IPyC debonding during irradiation. In several other particles, the buffer-IPyC bond remained intact and the outward densification of the buffer provided a volume for kernel expansion. Approximately $17 \%$ of the particles examined exhibited fractures in the buffer layer, but none of the IPyC or SiC layers exhibited any conspicuous damage caused by irradiation.

- Examining particles at many cross-sectional elevations is necessary to distinguish between particles with complete buffer-IPyC debonding and particles with only partial debonding.

- There was no apparent correlation of kernel, buffer, and IPyC morphology with the ratio of measured to calculated Ag-110m in the gamma-counted particles. However, it should be noted that the statistical sample size was extremely small, with only twelve gamma-counted particles examined.

- $\quad$ Pd-rich precipitates were identified near the IPyC-SiC interface of two particles examined using SEM/EDS. These were randomly distributed around the visible circumference of particle AGR1-411-021 and had a maximum penetration roughly half way through the SiC thickness (17.5 $\mu \mathrm{m}$ maximum penetration). The precipitates at the IPyC-SiC interface in particle AGR1-411-030 appeared to be preferentially located at an azimuthal location that roughly corresponds to the location where the kernel is closest to the interface due to displacement of kernel and buffer.

- No significant corrosion of the $\mathrm{SiC}$ layer was observed at the IPyC-SiC interface.

\section{LESSONS LEARNED AND RECOMMENDATIONS}

A significant amount of development was required to obtain satisfactory metallurgical mounts of the deconsolidated particles. At least two back-pots should be performed while grinding to midplane depth on particles. Even when particles are at consistent mount elevations, kernels and buffers surrounded by a buffer-IPyC gap can move away from the midplane of other TRISO layers before back-pot stabilization. Moreover, after grinding into them, fractured buffers may not provide adequate lateral support for holding kernels. The initial back-pot should be performed shortly after IPyC layers have been penetrated to fill the buffer-IPyC gaps. Another back-pot should be performed after kernels become exposed to fill any gaps between buffers and kernels, especially when buffers have fractured. Additional back-potting may be warranted by special circumstances.

In mounts where many particles are loaded in close proximity, gas trapped between particles after epoxy has been poured should be removed under vacuum to better bind the particles to the epoxy. Mounts should be ground and polished as soon as practicable after loading to limit radiation damage to epoxy surrounding the particles.

It is recommended that the EDS and WDS mapping be expanded to include more elements and also that the kernel and buffer layer be included in this analysis. In addition, it would be advantageous to examine the precipitate distribution at the IPyC-SiC interface on a larger number of particles. 


\section{REFERENCES}

Barnes, C. M., W. C. Richardson, D. Husser, M. Ebner, "Fabrication Processes and Product Quality Improvements in Advanced Gas Reactor UCO Kernels," HTR2008-58039, Proceedings of the 4th International Topical Meeting on High Temperature Reactor Technology, HTR2008, Washington, DC, USA, September 28 - October 2, 2008.

Chadwick, M. B. et al., ENDF/B-VII.1, "Nuclear Data for Science and Technology: Cross Sections, Covariances, Fission Product Yields and Decay Data," Nuclear Data Sheets, 112 (2011) 2887-2996. Specific decay data accessed at: http://www.nndc.bnl.gov/exfor/endf00.jsp.

Demkowicz, P. A., “AGR-1 Post-Irradiation Examination Plan,” PLN-2828, Rev 1, March 2010.

Demkowicz, P. A., L. Cole, S. Ploger, P. Winston, AGR-1 Irradiated Test Train Preliminary Inspection and Disassembly First Look, INL/EXT-10-20722, January 2011.

Demkowicz, P., J. Harp, P. Winston, S. Ploger, AGR-1 Fuel Compact 6-3-2 Post-Irradiation Examination Results, INL/EXT-12-27123, December 2012.

Demkowicz, P. A., J. M. Harp, P. L. Winston, S. A. Ploger, Analysis of Fission Products on the AGR-1 Capsule Components, INL/EXT-13-28483, March 2013.

Grover, S. B., D. A. Petti, J. T. Maki, "Completion of the First NGNP Advanced Gas Reactor Fuel Irradiation Experiment, AGR 1, in the Advanced Test Reactor," Paper 104, Proceedings of HTR-2010, Prague, Czech Republic, October 18-20, 2010.

Harp, J. M., S. A. Ploger, "Examination of Graphite Fuel Compact Holders for the AGR-1 TRISO Experiment Using Gamma Spectrometry," ECAR-1709, November 2011.

Harp, J. M., "Analysis of Individual Compact Fission Product Inventory and Burnup for the AGR-1 TRISO Experiment Using Gamma Spectrometry,” ECAR-1682, Rev. 2, June 2013.

Harp, J. M., P. A. Demkowicz, S. A. Ploger, "Post-irradiation Examination and Fission Product Inventory Analysis of AGR-1 Irradiation Capsules, HTR2012-3-006," Proceedings of the $6^{\text {th }}$ International Topical Meeting on High Temperature Reactor Technology HTR2012, October 28 November 1, 2012, Tokyo, Japan.

Hawkes, G. L., “AGR-1 Daily As-Run Thermal Analyses,” ECAR-968, Rev. 3, May 2012.

Hunn, J. D., A. K. Kercher, P. A. Menchhofer, and J. R. Price, 2005, Results from ORNL Characterization of Nominal $350 \mu \mathrm{m}$ NUCO Kernels from the BWXT 59344 Batch, ORNL/TM-2005/541, January 2005.

Hunn, J. D., F. C. Montgomery, and P. J. Pappano, 2006, Data Compilation for AGR-1 Variant 3 Compact Lot LEU01-49T-Z, ORNL/TM-2006/510, August 2006.

Hunn, J. D. and R. A. Lowden, 2006, "Data Compilation for AGR-1 Variant 3 Coated Particle Composite LEU01-49T,” ORNL/TM-2006/022.

Hunn, J. D. G. E. Jellison Jr., and R. A. Lowden, "Increase in pyrolytic carbon optical anisotropy and density during processing of coated particle fuel due to heat treatment," Journal of Nuclear Materials, v374, p. 445, 2007.

INL 2014, "Technical Program Plan for the Advanced Reactor Technologies Technology Development Office/Advanced Gas Reactor Fuel Development and Qualification Program,” PLN-3636, Rev. 4, May 2015.

Maki, J. T., AGR-1 Irradiation Experiment Test Plan, INL/EXT-05-00593, Rev. 3, October 2009. 
Ploger, S. A., P. A. Demkowicz, J. D. Hunn, J. S. Kehn, 2012, Ceramographic Examinations of Irradiated AGR-1 Fuel Compacts, INL/EXT-12-25301, Rev. 1, September 2012.

Sterbentz, J. W., "JMOCUP As-Run Daily Depletion Calculation for the AGR-1 Experiment in the ATR B-10 Position,” ECAR 958, Rev. 2, September 2013.

van Rooyen, I. J., B. D. Miller, D. E. Janney, J. Riesterer, P. A. Demkowicz, J. Harp, S. A. Ploger, 2012a, Electron Microscopic Examination of Irradiated TRISO Coated Particles of Compact 6-3-2 of AGR-1 Experiment, INL/EXT-11-23911, December 2012.

van Rooyen, I. J., D. E. Janney, B. D. Miller, P. A. Demkowicz, J. Riesterer, 2012b, “Electron Microscopic Evaluation and Fission Product Identification of Irradiated TRISO-coated Particles from the AGR-1 Experiment: A Preliminary Review," HTR2012-3-023, Proceedings of the $6^{\text {th }}$ International Topical Meeting on High Temperature Reactor Technology HTR2012, October 28 November 1, 2012, Tokyo, Japan.

van Rooyen, I. J., E. J. Olivier, J. H. Neethling, 2014, "Investigation of the Fission Products Silver, Palladium and Cadmium in Neutron-irradiated SiC Using a Cs-corrected HRTEM," Paper HTR2014 31255, Proceedings of the HTR2014, Weihai, China, October 27-31, 2014.

van Rooyen, I. J., C. Hill, H.Wen, T Trowbridge, 2015, Scanning Electron Microscopic Examination of Irradiated TRISO-Coated Particles of Compacts 4-1-1, 5-3-1, 1-3-1 and Safety Tested Compact 4-3-3 of AGR-1 Experiment, INL external report in preparation.

\section{APPENDIXES}

Appendix A, Deconsolidation-leach-burn-leach Procedure

Appendix B, Particle Inspection and Irradiated Microsphere Gamma Analysis

Appendix C, Ceramographic Morphology Classification 
Appendix A

\section{Deconsolidation-Leach-Burn-Leach Procedure}




\section{Appendix A}

\section{Deconsolidation-Leach-Burn-Leach Procedure}

The majority of the functions performed by the MFC Analytical Laboratory in support of the Advanced Gas Reactor (AGR) post-irradiation examination (PIE) occur in the MFC-752 Hot Cells. Each of the six cells, also known as the Junior Caves, has a nominal $6 \times 5$-ft floor area, 2-ft-thick concrete walls, a shielding window, and two Central Research Laboratory manual manipulators. They are supplied with compressed air, vacuum, and miscellaneous electrical and electronic connections integral to the cell. Tubing is available to provide liquid chemicals if direct flow is required. The cells have an air atmosphere and are maintained at a negative pressure to provide contamination control. Materials from the Hot Fuels Examination Facility or the Fuel Conditioning Facility may be received via pneumatic rabbit in Analytical Hot Cell 1 and transferred to other hot cells by a chain-driven cart that connects Hot Cells 1 through 6 .

The Analytical Laboratory performs the deconsolidation and leach-burn leach cycles according to Laboratory Instruction AL-5000-LI-018, "Electrolytic Deconsolidation and Leach-Burn-Leach Method." The task is to deconsolidate the compact, electrochemically breaking down the compact carbonaceous matrix and releasing the TRISO particles. The particles and matrix debris are then subjected to two 24-hour cycles submerged in hot concentrated nitric acid in a Soxhlet extractor. The particles and debris are transferred to a muffle furnace, where all exposed carbon is oxidized at $750^{\circ} \mathrm{C}$ in air for 72 hours. The burned-back particles and any remaining residue are then returned to the Soxhlet extractor for another two 24-hour extraction cycles in $16 \mathrm{M}$ nitric acid.

The compact is received via pneumatic rabbit in Analytical Laboratory Hot Cell 1 and is transferred to Hot Cell 5 by a chain-driven cart that connects Cells $1-6$. The compact is removed from the modified aluminum Swagelok bulkhead fitting that serves as a container and is weighed on the remote function balance in Cell 4 . The weight is taken by placing the compact in a clean, tarred glass scintillation vial and transferring it to the balance for measurement.

Once the compact weight is recorded, it is returned to Cell 5, where it is put into a clean, single-use deconsolidation tube. The entire deconsolidation setup is shown in Figure A-1. The deconsolidation tube is a 28-mm outer diameter glass tube that has a grating that supports the compact while the acid and applied electrical current break down the matrix. Based on experimentation during process development, it was concluded that a grating with 4-mm perforations allowed the particles to drop through with minimal plugging by the partially decomposed matrix. The deconsolidation tube fits loosely inside the Soxhlet thimble, which is a fused silica tube that has a porous No. 2 fused silica frit in the bottom that allows acid to flow through, but traps the majority of solids. The deconsolidation tube containing the compact is placed inside the thimble, which is in turn placed inside a glass tallform beaker. The two electrodes for the deconsolidation step are made of 20 -gauge platinum-rhodium wire. The cathode is placed in the acid, either between the thimble and the deconsolidation tube, or between the thimble and the tallform beaker. The anode is a platinum-rhodium wire that has been threaded through a glass tube that is flared at the base to form an "elephant foot." The anode wire is coiled at the bottom end to increase contact area where it sits on the compact. The beaker is filled with $4 \mathrm{M}$ nitric acid to nearly the level of the bottom of the compact. The Tenma Model 72-6908 DC power supply is energized and the current set at $1 \mathrm{amp}$. Acid is added until current flow is established, and filled to cover approximately the bottom $1 \mathrm{~mm}$ of the compact. During system development and testing, it was determined that more coverage led to larger quantities of the matrix flaking off and partially plugging the perforated support in the deconsolidation tube. An open crossbar support test showed large pieces falling through before the matrix was uniformly broken down. The 4-mm perforated support was chosen as an effective compromise. 


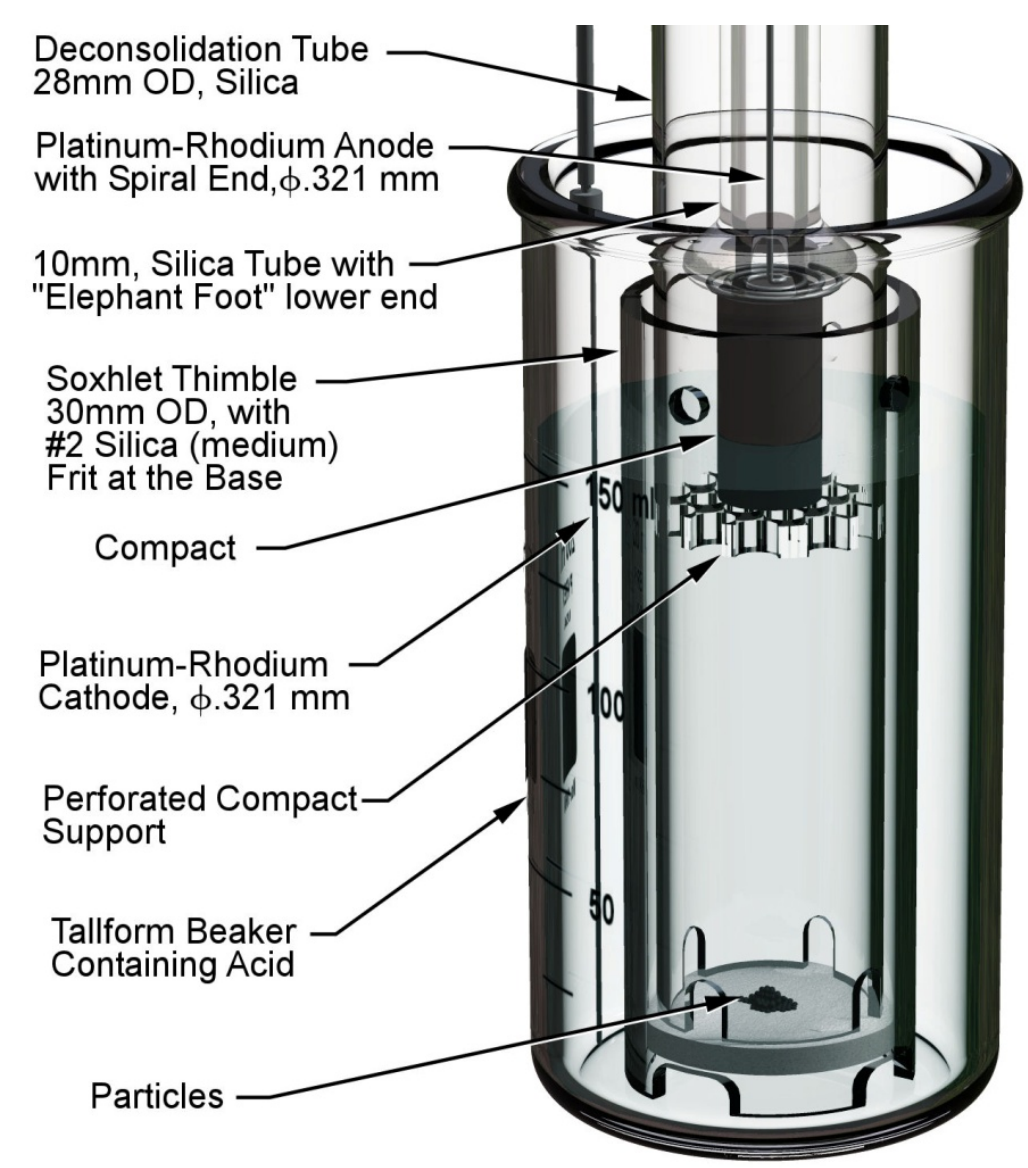

Figure A-1. Deconsolidation configuration.

The Soxhlet extractor system is composed of two standard glass units made in three sections: the boiling flask, situated in a heating mantle; the center section in which the thimble containing the specimen is located and condensate collects and periodically drains through siphon action; and the water cooled condenser located on top. Two units were installed in Cell 5 on the basis that it might be necessary to perform leach cycles in parallel. By procedure, the boiling flask is filled with $150 \mathrm{~mL}$ of concentrated nitric acid and placed in the heating mantle, the center section is inserted in the boiling pot and the thimble is placed inside the center section. The condenser is then attached and chilled water flow initiated. The chiller is installed outside the cell, at the rear, and maintains water temperature at $10^{\circ} \mathrm{C}$ with a flow of approximately $3.8 \mathrm{~L}$ per minute. The chiller is interlocked so that the heating mantles cannot be energized unless a minimum water flow is maintained. The acid vapor rises to the top, is condensed, and drains down to fill the volume containing the thimble. Periodically this volume fills to the level of a siphon tube that drains the collection volume back to the boiling flask. In this manner the specimen is continually flushed with freshly condensed acid solution. The assembly is shown in Figure A-2.

For heating, the Soxhlet boiling flasks are placed into electrical resistance mantles. The heating mantles are installed in Cell 5 and shown as item 7 in Figure A-2. The heater is operator controlled and monitored outside the cell at the Cell 5 and 6 power control panel. 


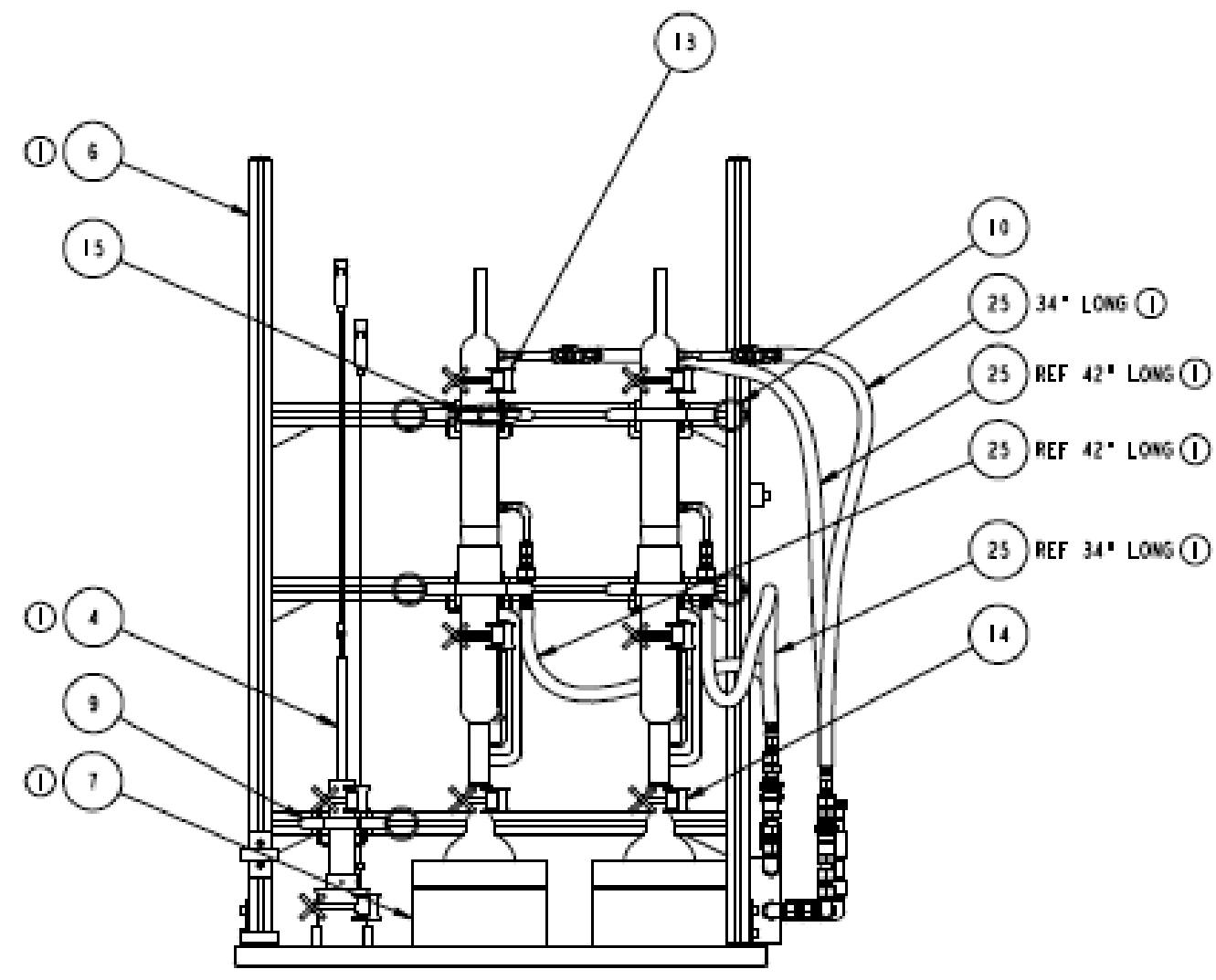

\section{- I ASSEMBLY}

Figure A-2. Framework with deconsolidation tube/vial (left) and two Soxhlet extractor stations.

The muffle furnace used for the burn-back phase is a Vulcan Model 3-55A bench top furnace, modified for installation in Hot Cell 5. An out-of-cell controller was fabricated to keep the electronics out of the radiation field. In this application, the furnace uses two 120 -volt elements that are operated as individual heaters, departing from the manufacturer's configuration where the elements are wired in series and operated at $240 \mathrm{~V}$. In the manufacturer's arrangement, a failure of either heater element would disable the furnace. The manufacturer's data indicates that one heater element is capable of maintaining the oven at $750^{\circ} \mathrm{C}$. Using the elements independently minimizes the need for heating element replacement in the event of failure. The furnace is equipped and controlled by a Type $\mathrm{K}$ thermocouple that is connected via the existing Hot Cell 5 Type K thermocouple wiring. An additional backup thermocouple has been installed in the furnace. The furnace is equipped with a door interlock switch and a fan. The door interlock switch deenergizes the heaters when the furnace door is not closed. The low-voltage direct current fan is powered by the temperature controller.

Following the two pre-burn leach cycles, the Soxhlet thimble containing the particles is transferred to the muffle furnace. The furnace is heated to $750^{\circ} \mathrm{C}$ and held at this temperature for 72 hours. Air flow is maintained by adjusting the fan voltage on the external control panel to provide a detectable movement of the pinwheel mounted over the exhaust chimney. Once the desired duration is reached, the furnace is allowed to cool to $<70^{\circ} \mathrm{C}$ and the thimble is returned to the Soxhlet extractor to perform the post-burn leaches. 
The two post-burn leaching steps are performed with the same procedure described above for the pre-burn leaches. The particles are allowed to air dry in the thimble following completion of the final post-burn leach cycles. When dry, the particles are transferred to a metal storage container from which fractions are removed for particle inspection and selection.

The deconsolidation and two pre-burn leaches are expected to provide information on fission products that were external to the $\mathrm{SiC}$ layer and leached from the remaining matrix debris. These leach solutions would also provide information on any failed particles present in the compact, as the kernels would be exposed following deconsolidation and would be dissolved in the nitric acid solution. The post-burn leaches provide two basic pieces of information. If any particles are present with defective or otherwise failed $\mathrm{SiC}$ layers (cracked or porous $\mathrm{SiC}$ but intact pyrocarbon), the kernels will be exposed by the burning of intact pyrocarbon and dissolved in the nitric acid solution. As the burn step will also burn all of the remaining matrix debris as well as the OPyC layers, the post-burn leaches will also dissolve any fission products that remained in these components and could not be dissolved during the pre-burn leaches. In the absence of any particles with defective $\mathrm{SiC}$, the total of all leach solutions should provide a total measure of fission products that were present outside of the SiC layers in the compact. 
Appendix B

Particle Inspection and Irradiated Microsphere Gamma Analysis 


\section{Appendix B}

\section{Particle Inspection and Irradiated Microsphere Gamma Analysis}

Following any of the deconsolidation-leach-burn-leach steps, particles can be visually inspected using a custom-designed optical macroscopy system. Individual particles can then be selected for specific purposes such as gamma spectrometery, burnup analysis, or microscopy. After completion of the second post-burn leach step, the particles are allowed to air dry and are then transferred from the thimble to a metal can for storage and handling. A fraction of the particles contained in the can (nominally 200 to 500 particles at a time) is transferred to an inspection dish, which is viewed on the shielded Leica macroscope that is installed in MFC Analytical Laboratory Hot Cell 5. The macroscope is connected to the control computer through a custom wall penetration that maintains shielding integrity.

A Leica Z16APO modular macroscope is oriented horizontally, viewing the sample array from below by a front surface mirror (Figure B-1 and Figure B-2). The horizontal reflex configuration allows shielding to be installed to protect the camera. It also requires a minimal working footprint. Viewing from below allows a clear overhead for particle manipulation and reduces interference with master slave manipulators. The Leica Z16 is equipped with an 8-megapixel DFC-490 CCD color camera that allows live video imaging at medium resolution and still image acquisition at high resolution. The unit is equipped with a $0.5 \mathrm{x}$ objective lens that allows a working distance of $187 \mathrm{~mm}$, maximizing distance between the radiation source and the optics and electronics while minimizing the working envelope. The lens combination provides a 16:1 zoom capability that yields a field of view ranging from approximately $26 \mathrm{~mm} \times 26 \mathrm{~mm}$ to $1.6 \mathrm{~mm} \times 1.6 \mathrm{~mm}$, meaning that a maximum of $\sim 1000$ particles could be viewed at the minimum magnification of $9 x$, and 4 particles at the maximum of $144 x$. The digital image is communicated via a combination Firewire-Ethernet cable to the computer located outside the cell and displayed on the computer monitor. Images are captured and saved on the computer.

Particles placed on the optically flat glass inspection dish are viewed from below, which allows the selection needle to operate for picking up particles from above. Lighting is provided by two high-intensity variable light-emitting diodes that are mounted in pivot posts on the top of the microscope mirror box. This arrangement allows for some adjustment of shadow and highlight, but imperfect uniformity. When particles are placed on the inspection dish for viewing, the dish stage can be translated to view the dish and the focus adjusted as needed. Newmark stepper motor-driven linear stages are used to position the viewing dish and vial tray platform in the $\mathrm{x}, \mathrm{y}$, and $\mathrm{z}$ directions as well as to raise and lower the vacuum needle during particle selection. The stages are controlled with joysticks that are able to achieve a nominal 0.2-mm precision of movement. Manual control using visual input from the microscope and through the cell window allows the operator to achieve consistent needle and visualization position, minimizing the need for electronic positioning tracking. Selected particles are picked up using a vacuum tweezer needle and photographed, then placed in glass V-vials for gamma spectrometry measurements. The needle stage moves up and down and can rotate the needle to allow a 360-degree view. Figure B-3 shows a particle attached to the vacuum needle.

Once particles have been selected from the inspection dish, they can be moved to individual Wheaton 0.3-mL V-vials, which are held in a rack on the inspection dish stage as shown in Figure B-2. Fifteen vials are arranged in the rack, which has an open bottom through which the V-vial can be viewed from below using the camera. The vacuum needle that is holding a particle is raised above rack height and the stage is positioned to align the needle with an open $\mathrm{V}$-vial. The needle is then lowered into the mouth of the vial, the vacuum is shut off, and as the vacuum leaks off, the particle drops into the vial. This is confirmed visually by watching the microscope image on the computer screen. 


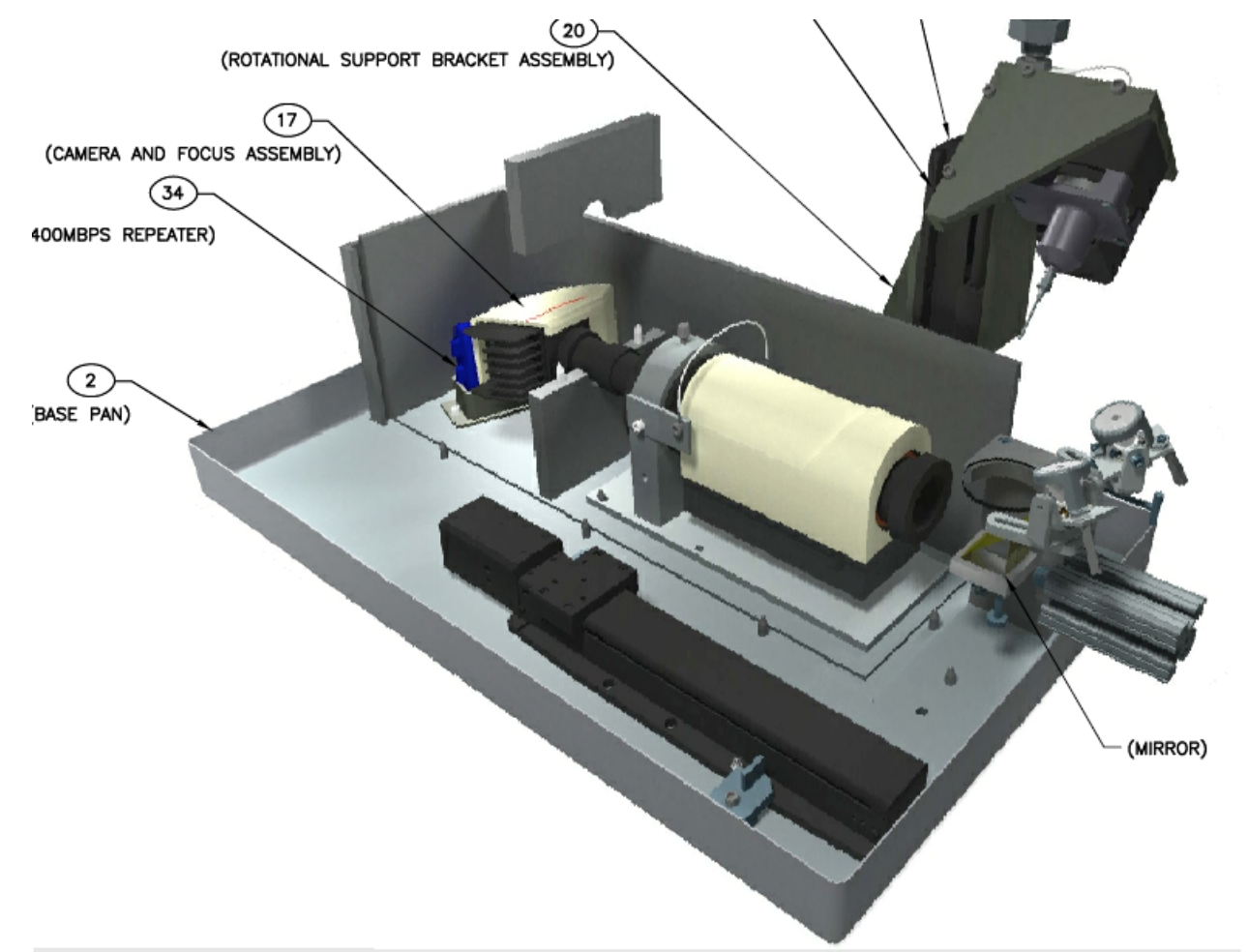

Figure B-1. Cutaway view of camera optical orientation without shielding.

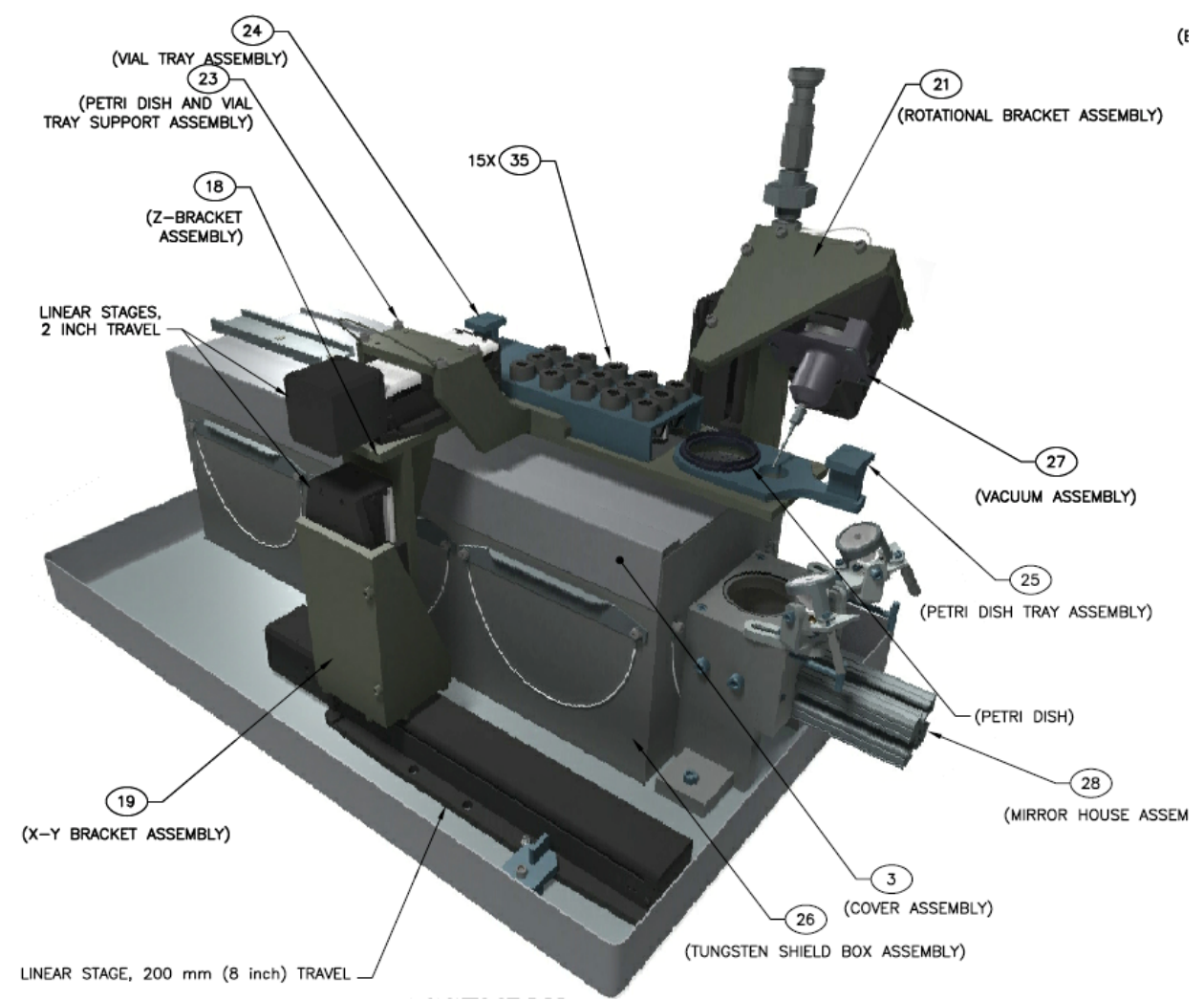

Figure B-2. Assembled isometric view of microscope stages and shielding. 


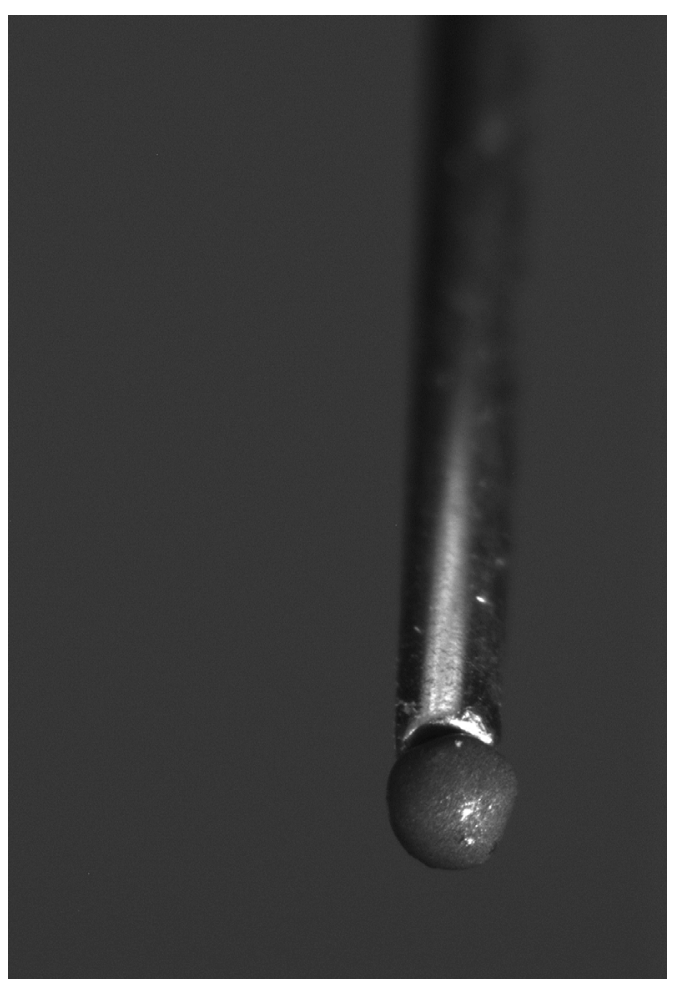

Figure B-3. Post deconsolidation particle viewed on the end of the vacuum tweezer needle.

Once particles have been selected and placed in the vials, the vials can be transferred to Analytical Laboratory Hot Cell 4, which is equipped with a gamma ray spectrometer that is located outside the hot cell, with gamma radiation transmitted through a port in the rear of the cell as shown in Figure B-4.

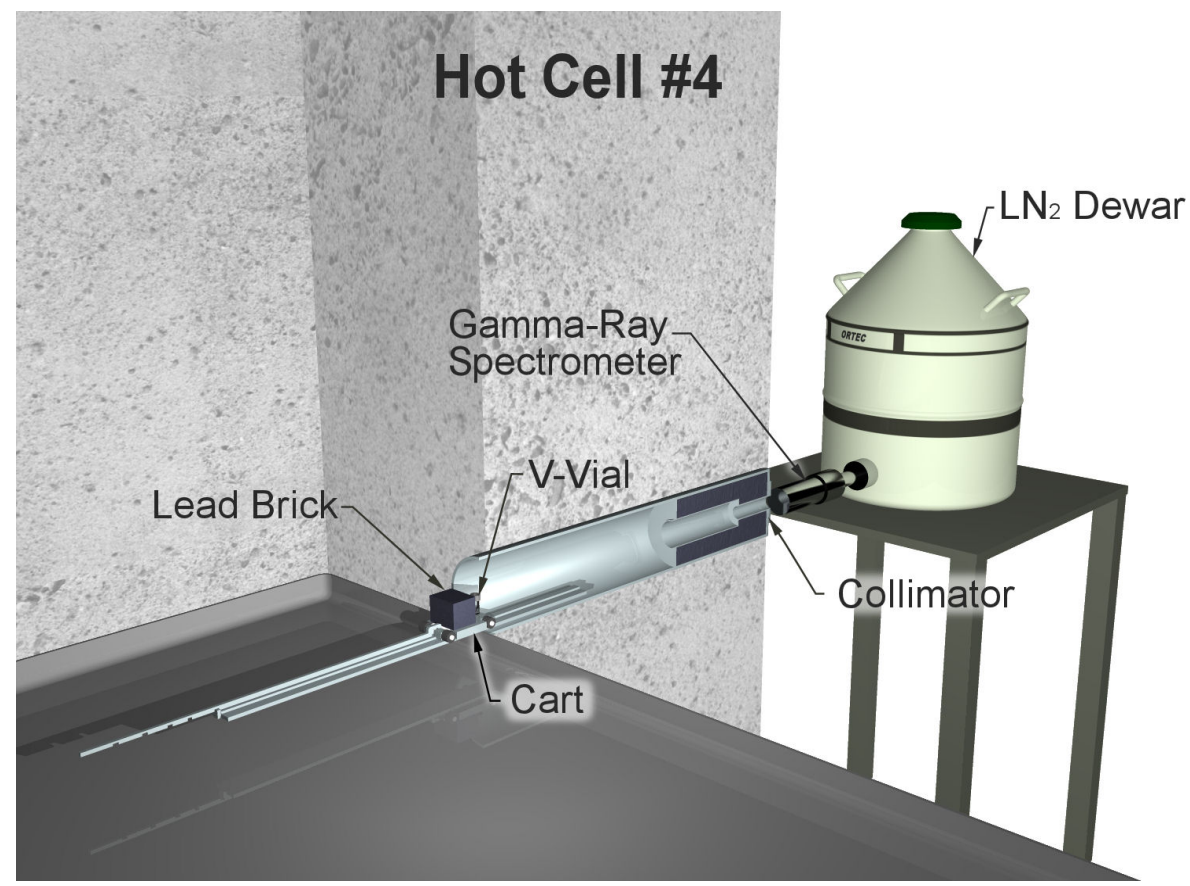

Figure B-4. MFC Analytical Laboratory Cell 4 spectrometer configuration. 
The vial is positioned on the cart and moved to the position nearest the collimator to minimize the amount of background radiation from other sources inside the cell. The gamma spectrometer is an 18\%-efficient Canberra germanium-lithium crystal that generates a signal that is parsed into specific energies by a Canberra Multi-Channel Analyzer and the spectrum is further analyzed using Apex software. The system is calibrated for particle measurement using a National Institute for Standards and Technology traceable Eu-152 source plated onto a polyethylene bead that approximates the size of a TRISO particle in a glass vial of the type used to hold the particles for counting.

The analysis in the Apex software quantifies any isotopes with measureable gamma emissions. The measured activity is based on a weighted average of all the detected gamma rays from a particular isotope, with weight given to the primary gamma-ray (typically the gamma ray with the highest branching ratio) and diminishing weight given to other gamma rays as their branching ratio decreases. Gamma rays with poor statistics or with known interferences are not used in the weighted average. Isotopes of particular interest include Ag-110m, Cs-134, Cs-137, Ce-144 (determined by measuring gamma emissions from Ce-144 and the daughter isotope Pr-144), Eu-154, Eu-155, Ru-106 (determined by measuring gamma emissions from the daughter isotope Rh-106). After the collected irradiated microsphere gamma analysis spectra were initially surveyed to identify which fission products were available for analysis, an AGR-1 specific library was created containing isotope, primary gamma energy, secondary gamma energy, and branching ratio. It included the isotopes of particular interest listed above. The default Apex library values for these isotopes were used with some notable exceptions. The primary gamma ray energy for Ag-110m was changed from 657 to $884 \mathrm{keV}$ to alleviate difficulties in resolving the $657 \mathrm{keV} \mathrm{Ag-110m} \mathrm{gamma} \mathrm{from} \mathrm{the} \mathrm{leading} \mathrm{tail} \mathrm{of} \mathrm{the} \mathrm{much} \mathrm{more} \mathrm{intense} \mathrm{Cs-137} 662 \mathrm{keV}$ gamma. The other Ag-110m lines often had too few counts in the peak for quantification. In addition to the primary isotopes of interest, the activities of several other isotopes or their minimum detectable activities were reported including activation products $\mathrm{Co}-58, \mathrm{Co}-60$, Eu-152, and $\mathrm{Mn}-54$, and fission products Zr-95(and it's Nb-95 daughter) and Ru-103. 
Appendix C

\section{Ceramographic Morphology Classification}




\section{Appendix C}

\section{Ceramographic Morphology Classification}

A comprehensive scheme for classifying AGR-1 particle morphologies was developed for analysis of cross-sectional particle images taken during ceramography of cross-sections from six irradiated AGR-1 fuel compacts (Ploger, S.A., et al. Ceramographic Examinations of Irradiated AGR-1 Fuel Compacts, INL/EXT-12-25301, Rev. 1, September 2012). Several characteristic morphologies came to be recognized as these images were examined. The most common feature was a radial gap between the buffer and IPyC layers where the buffer densified inward (outer surface moved toward kernel) during irradiation. In some particles with inward buffer densification the radial buffer-IPyC gap was interrupted by regions where the buffer stayed firmly bonded to the IPyC layer. Many of these particles debonded along most of the interface, while debonding was much less extensive on some other particles when the AGR-1 irradiation ended. The rarest case was where a particle had no buffer-IPyC gap. In these cases, the buffer stayed bonded to the IPyC layer around the entire circumference in the plane of the cross-section examined. The buffers in these particles still evidently densified, but the inner buffer surface moved radially outward rather than the outer buffer surface moving inward. Kernels in these particles often had larger pores than seen inside kernels within inwardly densified buffers.

The scheme for classifying irradiated AGR-1 particles by morphology in the plane of polish is presented with representative examples in 


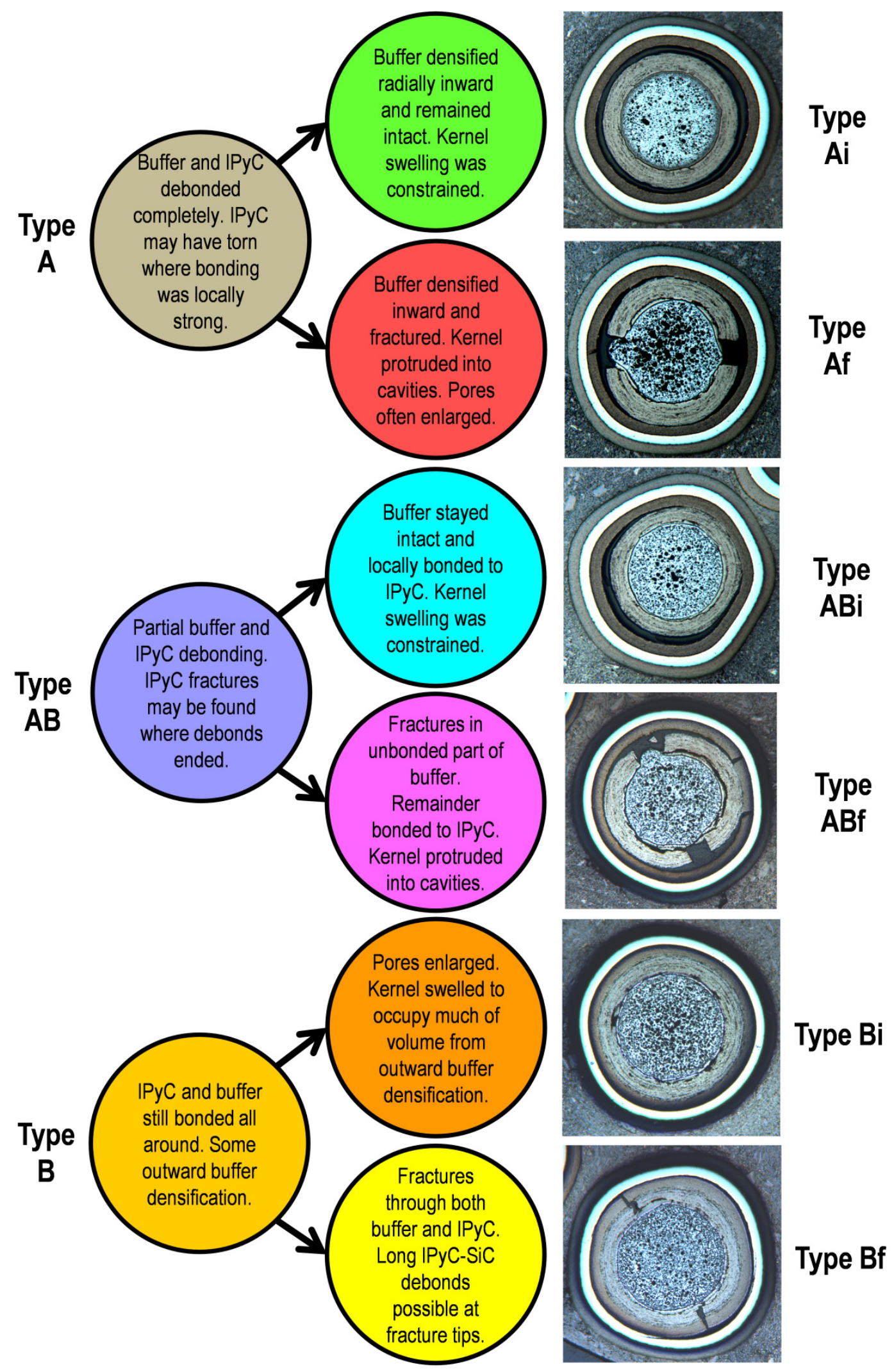

Figure C-1. A radial buffer-IPyC gap around the entire circumference (completely detached buffer-IPyC interface) is designated as a Type A end-state morphology. Particles with fully bonded buffer and IPyC 
layers are termed Type B particles. Debonding along only part of the buffer-IPyC interface is called a Type AB morphology. Buffer fracturing occasionally occurred in Types A, B, and AB, which resulted in the six characteristic morphologies displayed in 


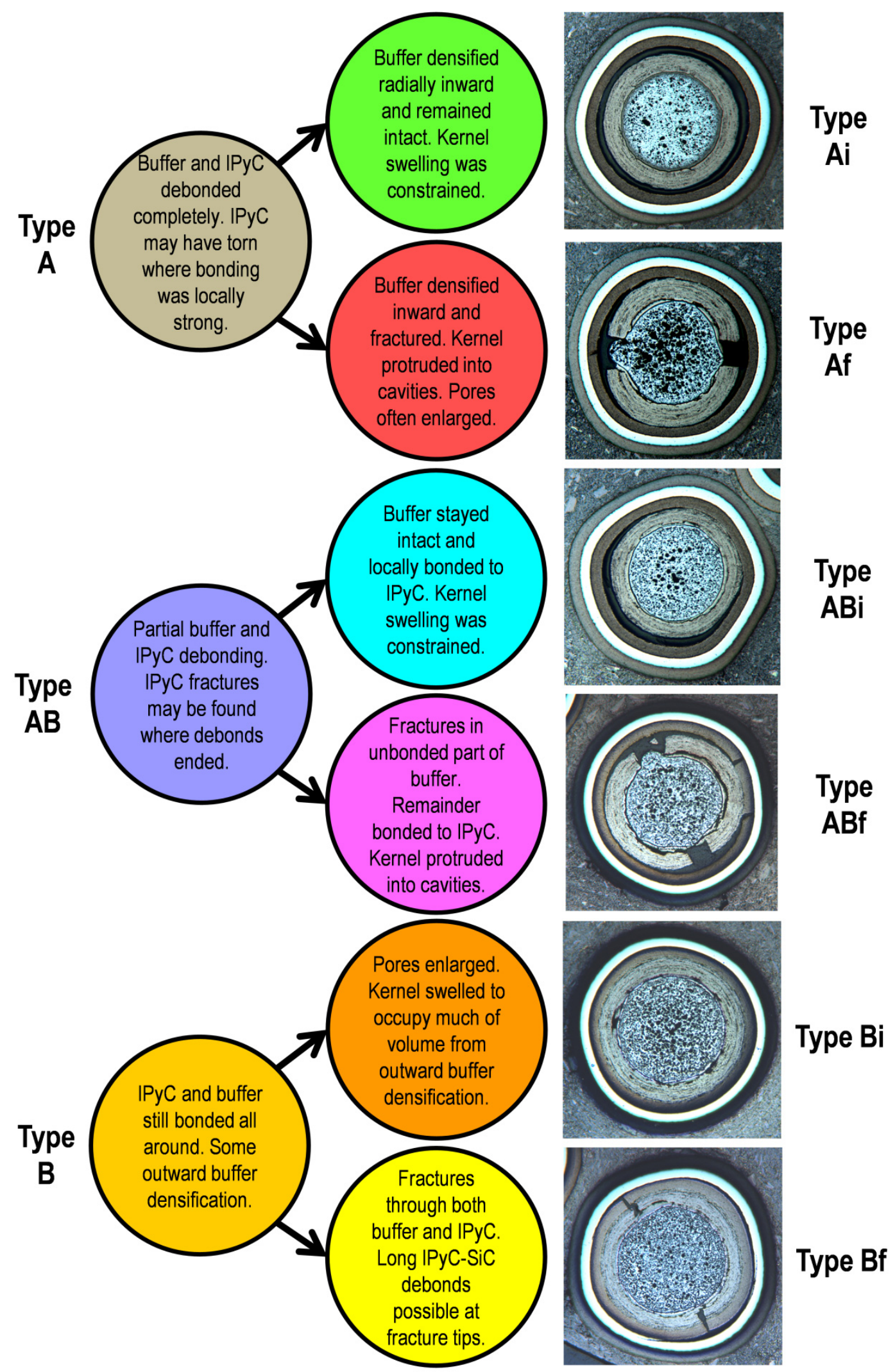

Figure C-1. 


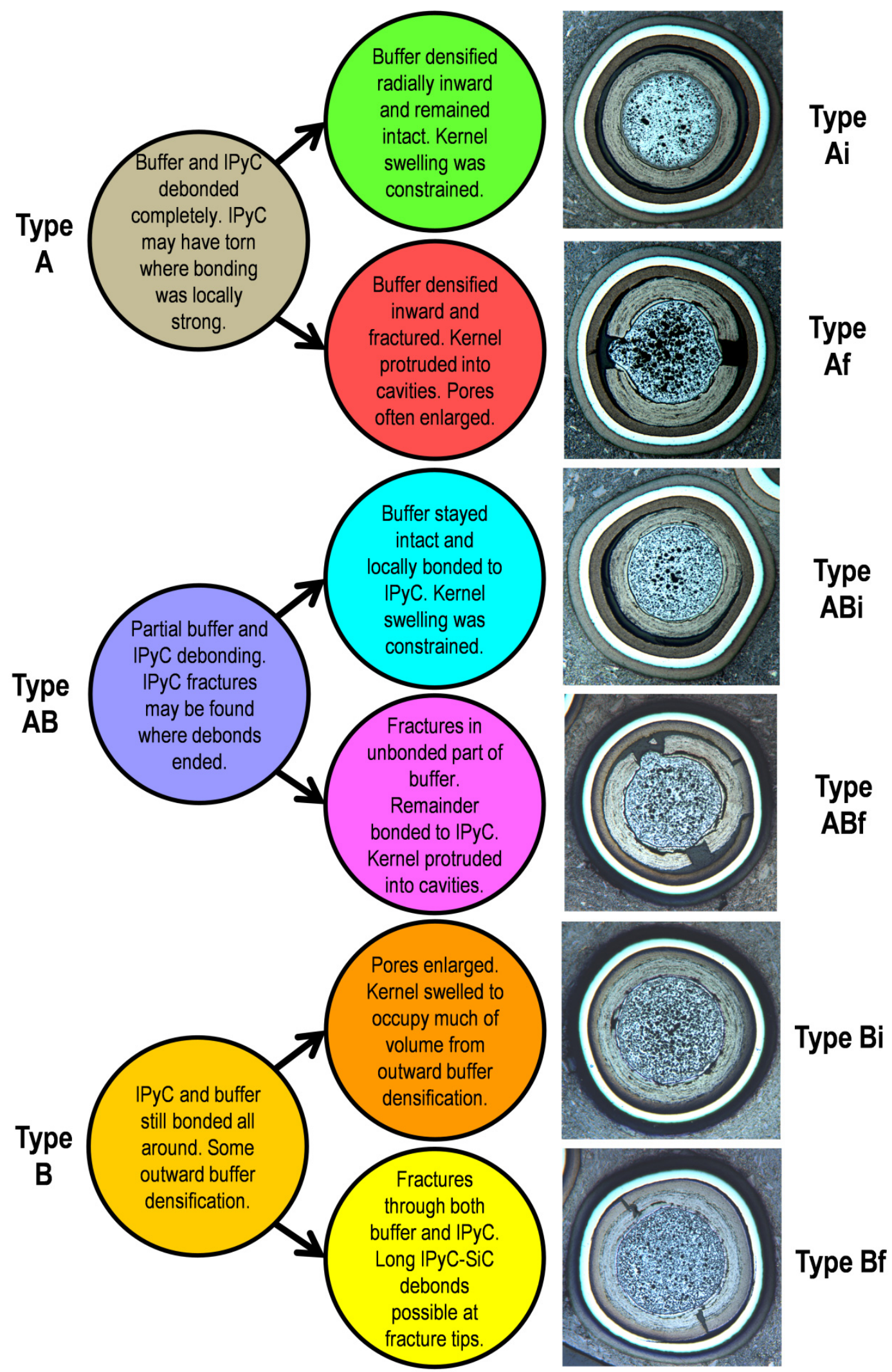

Figure C-1. Particle morphologies observed in AGR-1 fuel particle cross sections, where "i" denotes an intact buffer and "f" denotes a fractured buffer (Ploger et al. 2012). 